\title{
External Factors in Debt Sustainability Analysis: An Application to Latin America
}

\author{
Gustavo Adler \\ International Monetary Fund, USA \\ gadler@imf.org \\ Sebastian Sosa ${ }^{1}$ \\ International Monetary Fund, USA \\ ssosa@imf.org
}

Received: 30 January 2015 / Revised: 26 June 2015 / Accepted: 9 July 2015 / Published online: 21 January 2016

\begin{abstract}
This paper develops a framework for debt sustainability analysis that integrates econometric estimates of the effect of global factors on a set of key domestic variables that determines public and external debt dynamics. The methodology is applied to assess debt sustainability in Latin America - a region highly sensitive to external conditions. Results suggest that, while some countries in the region are well placed to withstand moderate or even large foreign shocks, many would benefit from strengthening their fiscal positions to be able to deploy countercyclical policies under adverse scenarios, especially tail events. External sustainability, on the other hand, does not appear to be a source of concern for most countries.
\end{abstract}

JEL classification: C32, E62, F41, F47, H62, H63

Key words: public debt, external debt, debt sustainability, Latin America

\section{INTRODUCTION}

Debt sustainability analysis (DSA) has become a widespread tool for policy-makers to assess an economy's fiscal and external vulnerability. However, despite the growing importance of external factors in increasingly integrated economies, existing frameworks are still not well equipped to assess how changes in external conditions affect debt dynamics, given their lack of linkages between global and domestic variables. Moreover, stress tests under these traditional DSA frameworks consider shocks to certain variables in isolation (output growth, interest rates, etc.), without taking into account the correlation among shocks and the joint dynamic response of some of these variables. This paper improves upon existing DSA frameworks by studying the link between global variables - such as commodity prices, world growth, and financial market conditions - and a set of domestic variables (GDP growth, trade balance, real exchange rate, and sovereign spreads) that explains the dynamics of public and external sustainability indicators. Specifically, it develops a simple framework that integrates (i) econometric estimates of the effect of exogenous external variables 
on these key domestic variables with (ii) the standard International Monetary Fund's (IMF) DSA framework. ${ }^{2}$ This integrated framework can be used to examine the evolution of public and external debt sustainability indicators (both in terms of stocks and flows) under alternative global scenarios; and consequently to assess the adequacy of a country's current fiscal and external position.

Our paper relates to a growing literature seeking to improve debt-sustainability analysis. Most of these recent contributions (Celasun et al., 2006; Favero and Giavazzi, 2007 and 2009; Tanner and Samake, 2008; Mendoza and Oviedo, 2009; Kawakami and Romeu, 2011; Cherif and Hasanov, 2012; Banbura et al., 2014; Barosso, 2014) have focused primarily on the joint stochastic properties of shocks, aiming at developing a probabilistic approach to DSA, including by incorporating explicit fiscal reaction functions to take into account the policy response to shocks and the feedback effects of fiscal policy on macroeconomic variables. Like our paper, they rely on a methodology that combines VAR models with debt feedback to assess the impact of a set of macroeconomic shocks on public debt dynamics. These studies, however, do not examine the impact of specific external shocks on debt dynamics - which are highly relevant for emerging markets, especially for those economies that are highly financially integrated with international capital markets and/or rely heavily on commodity exports. In addition, most of these papers focus on a limited set of countries, and solely on public debt - without looking into external debt. This paper contributes to the literature by filling this gap.

We then apply our framework to study the case of Latin America, evaluated at the end of 2012. The latter is of particular interest, as the region is highly sensitive to external conditions. ${ }^{3}$ Indeed, over the last decade most countries in Latin America experienced an impressive strengthening of key macroeconomic fundamentals (Figures 1 and 2), especially during the period 2003-2008, against a backdrop of a highly favorable external environment. During this period, the region not only displayed remarkable improvements in terms of stocks - reducing public and external debt levels, and accumulating public and foreign assets - but also notable changes towards less vulnerable debt structures - reducing the share denominated in foreign currency and extending maturity (see Annex Figure A1).

Figure 1.

Latin America. Key Fiscal Indicators, 2002-20121) (simple average and 20th and 80th percentiles)
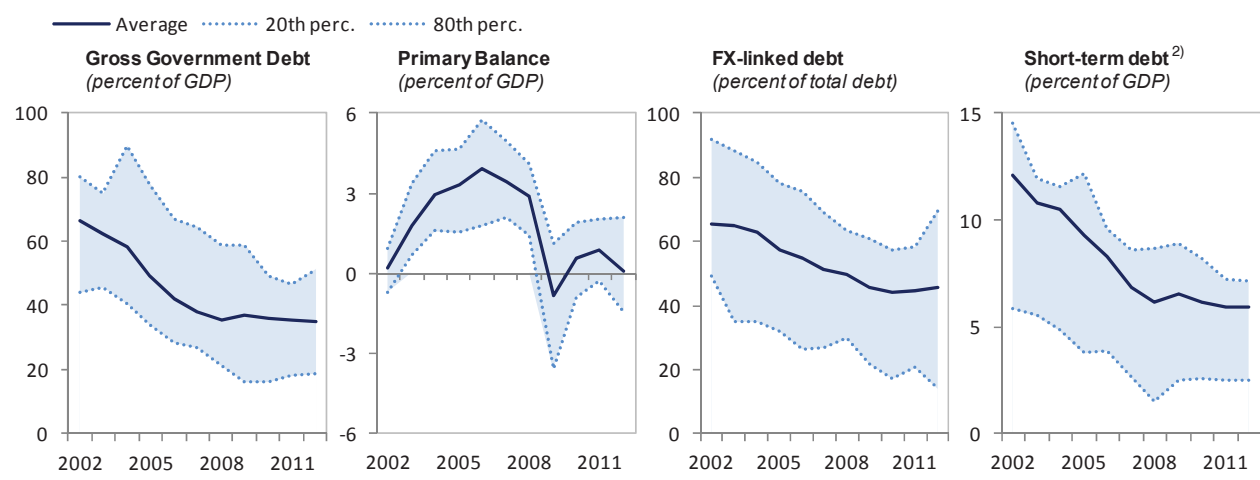

1) Latin America includes Argentina, Bolivia, Brazil, Chile, Colombia, Ecuador, Mexico, Paraguay, Peru, Uruguay and Venezuela. See Annex Figure A1 for country-by-country data.

2) At residual maturity. Excludes Bolivia and Paraguay.

Sources: IMF International Financial Statistics, and country desks.

For details about the IMF's DSA framework, see IMF (2002, 2003, 2005, 2011, and 2012b).

3 The role of external conditions in driving macroeconomic outcomes in Latin America has been studied extensively in the literature (see, for instance, Osterholm and Zettelmeyer, 2008, and Izquierdo et al., 2007) but without exploring the implications for either fiscal or external sustainability. 
Figure 2.

Latin America. Key External Indicators, 2002-20121) (simple average and 20th and 80th percentiles)

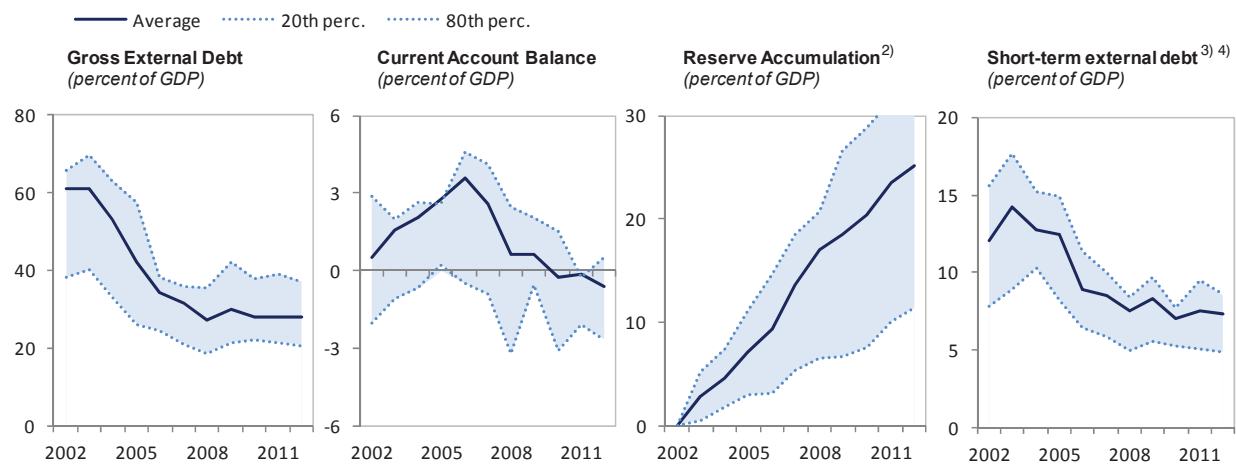

1) Includes Argentina, Bolivia, Brazil, Chile, Colombia, Ecuador, Mexico, Paraguay, Peru, Uruguay and Venezuela. See Annex Figure A1 for country-by-country data.

2) Cumulative flow of gross international reserves since 2002 .

3) At residual maturity.

4) Excludes Bolivia and Paraguay.

Sources: IMF International Financial Statistics, and country desks.

While prudent policies have played an important role, these gains also reflect to a significant extent the combination of a high sensitivity to external conditions and a highly favorable external environment - interrupted only temporarily during the 2008-2009 international financial crisis and characterized by strong external demand, an unprecedented boom in commodity prices, and very benign global financing conditions. ${ }^{4}$ However, with prospects of less favorable external conditions going forward, and even the possibility of a sharp deterioration associated with looming risks - e.g., an escalation of the euro area financial crisis - the strength of the region's fundamentals remains an open question. In other words, have countries in the region strengthened their fiscal and external positions enough to guard themselves from a weakening of external conditions? ${ }^{5}$

Our main results suggest that current fiscal positions in the region are, on average, adequate to deal with temporary and even moderate protracted external shocks, while fiscal space to face more severe protracted shocks could be limited. At the same time, there are important differences across countries especially with respect to their ability to deal with protracted shocks, with countries broadly falling into three groups: (i) a group (Argentina and Venezuela) that would likely need to undertake sizeable fiscal consolidation in the face of adverse shocks, to keep public debt on a sustainable path; (ii) a second group (Brazil, Ecuador, Mexico, and Uruguay) that could manage moderate shocks but would benefit from building additional buffers to be in a position to deploy countercyclical policies under adverse scenarios, without reaching debt levels that could raise concerns about fiscal sustainability; and (iii) a third group (Bolivia, Chile, Paraguay, Peru, and to a lesser extent Colombia) with a relatively solid position to withstand sizeable shocks - even responding with expansionary policies - without putting fiscal solvency at risk. In terms of the external position, our results indicate that, despite evidence of a recent widening in current account deficits, external sustainability does not appear to be a source of concern for Latin America in general.

The paper proceeds as follows: the next section describes the methodological approach used to examine how fiscal and external sustainability indicators would be affected under alternative (downside) scenarios. Section III describes the external scenarios under consideration and presents the main results for Latin America, deriving an assessment of the adequacy of current buffers. Section IV concludes with the key takeaways.

\footnotetext{
4 A detailed analysis of the drivers of these improvements in fiscal and external indicators in Latin America can be found in Adler and Sosa (2013).

The paper focuses on debt sustainability from the perspective of potential external shocks, leaving aside other objectives or possible shocks that could shape the desirability of larger buffers (e.g., management of non-renewable resources, buffers to deal with possible contingent liabilities arising from private sector excesses, etc.). The paper also leaves aside issues related to the appropriateness of the fiscal stance on cyclical grounds.
} 


\section{METHODOLOGICAL APPROACH}

\section{A. Public and External Debt Sustainability Analysis}

This section describes the framework to examine how external conditions affect, through their impact on key domestic variables, the dynamics of public and external debt ratios. ${ }^{6}$ The framework entails mapping, by means or econometric estimates, how shocks to key global variables - commodity prices, world growth, and financial market conditions - affect a set of domestic variables - GDP growth, trade balance, real exchange rate, and sovereign spreads - that enter into the laws of motion of public and external debt.

Once the econometric model is estimated and integrated with the DSA framework, scenario analysis can be performed to evaluate the adequacy of the current fiscal or external position, by generating conditional forecasts of the endogenous domestic variables.

Illustration of Integrated Public and External Debt Sustainability Approach ${ }^{1)}$

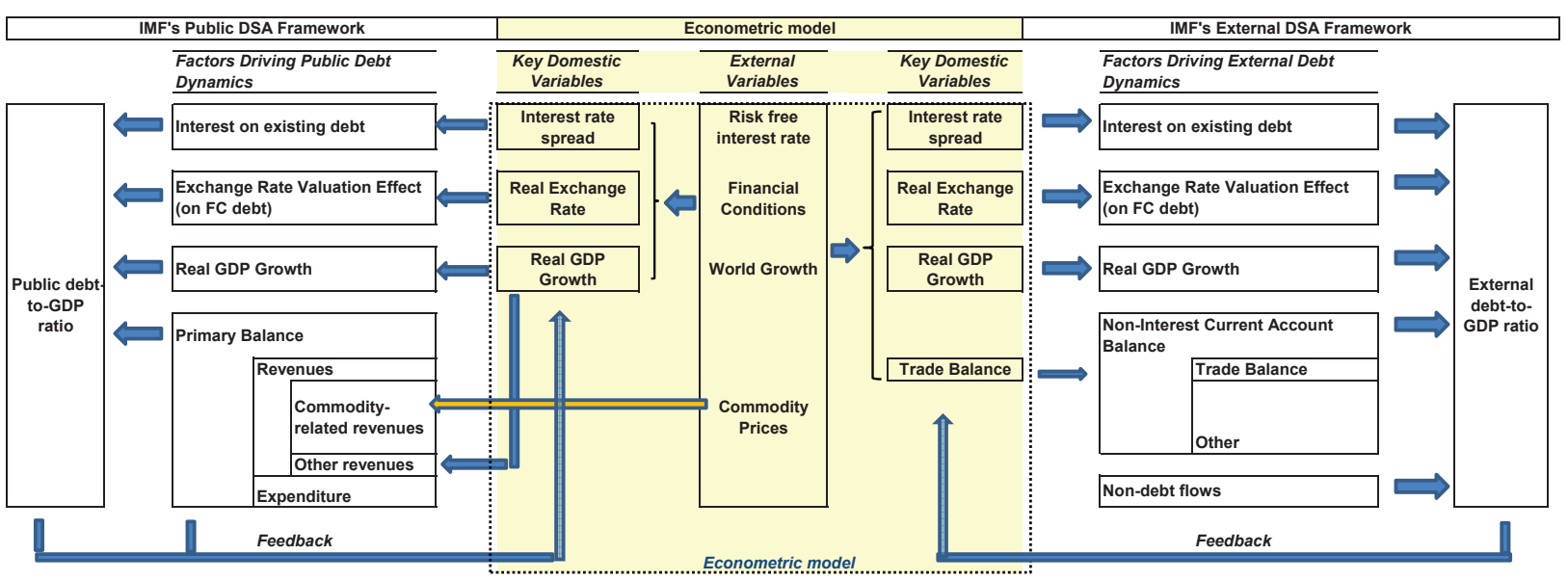

1) The diagram presents a simplif ied illustration of the integrated f ramew ork for public and external debt sustainability. Details and underlying assumptions are discussed in section III.

To start, we show how the law of motion of debt ratios can be expressed as a function of the small set of domestic variables mentioned above.

\section{Public Debt}

Consider the following equation that governs the path of public debt (in nominal, local currency, terms):

$$
D_{j, t}=E_{j, t} D_{j, t-1}^{F C}\left(1+r_{j, t-1}\right)+D_{j, t-1}^{L C}\left(1+i_{j, t-1}\right)-P B_{j, t}
$$

where $D_{j, t}$ is country $j$ 's nominal stock of public debt in period $t ; D_{j, t-1}^{F C}\left(D_{j, t-1}^{L C}\right)$ is the stock of foreign (domestic) currency-denominated debt; $E_{j, t}$ is the nominal exchange rate vis-à-vis the U.S. dollar; $r_{j, t-1}$ and $i_{j, t-1}$ are the average interest rates on foreign and local currency debt respectively, and $P B_{j, t}$ is the nominal primary fiscal balance.

Denote $x \equiv X_{t} / G D P_{t}$ as a nominal variable $X_{t}$ expressed in percent of GDP; $i_{j, t}^{e}=\alpha_{j, t} i_{j, t}+$ $+\left(1-\alpha_{j, t}\right) r_{j, t}$, as the effective average interest rate; $\pi_{j, t}$ as domestic inflation (GDP deflator); $g_{j, t}$ as real GDP growth and $\varepsilon_{j, t}$ as the nominal depreciation of the domestic currency vis-à-vis the US dollar. Then, defining $\alpha_{j, t}=D_{j, t}^{L C} / D_{j, t}$ as the share of local-currency denominated debt, one can reduce equation (1) to a small number of terms:

\footnotetext{
As in the IMF's standard debt sustainability framework, we focus on general government gross debt.
} 


$$
\Delta d_{j, t}=\left[i_{j, t-1}^{e}-\pi_{j, t}\left(1+g_{j, t}\right)\right] \theta_{j, t}-\left(g_{j, t}\right) \theta_{j, t}+\left[(1-\alpha)\left(1+r_{j, t}\right) \varepsilon_{j, t}\right] \theta_{j, t}-p b_{j, t}
$$

where $\theta_{j, t}=\left\{\frac{d_{j, t-1}}{\left(1+g_{j, t}\right)\left(1+\pi_{j, t}\right)}\right\}$. The first term of equation (2) broadly captures the (accounting) contribution of the real interest rate; the second term captures the effect arising from real GDP growth; the third term captures the impact of exchange rate movements (through valuation effects on foreign currency-denominated debt); and the last term reflects the contribution of the primary balance.

Taking into account the share of debt falling due in the current period $\left(\gamma_{j, t-1}\right)$ and subsequent periods $\left(1-\gamma_{j, t-1}\right)$, we can model the dynamics of the average interest rate as a function of marginal interest rates:

$$
i_{j, t}^{e}=\left(1-\gamma_{j, t}\right) i_{j, t-1}^{e}+\gamma_{j, t-1}\left\{\alpha i_{j, t}+(1-\alpha) r_{j, t}\right\}
$$

Assume the following pass-through structure from (global) risk-free interest rates $\left(r_{t}^{*}\right)$ and sovereign spreads $\left(s_{j, t}\right)$ into domestic interest rates $\left(i_{j, t}\right)$. That is, $\Delta i_{j, t}=\Delta r_{t}^{*}+\Delta s_{j, t}$. Assume also that real and nominal exchange rate shocks map one-to-one: $\Delta \ln \left(\right.$ reer $\left._{j, t}\right)=-\varepsilon_{j, t} .^{7}$

From equations (2) and (3), this set of (relatively innocuous) assumptions and from the fact that $r_{j, t}=r_{t}^{*}+s_{j, t}$, one can show that dynamics of the public debt-to-GDP ratio is governed by the behavior of only four (endogenous) domestic variables: $\{s, g$, reer, $p b\}$.

Furthermore, the primary balance can be modeled in a simple fashion by decomposing it into commodity revenues, non-commodity revenues, and expenditures (all in percent of GDP):

$$
p b=r e v^{C}+r e v^{N C}-\exp
$$

Subsequently, commodity revenues can be modeled as a function of the corresponding commodity prices:

$$
\operatorname{rev}_{S c e n}^{C}=\operatorname{rev}_{B L}^{C} *\left(\frac{P_{S c e n}^{C}}{P_{B L}^{C}}\right)
$$

where $\operatorname{rev}_{S c e n}^{C}\left(r e v_{B L}^{C}\right)$ are commodity-related revenues and $P_{S c e n}^{C}\left(P_{B L}^{C}\right)$ are world commodity prices under a specific scenario (under the baseline).

Finally, a constant non-commodity revenue-to-GDP ratio is assumed (i.e., an elasticity equal to one), such that: $\operatorname{rev}^{N C}=\eta$. Then, the dynamics of the public debt ratio is simply given by four endogenous domestic variables $\{s, g$, reer, exp $\}$ and a set of exogenous global variables. ${ }^{8}$

\section{External Debt Dynamics}

Similarly, to derive the set of variables that determine the path of the external debt-to-GDP ratio, we start from the law of motion of external debt:

$$
D_{j, t}^{E}=E_{j, t} D_{j, t-1}^{E, F C}\left(1+r_{j, t-1}\right)+D_{j, t-1}^{E, L C}\left(1+i_{j, t-1}\right)-n i c a_{j, t}-n d c f_{j, t}
$$

where $D_{j, t}^{E}$ is the nominal stock of total external debt (expressed in local currency); $D_{j, t-1}^{E, F C}\left(D_{j, t-1}^{E, L C}\right)$ is the stock of foreign (local) currency-denominated debt; $r_{j, t-1}\left(i_{j, t-1}\right)$ is the average interest rate on foreign (local) currency-denominated debt; $n i c a_{j, t}$ is the current account balance excluding interest payments; and $n d c f_{j, t}$ are the non-debt-creating flows (FDI and equity portfolio).

7 This implies that both $\pi_{t}$ and $\pi_{t}^{*}$ (international inflation) are invariant across the scenarios under consideration, so that movements in the real effective exchange rate mirror those of the nominal exchange rate.

8 The notion that public debt dynamics tends to be driven by a small number of variables is consistent with recent findings in the literature (see, for example, Banbura et al., 2014). 
Then, defining $\alpha_{j, t}^{E}=D_{j, t}^{E, L C} / D_{j, t}^{E}$ and $i_{j, t}^{e}=\alpha_{j, t}^{E} i_{j, t}+\left(1-\alpha_{j, t}^{E}\right) r_{j, t}$, we can derive the path of external debt in terms of a small set of factors:

$$
\Delta d_{j, t}^{E}=i_{j, t}^{e} \sigma_{j, t}-g_{j, t} \sigma_{j, t}+\left\{\left(1-\alpha_{j, t}^{E}\right)\left(1+r_{j, t}\right) \varepsilon_{j, t}\right\} \sigma_{j, t}-n i c a_{j, t}-n d c f_{j, t}
$$

where $\sigma_{j, t}=\frac{d_{j, t-1}^{E}}{\left(1+g_{j, t}\right)\left(1+\pi_{j, t}\right)}$. The first term reflects the contribution of interest payments; the second term captures the contribution of real GDP growth; the third component measures the valuation effect arising from movements in the real exchange rate; and the last two terms reflect the contributions of the current account balance (excluding interest payments) and non-debt financing flows respectively.

Modeling the non-interest current account as nica $a_{j, t}=t b_{t}+\theta$ (where $t b_{t}$ is the trade balance in period $t$ ) and using our previous assumption on the behavior of the real exchange rate $\left(\Delta \ln \left(\right.\right.$ reer $\left.\left._{j, t}\right)=-\varepsilon_{j, t}\right)$, the external debt dynamics can be fully characterized by the path of a set of few domestic variables: $\{s, g$, reer $, t b, n d c f\} .^{9}$

Treating $n d c f_{j}$ as exogenous (as we are primarily interested in externally-triggered shocks), and putting together the systems of equations derived for public and external debt, it can be shown that both debt ratios are ultimately driven by five domestic variables, $\{s, g$, reer, $t b, \exp \}$, and a set of exogenous global variables. The next section discusses how to estimate the impact of external variables on the first four variables in this set, while the behavior of the last variable (exp) is evaluated under different policy rules.

\section{B. Conditional Forecasting of Key Domestic Variables: a VAR approach}

Country-specific VAR models are estimated in order to quantify the sensitivity of the variables (specified above) that characterize debt dynamics to external conditions. Specifically, the VARs are used to obtain forecasts of these domestic variables, conditional on a set of assumed global variables (global scenarios). A key feature of our framework is that primary balances and debt levels are included in the VAR in order to allow feedback effects from these variables to the other domestic variables that determine debt dynamics. We depart from the probabilistic approach taken in other papers, as our interest lies on specific scenarios of external factors, instead of analyzing the probability distribution of outcomes. ${ }^{10}$

Each (reduced form) country-specific VAR model can be written as:

$$
y_{t}=B(L) y_{t-1}+H(L) z_{t}+u_{t}
$$

where $y_{t}=\left(g_{t} d T B_{t} d \ln \left(\text { reer }_{t}\right)\right)^{\prime}$ is a vector of endogenous variables and $z_{t}=\left(1 g_{t}^{W} \text { vix }_{t} P_{t}^{A} P_{t}^{E} P_{t}^{M} p b_{t-1} d_{t-1}^{P}\right)^{\prime}$ is a vector of exogenous variables. The vector $y_{t}$ includes real GDP growth $\left(g_{t}\right)$, the change in the trade balance in percent of GDP $\left(d T B_{t}\right)$, and the (log difference of) the real effective exchange rate $\left(d \ln \left(\right.\right.$ reer $\left.\left._{t}\right)\right) .{ }^{11}$ The vector $z_{t}$, in turn, includes global real GDP growth $\left(g^{W}\right)$, the S\&P 500 Chicago Board Options Exchange Market Volatility

\footnotetext{
We focus on the trade balance, rather than the non-interest current account, as the former is the main driver of the latter and is likely to have more stable relationships with the other key endogenous variables (real exchange rate, real GDP growth, etc.).

10 A criticism of the probabilistic setting is that it uses historical observations to infer the probability distribution of exogenous variables, although the latter may not be the most relevant piece of information going forward, for example due to structural breaks in the relationship. An example of this may be the behavior of commodity prices, which patterns over the last 10 years seem to have departed from their historical stochastic processes.

11 In the case of countries with a significant fraction of debt denominated in foreign currency (e.g., Bolivia, Ecuador, Paraguay, Peru, and Uruguay), the use of the real effective exchange rate could result in some underestimation of potential valuation effects. At the same time, while the bilateral exchange rate vis-à-vis the U.S. dollar would better capture these effects, their inclusion would significantly complicate the VAR specification.
} 
Index (vix) as a proxy for international financial conditions, ${ }^{12}$ the (log differences of) agriculture, energy, and metals prices ( $P_{t}^{A}, P_{t}^{E}$, and $P_{t}^{M}$ respectively), ${ }^{13}$ the primary balance in percent of GDP $(p b)$, and the debt-to-GDP ratio $\left(d^{p}\right) . B(L)$ and $H(L)$ are lag polynomial matrices, which include up to four lags. ${ }^{14}$

The VAR models are estimated using quarterly data from 1990:Q1 through 2012:Q1. ${ }^{15}$ The data sources are primarily the IMF's International Financial Statistics (IFS) and World Economic Outlook (WEO), and Haver Analytics. ${ }^{16}$ It is worth noting that since our main interest resides in obtaining conditional forecasts and not standard VAR tools such as impulse response functions and variance decompositions, there is no need for identification restrictions to recover the structural parameters of the model. Similarly, as our interest is on the conditional forecasting performance of the model during negative external scenarios, specifications are selected based on their out-ofsample forecast power during the Lehman event (see Annex Figure A2). ${ }^{17}$

Unlike that of other papers in the literature, our approach does not entail estimating a fiscal reaction function, (i.e., there is no equation for the primary balance). This is deliberate, as our objective is not to obtain alternative debt paths under the assumption that fiscal responses to the negative shocks mirror those of the past - which may have been constrained (or sub-optimal) in many cases - but rather under broadly unconstrained (either neutral or countercyclical). ${ }^{18}$ This does not mean that the VAR does not control for the fiscal stance but instead that the primary balance is treated as exogenous for the purpose of estimation only. For projections, the primary balance under alternative scenarios is constructed as follows: revenues are projected based on the forecast for output (conditional on the exogenous path of the foreign variables) and on standard assumptions about the output elasticity of non-commodity revenues. Commodity-related revenues, in turn, are projected based on the exogenously determined path of the relevant commodity prices. On the expenditure side, we consider alternative responses - both neutral and countercyclical (explained in detail later) - to the negative shock. This approach allows us to better assess the impact of different components of the primary balance (commodity revenues, revenues linked to economic activity, and expenditure). Finally, as stated before, the primary balance enters the growth equation, so our approach incorporates the feedback effects of different fiscal responses on output.

\section{Sovereign Spreads Module}

A sovereign spread equation - one of the variables that determine debt dynamics - is estimated separately since data availability is significantly more limited (starting only after 1998, and varying by country $)^{19}$ than in the case of other variables included in the model. The spread equation includes key macroeconomic fundamentals and exogenous global variables:

\footnotetext{
The VIX index has recently been used as a measure of global uncertainty or financial stress. Bloom (2009), for instance, shows that this volatility index is highly correlated with measures of micro and macro-level uncertainty, including from financial variables. More recently, IMF (2012), Adler and Tovar (2012), and Carrière-Swallow and Céspedes (2011) also used the VIX to measure global uncertainty shocks.

13 International commodity prices are measured in real terms and stripped of exchange rate effects, as in Adler and Sosa (2011).

14 As the global variables included in vector $\boldsymbol{z}$ are exogenous to the model, this approach does not allow to capture correlations among shocks to these variables. However, the assumptions about the path of the global variables under each scenario, discussed in the next section, are based on broad patterns observed in previous episodes of external shocks.

15 A possible concern is that some countries may have experienced structural breaks during the sample period, and thus changes in the way hat external conditions affected domestic variables. Our econometric results, however, indicate a high predictive power when doing out-of-sample forecast for the period of the 2008-2009 crisis.

16 The sample includes all South American economies (except Guyana and Suriname) and Mexico, representing about 95 percent of Latin America's GDP.

17 Annex Table A1 presents the estimation output for each of the country-specific VARs.

18 Whether past fiscal policies were socially optimal or not is still a matter of debate. While there is a vast literature trying to explain the suboptimality of procyclical policies with political economy and capital market frictions, (e.g., Talvi and Vegh, 2005; or Tornell and Lane, 1999) some authors have recently argued that procyclical responses were optimal in the context of countercyclical sovereign spreads (e.g. Cuadra et al., 2010; and Hatchondo et al., 2012).

19 Sufficiently long series of EMBI spreads are not available for Bolivia and Paraguay. In these cases, sovereign spreads are modeled using the average coefficients of the other countries of the region.
} 


$$
\Delta s_{i, t}=\beta_{i, 0}+\sum \boldsymbol{\beta}^{\prime} \Delta \boldsymbol{z}_{\boldsymbol{i}, \boldsymbol{t - 1}}+\sum \boldsymbol{\gamma}_{\boldsymbol{i}}^{\prime} \Delta \boldsymbol{x}_{\boldsymbol{i}, \boldsymbol{t}-\mathbf{1}}+\varepsilon_{i, t}
$$

where $\boldsymbol{z}_{i, \boldsymbol{t}}=\left(p d_{i, t} p b_{i, t} p d_{i, t}^{2}\right.$ ed $_{i, t}$ ca $_{i, t}$ fxres $_{i, t}$ nnreer $\left._{i, t}\right)$ is a vector of potential predetermined and exogenous variables, which are expected to have similar impact across countries, and $\boldsymbol{x}_{\boldsymbol{i}, \boldsymbol{t}}=\left(v i x_{t} i_{t}^{*} \boldsymbol{\operatorname { l n }} \boldsymbol{P}_{\boldsymbol{t}}^{\boldsymbol{W}}\right)$ is a vector of predetermined and exogenous variables with different effects across countries. We estimate this equation using a simple OLS regression (without constant). ${ }^{20}$

Of the country fundamentals considered only the level of public debt, international reserves and the real exchange rate appear to have a statistically significant role. Of the exogenous variables considered, only the VIX produces statistically significant and robust results, with important differences across idiosyncratic coefficients. Surprisingly, commodity prices do not appear to be important, perhaps because of their close correlation with the VIX and the fact that the real exchange rate captures much of the impact of changes in trade prices.

As before, our interest resides primarily in the forecast properties of the model, especially during bad external scenarios. Thus, we choose a specification that displays good forecasting performance both for crisis periods as well as subsequent normal times. We do this by evaluating the out-of-sample forecasting accuracy of the different specifications and estimation methods for the period 2008:M6 to 2012:M12 (see specification 6 in Annex Table A2).

\section{DEBT DYNAMICS UNDER ALTERNATIVE GLOBAL SCENARIOS}

\section{A. Scenarios}

We first focus on debt dynamics under "baseline" global assumptions (i.e., IMF's World Economic Outlook latest projections). ${ }^{21}$ Then, we study how debt sustainability in the region would change under four alternative (adverse) global scenarios, each defined by exogenously determined paths for the exogenous variables. We explore two scenarios of temporary shocks and two others where shocks have more permanent effects. A brief characterization of each scenario is as follows: ${ }^{22}$

\section{Scenario 1: Temporary Financial Shock}

This scenario entails a temporary 'pure' financial shock, reflected in a spike of the VIX in 2013 of similar magnitude than the one observed after the Lehman event, with the VIX returning to baseline levels in 2014. Real variables, such as global growth and commodity prices are assumed to remain unchanged at baseline levels. While the latter is a strong assumption, it is meant to allow the scenario to capture the effect of a shock that is mostly financial.

\section{Scenario 2: Temporary Real Shock}

This scenario assumes a temporary global recession, with lower growth and commodity prices during 2013-2014, returning to the baseline path afterwards. This scenario can be characterized as a backdrop where global uncertainties remain somewhat elevated for some time - leading to a global economic slowdown, but no crisis - and are eventually resolved.

\footnotetext{
20 We also considered two alternative estimation methods: panel with fixed effects and panel with random effects, and the results did not change significantly. We chose the OLS approach, since it appears to display the best (out-of-sample) forecasting properties.

21 The analysis leaves aside any issue related to possible changes in the (currency or maturity) composition of public and external debt following a shock, as these would require a much stronger set of behavioral assumptions.

22 A detailed description and the path of external variables, both under the baseline and the alternative scenarios, are presented in Table 1 and Figure 3. It is worth noting that the analysis does not consider adverse scenarios that are country-specific in nature. For example, shocks stemming from large neighbors (e.g., Brazil) could be an additional relevant shock, not studied here, for several Mercosur members (Argentina, Uruguay, and Paraguay - see Adler and Sosa, 2014).
} 


\section{Scenario 3: A Protracted Global Slowdown}

This scenario entails a relatively high level of uncertainty (as reflected by current levels of the VIX), lower commodity prices and lower global growth (all relative to the baseline). The scenario does not assume abrupt changes, but rather protracted weakness in real global variables.

\section{Scenario 4: A Tail Event}

In contrast to scenario 3, this is an extreme event meant to study the implications of a crisis with an impact on global variables (VIX, global GDP growth, and commodity prices) of magnitudes similar to those observed after the Lehman event. Unlike that episode - which displayed a quick rebound of commodity prices, and, to a lesser extent, global growth - this scenario assumes that a new Lehman-like event would have more protracted effects on the global economy, as fiscal and monetary space in advanced economies is today much more limited than in 2008.

For each of these scenarios, a path of global exogenous variables is assumed (Table 1 and Figure 3). These variables include: global growth, the VIX index, the 10-year U.S. T-bill interest rate, commodity prices (food, energy and metals). Some general assumptions on the extent of non-debt creating capital inflows and on reserve accumulation are also made in order to fully specify the set of exogenous variables.

Table 1.

Key Global Assumptions under Alternative Scenarios

\begin{tabular}{|c|c|c|c|c|c|c|}
\hline \multirow{3}{*}{\multicolumn{2}{|c|}{ Global Assumptions }} & \multicolumn{5}{|c|}{ Scenarios } \\
\hline & & \multicolumn{2}{|r|}{1} & 2 & 3 & \multirow[b]{2}{*}{ Tail Ev } \\
\hline & & $\begin{array}{l}\text { Baseline (BL) } \\
\text { 2013-2017 avg. }\end{array}$ & Financial Shock $^{1)}$ & $\begin{array}{c}\text { Global } \\
\text { Recession }^{2)}\end{array}$ & $\begin{array}{l}\text { Protracted } \\
\text { Global } \\
\text { Slowdown }\end{array}$ & \\
\hline \multicolumn{2}{|c|}{$\begin{array}{l}\text { G8+China GDP Growth } \\
\text { (percent) }\end{array}$} & 3,6 & BL & $\begin{array}{l}\text { 2013: BL-1.5\% } \\
\text { 2014: BL-0.5\% } \\
\text { 2015-2017: BL }\end{array}$ & BL-1\% & $\begin{array}{l}\text { 2013: Lehman-like } \\
\text { 2014-2017: BL-1\% }\end{array}$ \\
\hline \multicolumn{2}{|l|}{ VIX (points) } & 17 & $\begin{array}{l}\text { 2013: Lehman-like } \\
\text { 2014-2017: = BL }\end{array}$ & $\mathrm{BL}$ & $\mathrm{BL}+4 \mathrm{pts}$ & $\begin{array}{l}\text { 2013: Lehman-like } \\
\text { 2014-2017: BL+2pts }\end{array}$ \\
\hline \multicolumn{2}{|c|}{$\begin{array}{l}\text { 10-year US Treasury } \\
\text { Interest Rate (basis points) }\end{array}$} & 300 & $\begin{array}{l}\text { 2013: BL-100bps } \\
\text { 2014-2017: BL }\end{array}$ & $\sqrt{ }$ & BL-50bps & $\begin{array}{l}\text { 2013-2014: BL-100bps } \\
\text { 2015-2017: BL-50bps }\end{array}$ \\
\hline \multirow{3}{*}{$\begin{array}{l}\text { Commodity } \\
\text { Prices }\end{array}$} & Food & $-10^{5)}$ & $\mathrm{BL}$ & $\begin{array}{l}\text { 2013: } \mathrm{BL}-10 \%{ }^{7)} \\
\text { 2014-2017: } \mathrm{BL}\end{array}$ & BL-7\% & $\begin{array}{l}\text { 2013: BL-15\% } \%^{8)} \\
\text { 2014-2017: BL-5\% }\end{array}$ \\
\hline & Energy & $-8^{5)}$ & $\sqrt{ }$ & $\begin{array}{l}\text { 2013: } \mathrm{BL}-25 \% 7) \\
\text { 2014-2017: BL }\end{array}$ & BL- $15 \%$ & $\begin{array}{l}\text { 2013: BL-45\%8) } \\
\text { 2014-2017: BL-10\% }\end{array}$ \\
\hline & Metals & $-8^{5)}$ & $\sqrt{ }$ & $\begin{array}{l}\text { 2013: } \mathrm{BL}-20 \% 7) \\
\text { 2014-2017: } \mathrm{BL}\end{array}$ & BL- $15 \%$ & $\begin{array}{l}\text { 2013: BL-35\%8) } \\
\text { 2014-2017: BL-10\% }\end{array}$ \\
\hline \multicolumn{2}{|c|}{ Non-debt flows } & by country ${ }^{6}$ & $\sqrt{ }$ & $\mathrm{BL}$ & $\mathrm{BL} * 0.7$ & $\begin{array}{l}\text { 2013: } \mathrm{BL}+2008-2009 \\
\text { change } 2014-2017: \mathrm{BL} * 0.8\end{array}$ \\
\hline
\end{tabular}

1) Temporary financial shock affecting 2013 only. Financial variables return to projected path under the baseline in 2014.

2) Temporary real shock (commodity prices and world growth) in 2013-2014. Variables return to projected path under the baseline in 2015 .

3) Global slowdown over the whole forecast horizon.

4) Lehman-like event in 2013-2014, with protracted impact on global growth, commodity prices and the VIX.

5) Relative to 2012 level.

6) As projected by IMF country desks for each country.

7) Reported gap vis-à-vis baseline is reached by end-2013. Prices recover gradually afterwards to reach baseline by end-2014.

8) Reported gap vis-à-vis baseline is reached by 2013-Q2. Prices recover gradually afterwards to reach new path by end-2014. 
Figure 3.

Global Variables under Alternative Scenarios, 2003-2017

Baseline

Commodity Prices

(Index, in real terms)

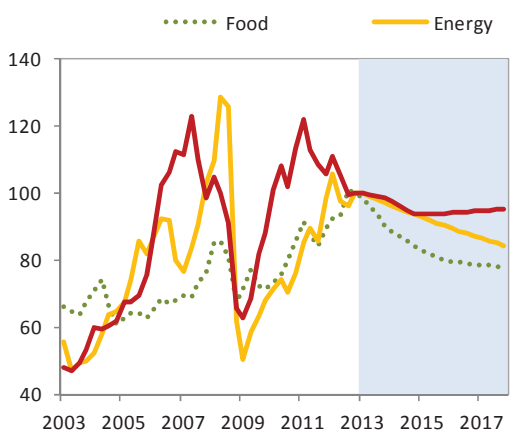

Growth and Financial Variables (percent and points)

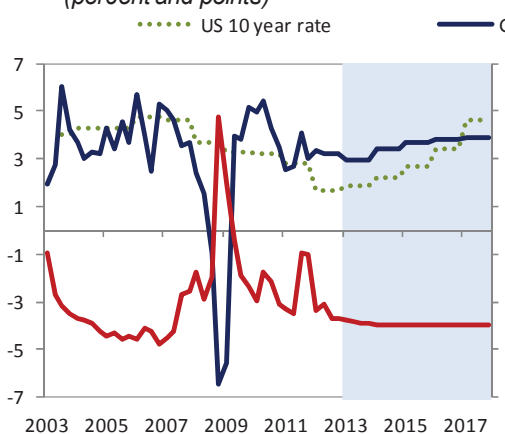

Scenario 1

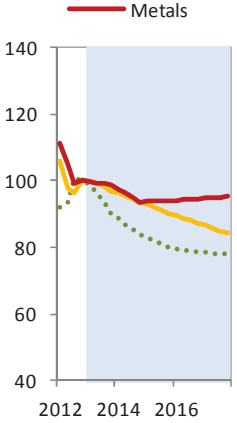

Scenario 2

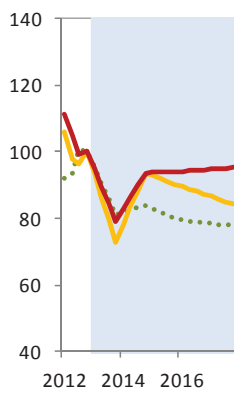

Scenario 3

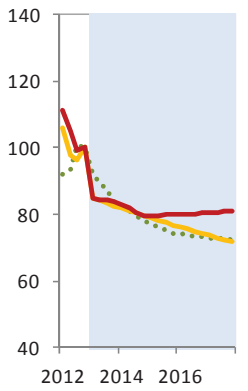

Scenario 4

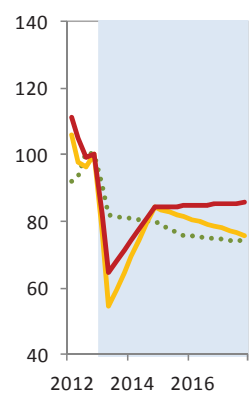

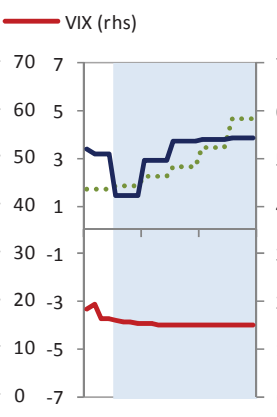

201220142016

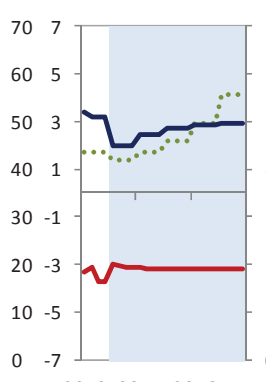

201220142016

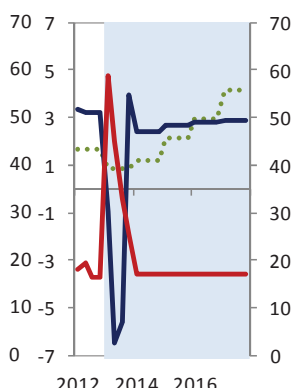

Sources: IMF's World Economic Outlook and authors' assumptions.

The VAR model (together with the spread equation) and the debt motion equations capture the key linkages between domestic and external variables. To fully determine the dynamics of debt ratios, however, a few assumptions on domestic policy are also necessary, as noted in section II. These include: (i) the output elasticity of non-commodity fiscal revenue; (ii) real public expenditure policy; and (iii) the extent of reserve accumulation. ${ }^{23}$ Table 2 details these key assumptions under each of the four alternative scenarios.

The assumptions on real expenditure growth deserve special attention as they determine the degree of cyclicality of the fiscal stance, given the endogeneity of the other components of the primary balance. ${ }^{24}$ For each scenario we study three different expenditure rules:

Baseline fiscal policies. In this case, real expenditure growth behaves as in the baseline projection, regardless of the scenario under consideration. The idea is to focus on the 'pure' impact of changing external conditions, maintaining policies unchanged.

Neutral fiscal policy. Fiscal policy, however, is likely to react to negative external shocks. Thus, we consider an expenditure rule that implies a broadly neutral stance - i.e., expenditure growing at potential GDP growth rates under each of the four scenarios; thus only allowing for automatic stabilizers to operate. ${ }^{25}$

\footnotetext{
23 The assumption about accumulation of reserves is needed to determine the path of sovereign spreads.

24 Commodity revenues are assumed to vary primarily with commodity prices, while non-commodity revenues vary with nominal GDP, as the elasticity of non-commodity revenues to output is assumed to equal one. While this elasticity may deviate from one at times - including because of possible revenue measures - the evidence suggests that, over the last decade, on average it has indeed been close to one.

25 An exception to this rule is introduced in cases where IMF baseline projections for 2013-2014 assume expenditure growth above potential GDP growth. In these cases, we assume expenditure growth equals the baseline projections, to avoid a situation where fiscal policy is more expansionary in the baseline than in the negative scenario. This exception also recognizes the fact that IMF country desks (and their projections) may have specific information about expenditure plans already in the pipeline.
} 
Counter-cyclical fiscal policy. Finally, we consider the possibility of counter-cyclical policies beyond the effect of automatic stabilizers. To make policies comparable across countries, we specify a simple rule such that, in each scenario, expenditure grows above potential GDP growth rate by a margin that is proportional (one-to-one) to the gap between actual GDP growth and potential GDP growth.

Exploring these alternative rules allows us to assess the extent to which, under each of the negative external scenarios, fiscal buffers are large enough to (i) respond by deploying countercyclical fiscal policy, (ii) just enough to allow automatic stabilizers to work, or (iii) there is no fiscal space for stimulus and a fiscal tightening is necessary to ensure debt sustainability. Our assessment focuses on sustainability, leaving aside risks related to possible financing (i.e., liquidity) shocks. It is important to stress that, for countries with well-established fiscal rules (e.g. Brazil, Chile, Mexico), the reported dynamics under the different scenarios should be interpreted as an illustration of how fiscal variables would behave in the event of a temporary deviation from the existing rules and, as such, of the magnitude of the fiscal adjustments that would be required to return to the target under the corresponding rule after the shock.

Table 2.

Key Domestic Policy Assumptions under Alternative Scenarios

\begin{tabular}{|c|c|c|c|c|c|c|}
\hline \multirow{3}{*}{\multicolumn{2}{|c|}{ Policy Assumptions }} & \multicolumn{5}{|c|}{ Scenarios } \\
\hline & & \multirow{2}{*}{$\begin{array}{l}\text { Baseline } \\
\text { (BL) } \\
\text { 2013-2017 avg. }\end{array}$} & \multirow[b]{2}{*}{$\begin{array}{l}\text { Financial } \\
\text { Shock }^{1)}\end{array}$} & 2 & 3 & 4 \\
\hline & & & & $\begin{array}{c}\text { Global } \\
\left.\text { Recession }^{2}\right)\end{array}$ & $\begin{array}{l}\text { Protracted } \\
\text { Global } \\
\text { Slowdown }\end{array}$ & Tail Event ${ }^{4)}$ \\
\hline \multicolumn{2}{|c|}{$\begin{array}{l}\text { Non-Commodity Revenue } \\
\text { Elasticity to Output }\end{array}$} & $\mathrm{BL}^{5)}$ & \multicolumn{4}{|c|}{1} \\
\hline \multirow{4}{*}{$\begin{array}{l}\text { Real } \\
\text { Expenditure } \\
\text { Growth } \\
\text { (percent) }\end{array}$} & BL & $\mathrm{BL}^{5)}$ & \multicolumn{4}{|c|}{$\mathrm{BL}^{5)}$} \\
\hline & Neutral & $\cdots$ & \multicolumn{4}{|c|}{$\begin{array}{l}\text { 2013-2014: } \max \{\text { scenario potential GDP growth; BL\} } \\
\text { 2015-2017: scenario potential GDP growth }\end{array}$} \\
\hline & \multirow[t]{2}{*}{ Counter-cyclical } & $\ldots$ & \multirow{2}{*}{\multicolumn{4}{|c|}{$\begin{array}{l}\text { 2013-2014: Neutral }+(-1) *(\text { current year growth }- \\
\text { scenario potential GDP growth) } \\
\text { 2015-2017: scenario potential GDP growth }\end{array}$}} \\
\hline & & & & & & \\
\hline \multicolumn{2}{|c|}{$\begin{array}{l}\text { Reserve Accumulation } \\
\text { (percent of } G D P \text { ) }\end{array}$} & $\mathrm{BL}^{5)}$ & $\mathrm{BL}$ & $\mathrm{BL}$ & 0 & $\begin{array}{c}2013:-2.0 \\
2014-2017: 0.0\end{array}$ \\
\hline
\end{tabular}

1) Temporary financial shock affecting 2013 only. Financial variables return to projected path under the baseline in 2014.

2) Temporary real shock (commodity prices and world growth) in 2013-2014. Variables return to projected path under the baseline in 2015 .

3) Global slowdown over the whole forecast horizon.

4) Lehman-like event in 2013-2014, with protracted impact on global growth, commodity prices and VIX.

5) As projected by IMF country desks for each country. 


\section{B. Key Results}

\section{Latin America's overall picture}

\section{WEO Baseline projections}

We first examine the projected trajectories of public and external debt under the baseline, with the path of global variables as in the Fall 2012 IMF's World Economic Outlook (WEO). The dynamics under the baseline sheds light on the region's debt sustainability in the absence of unexpected foreign shocks. It also plays a role in assessing debt sustainability under the alternative scenarios, as projected debt ratios are computed by adding to the WEO baseline the estimated impact of changes in external conditions. The latter is computed as the difference between the debt projection under each VAR scenario forecast and the projection under the VAR baseline forecast. ${ }^{26}$ By focusing on the 'marginal' impact of changes in global conditions on WEO's baseline projection, this approach ensures that country-specific information embedded in the latter - such as revenue measures or investment plans already in the pipeline - is incorporated in the scenario projections.

$$
\left.d_{t}\right|_{\text {Scenario } i}=\left.d_{t}\right|_{\text {WEO Baseline }}+\left(\left.d_{t}\right|_{\text {VAR Forecast } i}-\left.d_{t}\right|_{\text {VAR Forecast Baseline }}\right)
$$

Under the baseline both public and external debt ratios are, on average, expected to decline only slightly (less than 2 percentage points of GDP) through 2017, continuing with the trend observed since 2009 (Figure 4). In the case of public debt, commodity-related revenues will continue to be a major factor pushing debt down, although they will be mostly offset by the continuation of non-commodity primary deficits. With (non-interest) current accounts broadly balanced on average, Latin America's external debt dynamics will be largely determined by the offsetting forces of still large non-debt-creating capital inflows (FDI and equity portfolio flows) and further foreign asset accumulation.

\section{Alternative downside scenarios}

Next, we analyze the results across different scenarios, considering baseline policies - to identify the 'pure' impact of changes in external conditions, maintaining expenditure policy unchanged - as well as policies that entail a neutral stance or a counter-cyclical fiscal stance.

\section{(i) Baseline policies}

The results suggest that the impact of temporary negative external shocks (either financial or real, as depicted by scenarios 1 and 2) both on public and external debt would be, in general, limited (Figure 4) ${ }^{27}$ A temporary financial shock (scenario 1) would lead to an increase of public debt of about 7 percentage points of GDP by 2017 (relative to the baseline), with most of the impact arising from the deterioration in economic activity and the associated weakening of primary balances, reinforced by the effect of the real depreciation in countries with foreigncurrency denominated debt. A temporary real shock (scenario 2) would have a much more muted impact on public debt. Transitory shocks would not have visible effects on external debt dynamics. In the case of a financial shock (scenario 1) the effects of the associated real depreciation and rise in external interest rates (due to an increase in spreads) would be non-negligible, but they would be fully offset by the projected current account adjustment that would accompany this shock. Interestingly, the sharp increase in sovereign spreads under scenario 1 (Figure 4, lower panel)

\footnotetext{
26 VAR-estimated baseline projections are those resulting from the use of the VAR model under WEO baseline global assumptions. These may differ from the (IMF country desks') WEO baseline projections.

27 See country-by-country figures in Annex Figures A3-A13.
} 
would induce only a mild effect on average interest rates - and thus on debt dynamics - as a result of the relatively low levels of short-term debt. Annex Figures A3-A13 (lower panels) illustrates the (country-by-country) responses of the key variables under each of the alternative scenarios, based on the conditional forecasts obtained from the country-specific VAR models.

The impact of more persistent shocks to foreign variables (scenarios 3 and 4) on public debt trajectories would be, however, significantly higher. Under scenario 4, public debt would increase, on average, by 20 percentage points of GDP (to around 55 percent) by 2017, due to the combination of a sharp decline in output and the associated weakening of non-commodity primary balances, considerably lower commodity revenues, and a non-negligible effect stemming from the real depreciation. External debt, on the other hand, would remain at manageable levels under these scenarios, with increases of only 5-6 percentage points of GDP by 2017 - mainly reflecting lower growth, the effects of real depreciations, and a likely drop in non-debt capital inflows, offset partially by projected current account improvements.

\section{(ii) Active (Neutral and Countercyclical) Policies}

If authorities were to respond to the negative shocks of scenarios 1 and 2 by implementing either neutral or countercyclical policies (as defined earlier) the impact on public debt levels would be more pronounced, with stocks reaching about 46-51 percent and 41-44 percent of GDP by 2017, respectively (Figure 5, upper panel). While representing a sizeable impact, these levels do not appear to be particularly worrisome, especially given that primary balances would deteriorate only marginally and would not require to be adjusted significantly to keep public debt on a sustainable path. These scenarios would not entail a significant impact on external debt paths even under active policies.

Interestingly, under scenario 3, the debt trajectory associated with a counter-cyclical fiscal policy response would be very similar to the one resulting from a policy reaction that is essentially neutral. This reflects the fact that this scenario would imply not only a decline in actual GDP growth but also in potential growth, and thus the output gap - measured relative to the new potential - would be rather small (Figure 4, lower panel), and so would be the scope for expansionary fiscal policy. It is also worth highlighting that, if authorities failed to recognize that under this scenario the new potential growth rate is lower than previously estimated, what may be intended as a neutral stance would, in fact, be stimulative and would lead to a worsening of the primary balance and thus public debt dynamics.

Under scenario 4, there would be more scope for expansionary countercyclical policies, as output would fall significantly below (the new lower) potential levels. Both a neutral policy response - allowing automatic stabilizers to operate - and a countercyclical one would lead to substantial increases in public debt (of more than 20 and 30 percentage points of GDP by 2017, relative to the baseline, respectively). At those levels (65 percent of GDP in the case of countercyclical policies), concerns about fiscal sustainability may emerge, especially in countries where the required adjustment in the primary balance to stabilize debt ratios would be large.

Finally, external debt would increase to around 35 percent of GDP in the face of more persistent negative external shocks (scenarios 3 and 4), irrespective of policies. As discussed earlier, this partly reflects that current accounts in Latin America tend to improve after negative external (financial) shocks. 
Figure 4.

Latin America. Factors Driving Public and External Debt Dynamics under Alternative Global Scenarios, 2003-2017 ${ }^{1)}$ (contributions to change in debt-to-GDP ratio, in percent of GDP)
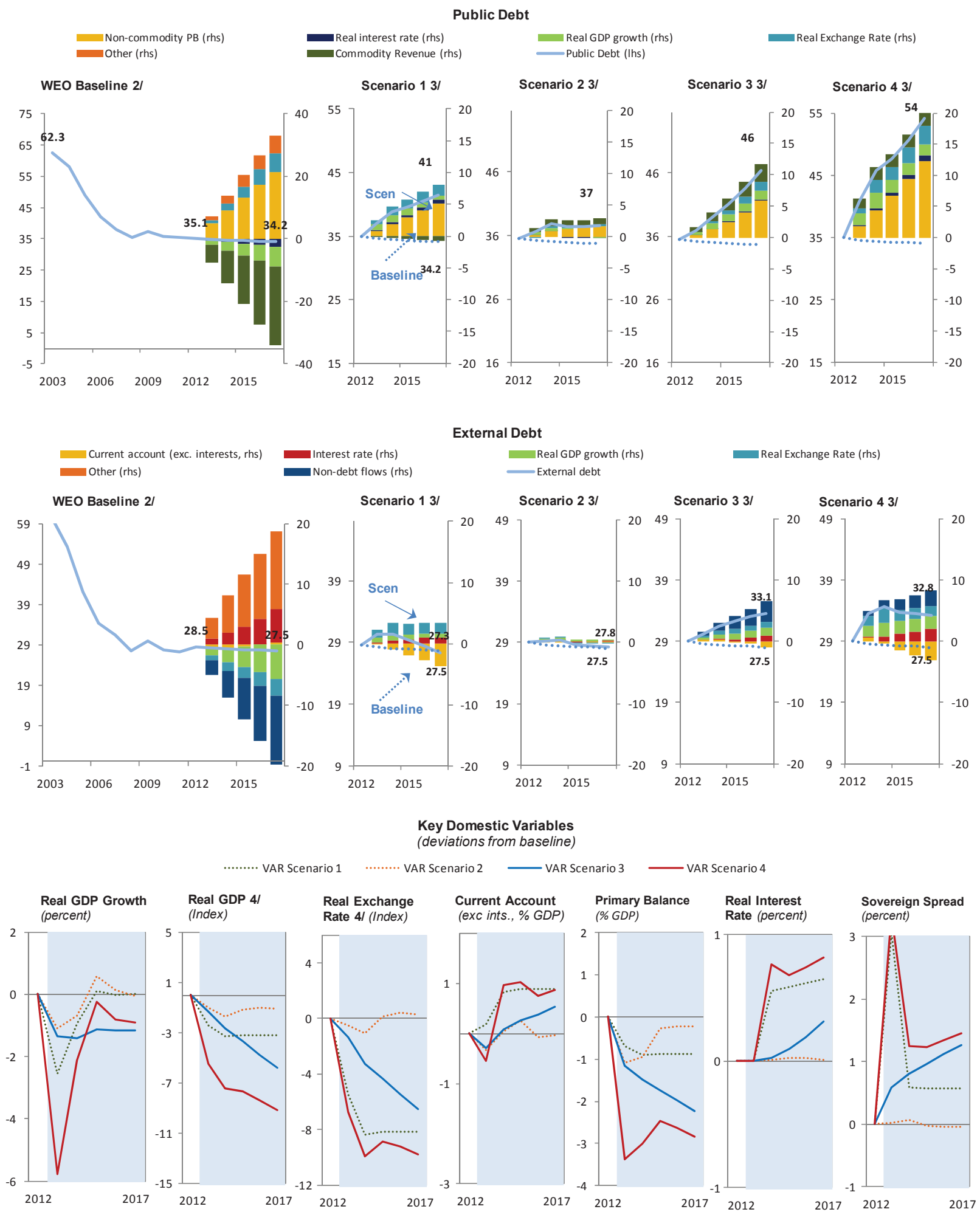

1) Simple average for Argentina, Bolivia, Brazil, Chile, Colombia, Ecuador, Mexico, Peru, Uruguay and Venezuela.

2) Country desk projections (based on WEO baseline assumptions).

3) Based on differential between VAR forecasts and VAR baseline. Bars denote contributions of different factors to the deviation of the debt ratios from the baseline. Fiscal (public expenditure) policies are maintained unchanged from the baseline.

4) Deviation in percent of baseline.

Sources: IMF International Financial Statistics and authors’ estimations. 
Figure 5.

Latin America. Public and External Debt under Alternative Scenarios and Policies, 2012-2017

(In percent of GDP, simple averages)
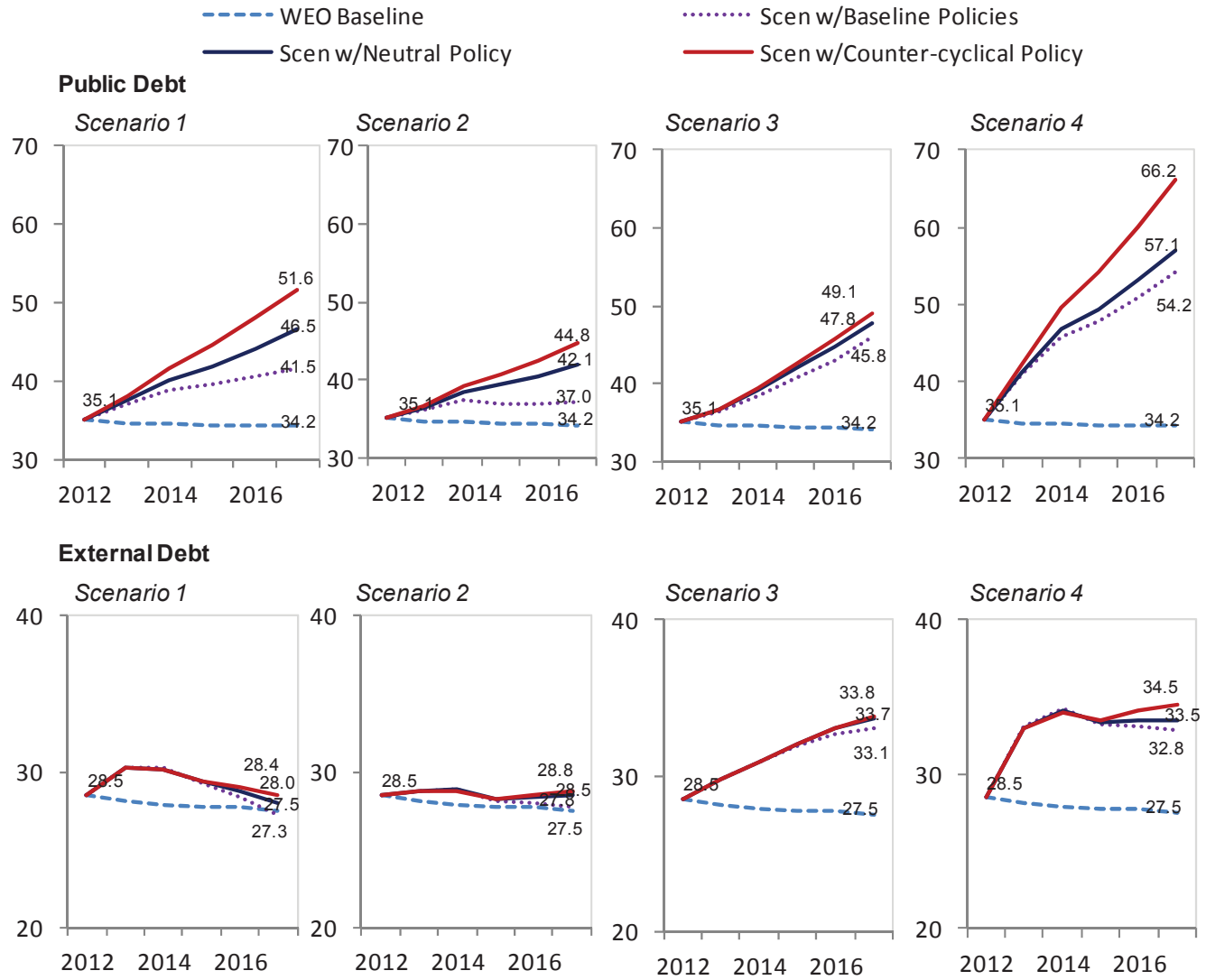

Source: authors' estimations.

\section{Country-specific results}

Averages for the region, however, mask important differences across countries (Figures 6 and 7).

\section{WEO Baseline projections}

Under baseline external conditions, public debt ratios will continue to decline moderately in most countries (Brazil and Uruguay, starting from higher initial levels, would experience the largest decreases), with primary balance gaps generally improving. A notable exception is Venezuela, where debt is projected to increase by 30 percentage points of GDP, reaching 80 percent of GDP, by $2017 .{ }^{28}$ External debt, in turn, is projected to remain broadly stable in most countries under the baseline external scenario.

\section{Alternative downside scenarios}

Most countries in the region should be in a position to undertake an expansionary countercyclical policy response in the event of temporary shocks (scenarios 1 and 2), without raising debt sustainability concerns (i.e., high debt and primary gap levels). An exception would be Venezuela, which would likely have limited or no scope for countercyclical policy, reflecting the combination of relatively weak initial positions and high sensitivity to these shocks (that could rapidly lead to large deficits).

28 In a few countries (mainly Argentina, Chile, Ecuador, Mexico and Venezuela), this baseline already projects fiscal consolidation to varying degrees. If such projections did not materialize, debt dynamics would worsen both under this baseline and the alternative scenarios (by construction). 
In case of external shocks with more protracted effects (scenarios 3 and 4), countries can be classified into three different groups based on the extent of fiscal buffers to implement either neutral or countercyclical fiscal policy responses, defined on the basis of the level of debt and primary balance gap that countries are forecasted to reach by the end of the forecast horizon (Figure 6):

First, a group of countries (Argentina and Venezuela) that would likely need to undertake sizeable fiscal consolidation in the face of adverse shocks, including - although to a lesser extent - moderate ones, to keep public debt on a sustainable path.

Second, a group (including Brazil, Mexico, Uruguay, and - to a lesser extent - Ecuador), which public debt dynamics would be less vulnerable to moderate shocks, although still significantly sensitive to tail events. In particular:

- This group should be in a position to deal with a moderate deterioration of the external environment (scenario 3), although debt ratios could reach levels (ranging from 55 to 65 percent of GDP) that - while manageable - would be relatively high for emerging market standards, and could make these economies vulnerable to possible subsequent adverse shocks. ${ }^{29}$

- Under a more severe event (scenario 4), scope for counter-cyclical policy, and to some extent even for neutral policies, would be limited without raising concerns about debt sustainability, as indicated by the sharp deterioration in debt levels and/or primary balance gaps. ${ }^{30}$

- In countries with well-established fiscal rules (Brazil, Mexico), adherence to the rule following a temporary deviation at the time of the adverse shock would, of course, ensure that public debt remains on a sustainable path. In some cases, however, returning to the fiscal targets under the rule could entail significant fiscal consolidation. ${ }^{31}$

Finally, a group of countries (Bolivia, Chile, Colombia, Paraguay, and Peru) that, to varying degrees, appear to be in a position to weather a marked worsening of external conditions - even undertaking countercyclical policies - without jeopardizing fiscal solvency. Peru appears to exhibit the strongest position, even under the described extreme circumstances. While in Chile and Paraguay, under scenario 4 and assuming countercyclical policies, both the primary balance gap and debt ratios could increase significantly, debt would still remain at relatively moderate levels. ${ }^{32}$ Colombia, with debt levels reaching over 50 percent of GDP and the primary balance gap over 4 percent of GDP, appears to exhibit a somewhat less solid fiscal position, though those figures should not raise concerns about fiscal solvency.

On the external front, even under the more extreme scenarios ( 3 and 4$)$ countries in the region would be in a position to maintain external sustainability under check (Figure 7). ${ }^{33}$ In fact, under both scenarios (and even assuming active policy responses) debt levels would remain moderate, and current account balance gaps would be either closed or positive. A key factor driving this result is - as noted earlier - the fact that current accounts tend to improve in the face of large negative external shocks (especially financial ones).

\footnotetext{
29 Furthermore, in the cases of Ecuador and Mexico, the baseline already assumes a path of fiscal consolidation (with public expenditure growing below potential GDP growth). If such consolidation did not take place, debt dynamics would worsen both under the baseline and the alternative scenarios.

30 For instance, countercyclical responses would lead to a sizeable jump in debt ratios to substantially high levels in Brazil, a sharp deterioration of the primary balance gap in Ecuador, or a combination of both in Mexico and Uruguay.

31 As indicated before, the focus of this paper is on the sustainability impact of external shocks, leaving aside the desirability of larger buffers to guard against possible idiosyncratic shocks. The latter could be of particular importance in resource-rich economies (e.g., Bolivia and Ecuador). For a further discussion of these issues, see IMF (2012b).

32 The fiscal position in Chile is further strengthened by the substantial stock of foreign assets in sovereign funds (about 11 percent of GDP in 2012).

33 An exception is Venezuela, where external sustainability concerns could be raised in case of a tail event.
} 
Figure 6.

Key Fiscal Indicators under Different Scenarios, 2012-2017¹) (percent of GDP)

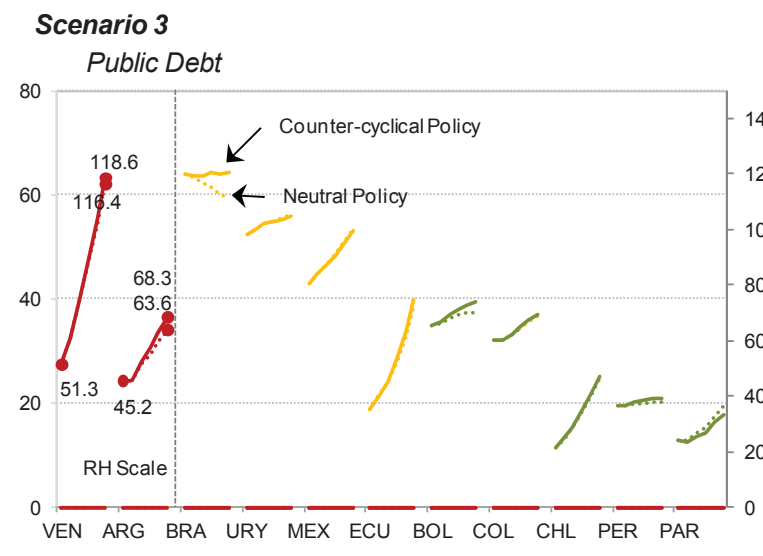

\section{Scenario 4}
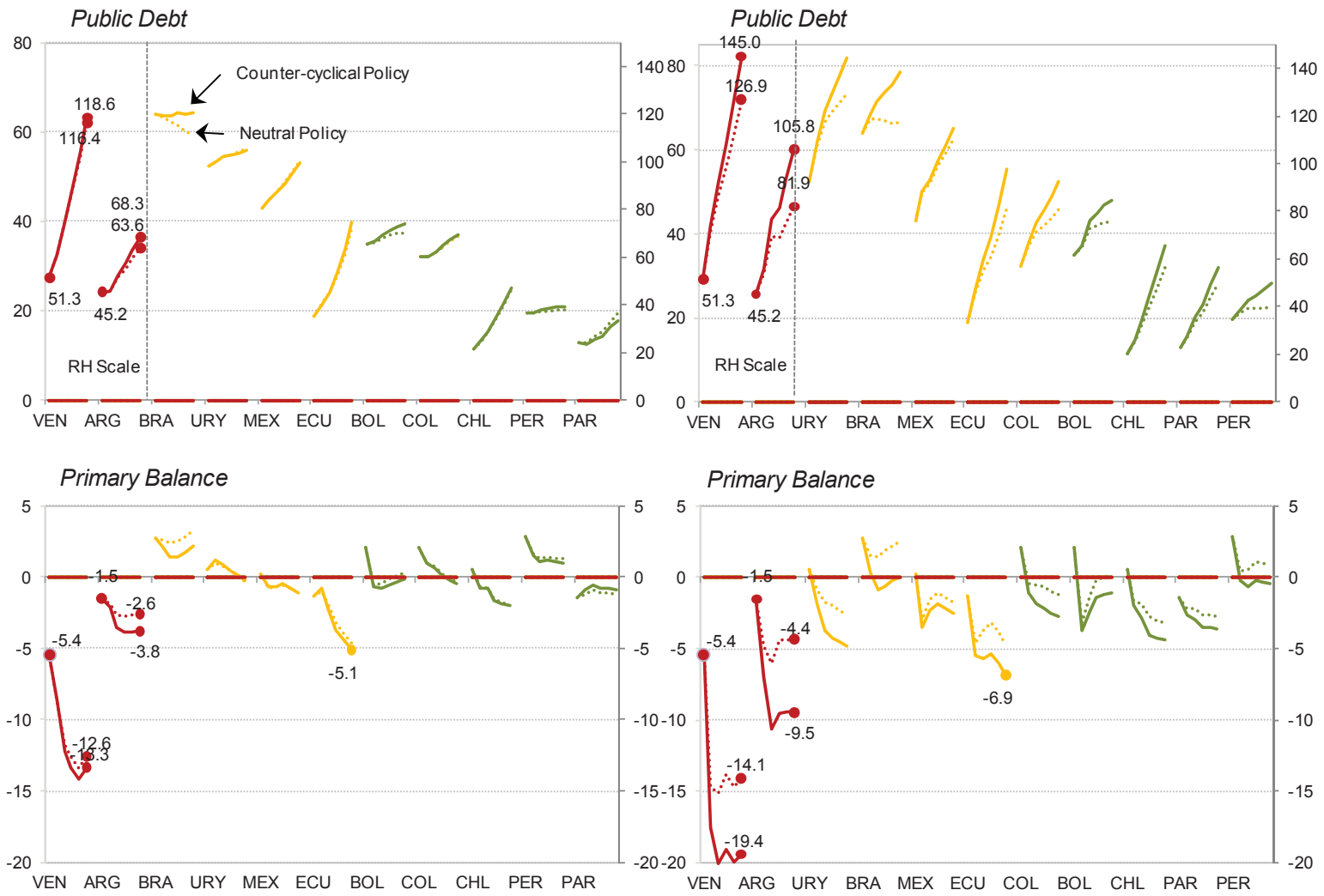

Primary Balance Gap 2)
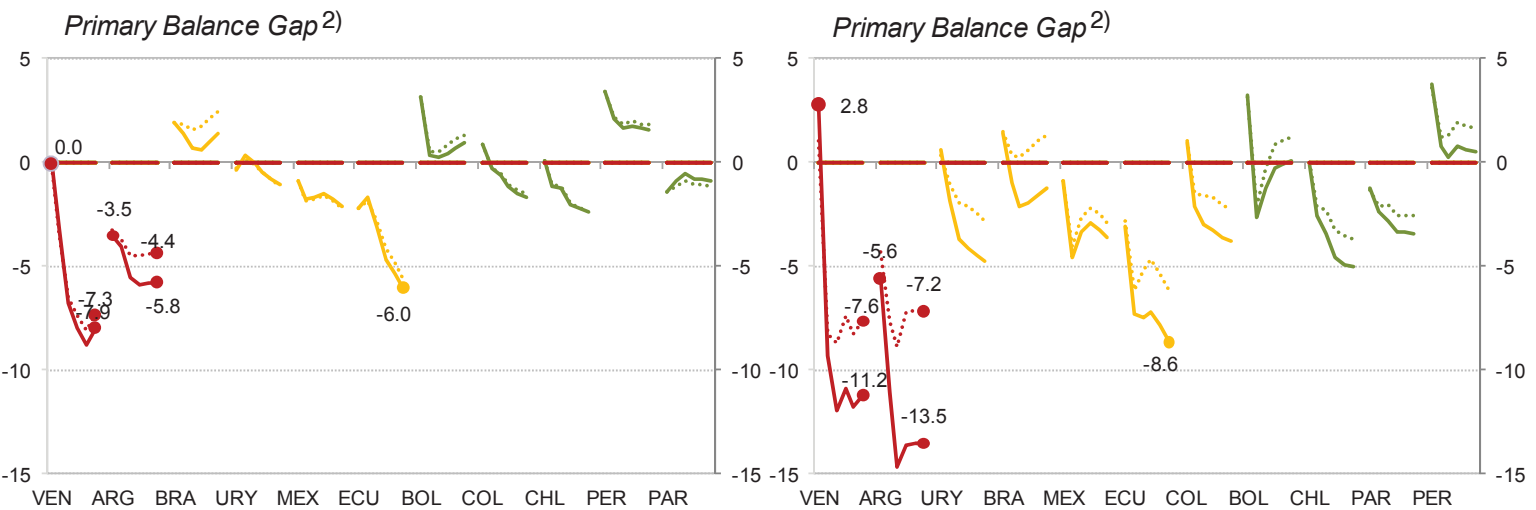

1) Series indicate the path of public debt and primary balance gap from 2012 to 2017 for each country. Solid lines denote path under neutral policies. Dotted lines corresponds to counter-cyclical policies.

2) Primary balance at year $t$ minus debt-stabilizing primary balance at 2017 , as defined in IMF DSA template. 
Figure 7.

Key External Indicators under Different Scenarios, 2012-2017 ${ }^{1)}$ (percent of GDP)
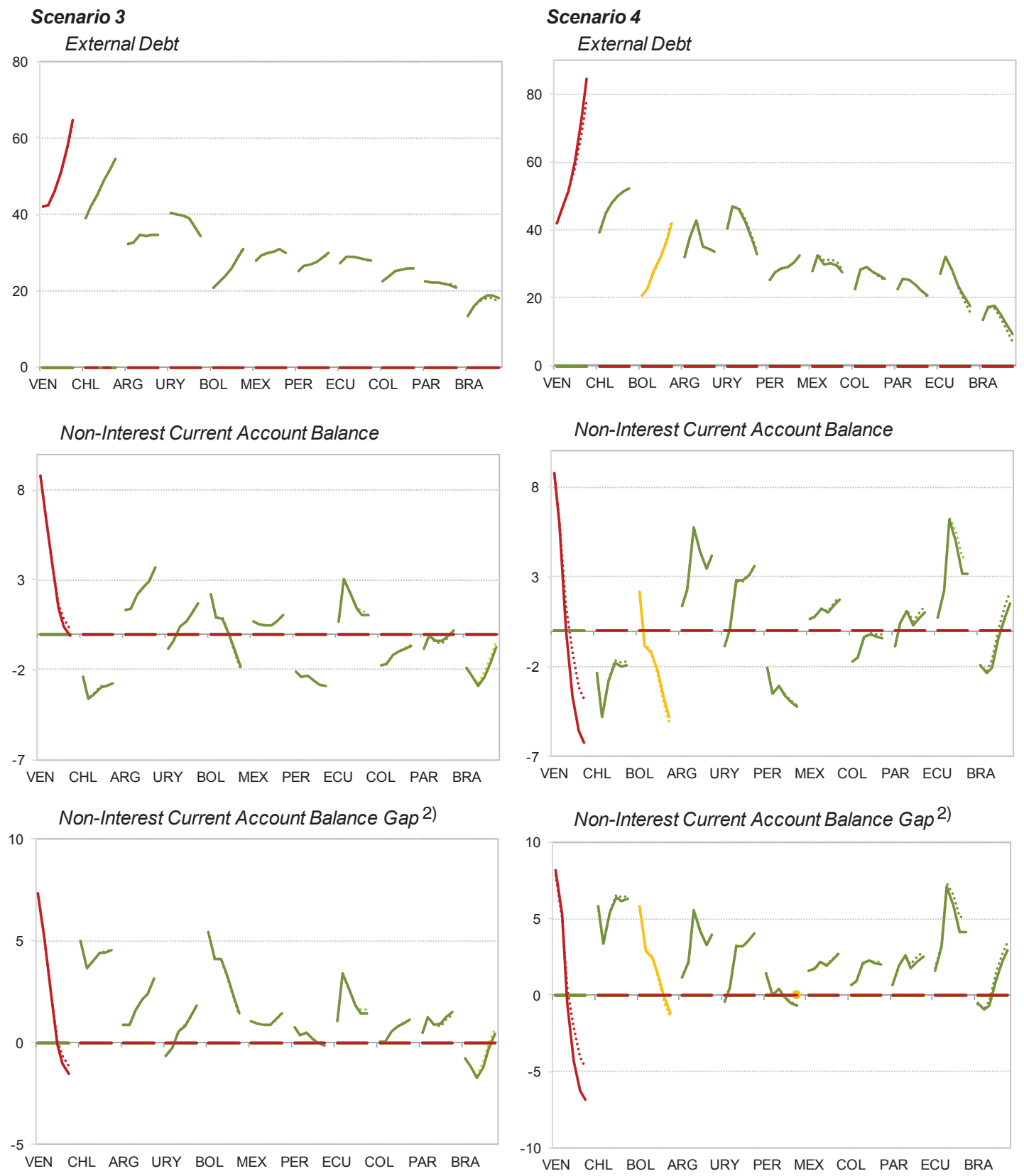

1) Series indicate the path of external debt and non-interest current account balance gap from 2012 to 2017 for each country. Solid lines denote path under neutral policies. Dotted lines corresponds to counter-cyclical policies.

2) Non-interest current account (NICA) balance at year t minus debt-stabilizing NICA balance at 2017, as defined in the IMF DSA template.

\section{CONCLUSIONS}

The paper proposes a simple framework that improves upon existing debt sustainability tools, incorporating the analysis of the impact of changes in external variables. Using this new framework, we examine the dynamics of Latin America's public and external debt sustainability indicators under alternative adverse external scenarios, thus informing the discussion on whether current fiscal and external positions are adequate to withstand a deterioration of the global environment.

The main results indicate that while external sustainability does not appear to be source of concern for Latin America in general, fiscal space to deal with a protracted deterioration of the 
external environment may still be limited in several countries. These results suggest that the region would benefit from further strengthening buffers, while favorable conditions last, to be in a position to actively use fiscal policy should the external environment deteriorate markedly.

There are, however, some important differences across countries and three groups can be identified according to the degrees of fiscal space to deal with negative external shocks: (i) a group (Argentina and Venezuela) that would face tight fiscal constraints even in the face of relatively moderate shocks, likely precluding the deployment of counter-cyclical policy; (ii) a group (Brazil, Mexico, Uruguay, and - to a lesser extent - Ecuador) that would have some space to run countercyclical fiscal policy but would benefit from building further space to be able to respond actively without raising concerns about fiscal sustainability or requiring large subsequent fiscal consolidations, specially under severe scenarios; and finally (iii) a group (Bolivia, Chile, Paraguay, Peru, and - to a lesser extent - Colombia) that appears to be today in a position to weather sizeable shocks with counter-cyclical policies without compromising debt sustainability.

\section{Acknowledgment}

We thank Saúl Lizondo, Miguel Savastano, Charles Kramer, Dora Iakova, Gian Maria Milesi-Ferretti, Luis Cubeddu, Oya Celasun, Ulric Erickson von Allmen, Herman Kamil, Leonardo Martinez, Esteban Vesperoni, and participants at the International Monetary Fund's Western Hemisphere Department seminar series for their useful comments and feedback, and Andresa Lagerborg for her excellent research assistance. We also thank two anonymous referees for their detailed and valuable feedback. The views expressed in this paper are those of the authors and do not necessarily represent the views of the IMF, its Executive Board, or IMF management.

\section{References}

Adler, G., and Sosa, S. (2011). Commodity Price Cycles: The Perils of Mismanaging the Boom. IMF Working Paper 11/283. Washington: International Monetary Fund.

Adler, G., and Sosa, S. (2013). External Conditions and Debt Sustainability in Latin America. IMF Working Paper 13/27. Washington: International Monetary Fund.

Adler, G., and Sosa, S. (2014). Intra-Regional Spillovers in South America: Is Brazil Systemic after All? The World Economy Vol. 37, Issue 3, pp. 456-480. doi: 10.1111/twec.12094

Adler, G., and Tovar, C. (2012). Riding Global Financial Waves: The Economic Impact of Global Financial Shocks on Emerging Market Economies. IMF Working Paper 12/188. Washington: International Monetary Fund.

Banbura, M., Giannone, D., and Lenza, M. (2014). Conditional forecasts and scenario analysis with vector autoregressions for large cross-sections, CEPR Discussion Papers 9931, C.E.P.R.

Barroso, J.B.R.B. (2014). External Sustainability and Gross Positions: are Brazilian external accounts sustainable? Working Papers Series 362, Central Bank of Brazil.

Bloom, N. (2009). The Impact of Uncertainty Shocks. Econometrica, Vol. 77, No. 3.

Carriere-Swallow, Y., and Cespedes, L.F. (2011). The Impact of Uncertainty Shocks in Emerging Economies. Documento de Trabajo $\mathrm{N}^{\circ} 646$, Central Bank of Chile.

Celasun, O., Debrun, X., and Ostry, J.D. (2006). Primary Surplus Behavior and Risks to Fiscal Sustainability in Emerging Market Countries: A ‘Fan-Chart' Approach. IMF Working Paper 06/67. Washington: International Monetary Fund.

Cespedes, L.F., and Velasco, A. (2011). Was this Time Different?: Fiscal Policy in Commodity Republics. BIS Working Paper No 365. Basel: Bank of International Settlements.

Cuadra, G., Sanchez, J., and Sapriza, H. (2010). Fiscal Policy and Default Risk in Emerging Markets. Review of Economic Dynamics, Vol. 13 (2).

Cherif, R., and Hasanov, F. (2012). Public Debt Dynamics: The Effects of Austerity, Inflation, and Growth Shocks. IMF Working Paper 12/230. Washington: International Monetary Fund. 
Favero, C., and Giavazzi, F. (2007). Debt and the Effects of Fiscal Policy. NBER Working Paper No. 12822. Cambridge, Massachusetts: National Bureau of Economic Research.

Favero, C., and Giavazzi, F. (2009). How Large are the Effects of Tax Changes? NBER Working Papers No. 15303. Cambridge, Massachusetts: National Bureau of Economic Research.

Frankel, J.A., Végh, C., and Vuletin, G. (2011). On Graduation from Fiscal Procyclicality. NBER Working Paper No. 17619. Cambridge, Massachusetts: National Bureau of Economic Research.

Hatchondo, J.C., Martinez, L., and Roch, F. (2012) Fiscal Rules and the Sovereign Default Premium. IMF Working Paper 12/30. Washington: International Monetary Fund.

Inter-American Development Bank. (2008). All that Glitters May Not be Gold. Assessing Latin America`s Recent Macroeconomic Performance. Annual Report. Washington: Inter-American Development Bank.

International Monetary Fund. (2002). Assessing Sustainability. SM/O2/166. Washington: International Monetary Fund. Available at: https://www.imf.org/external/np/pdr/sus/2002/eng/052802.htm

International Monetary Fund. (2003). Sustainability Assessments-Review of Application and Methodological Refinements. SM/O3/206. Washington: International Monetary Fund. Available at: https://www.imf.org/ external/np/pdr/sustain/2003/061003.htm

International Monetary Fund. (2005). Information Note on Modifications to the Fund's Debt Sustainability Assessment Framework for Market Access Countries. Washington: International Monetary Fund. Available at: https://www.imf.org/external/np/pp/eng/2005/070105.pdf

International Monetary Fund. (2011). Modernizing the Framework for Fiscal Policy and Public Debt Sustainability Analysis. Washington: International Monetary Fund. Available at: http://www.imf.org/external/np/pp/ eng/2011/080511.pdf

International Monetary Fund. (2012a). Regional Economic Outlook: Western Hemisphere-Rebuilding Strength and Flexibility. Washington: International Monetary Fund. Available at: https://www.imf.org/external/pubs/ft/ reo/2012/whd/eng/wreo0412.htm

International Monetary Fund. (2012b). Macroeconomic Policy Frameworks for Resource-Rich Developing Countries. Washington: International Monetary Fund. Available at: https://www.imf.org/external/np/pp/ eng/2012/082412.pdf.

Izquierdo, A., Romero, R., and Talvi, E. (2007). Booms and Busts in Latin America: The Role of External Factors. $I A D B$ Working Paper No. 631. Washington: Inter-American Development Bank.

Kawakami, K., and Romeu, R. (2011). Identifying Fiscal Policy Transmission in Stochastic Debt Forecasts. IMF Working Paper 11/107. Washington: International Monetary Fund.

Mendoza, E., and Oviedo, P. (2009). Public Debt, Fiscal Solvency and Macroeconomic Uncertainty in Latin America The Cases of Brazil, Colombia, Costa Rica and Mexico. Economía Mexicana NUEVA ÉPOCA, Vol. (2), pp. 133-173.

Oreiro, J.L. and Passos, M. (2005). A Governança da Política Monetária Brasileira: Análise e proposta de mudança. Working Papers 0008, Universidade Federal do Paraná, Department of Economics.

Osterholm, P., and Zettelmeyer, J. (2008). The Effect of External Conditions on Growth in Latin America. IMF Staff Papers, Volume 55, Number 4.

Talvi, E., and Vegh, C. (2005). Tax Base Variability and Procyclicality of Fiscal Policy. Journal of Development Economics, 78 (1).

Tanner, E., and Samake, I. (2008). Probabilistic Sustainability of Public Debt: A Vector Autoregression Approach for Brazil, Mexico, and Turkey. IMF Staff Papers Vol. 55, No 1.

Tornell, A., and Lane, P. (1999). The Voracity Effect. American Economic Review, 891: 22-46. 


\section{APPENDIX}

Figure A1. Latin America. Key Fiscal Indicators, 2002-20121)
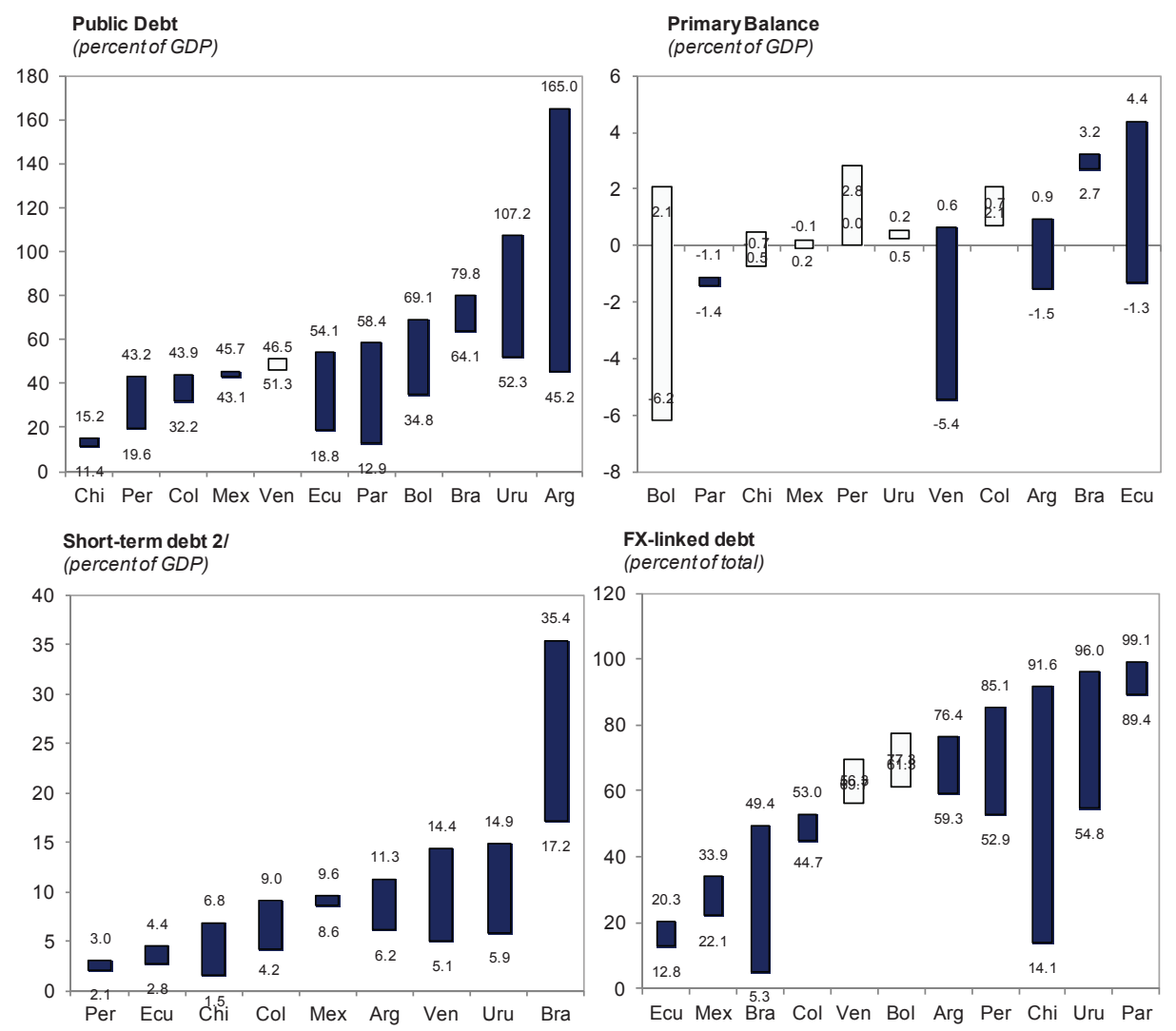

FX-linked debt
(percent of total)


1) Blue (white) filled bars indicate a decrease (increase) in the variable from 2002 to 2012.

2) At residual maturity.

3) Cumulative change of gross international reserves since 2002.

Sources: IMF International Financial Statistics, and country desks.

\section{(c) Faculty of Management University of Warsaw. All rights reserved.}


Figure A2. Forecasting Power of VAR Model During the Lehman Event


... 95\% C.I.

Figure A2 (cont.). Forecasting Power of VAR Model During the Lehman Event
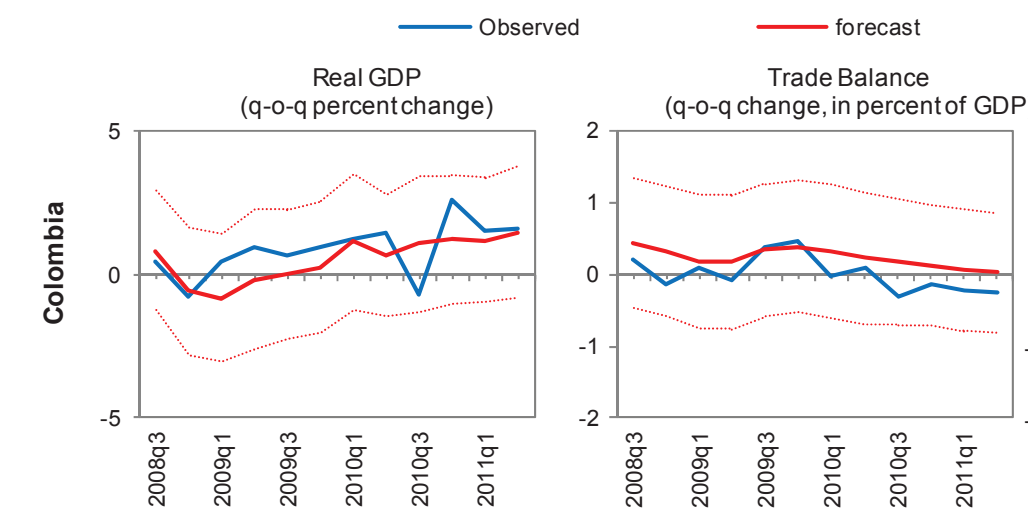

……........ 95\% C.I.

REER
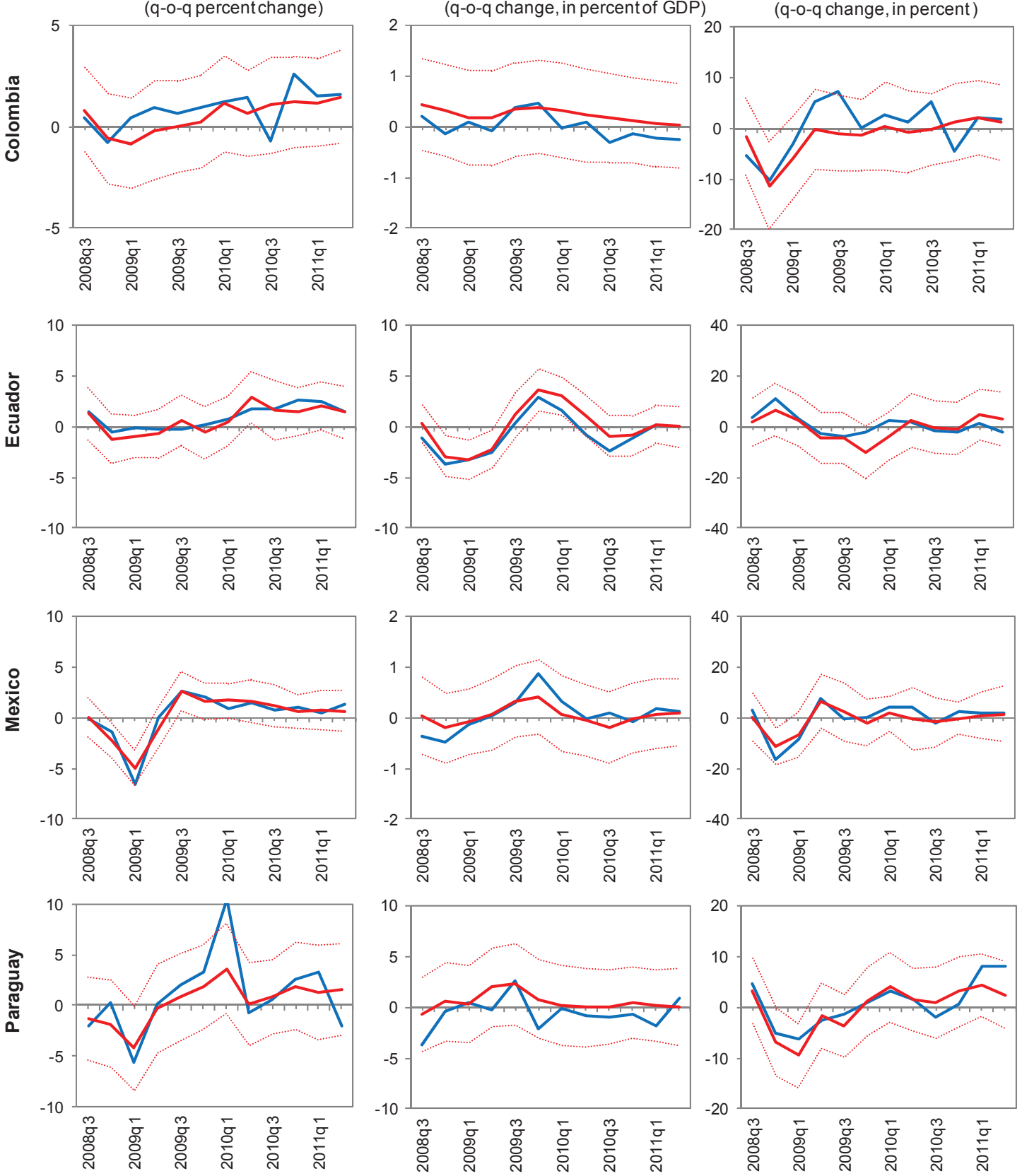
Figure A2 (cont.). Forecasting Power of VAR Model During the Lehman Event
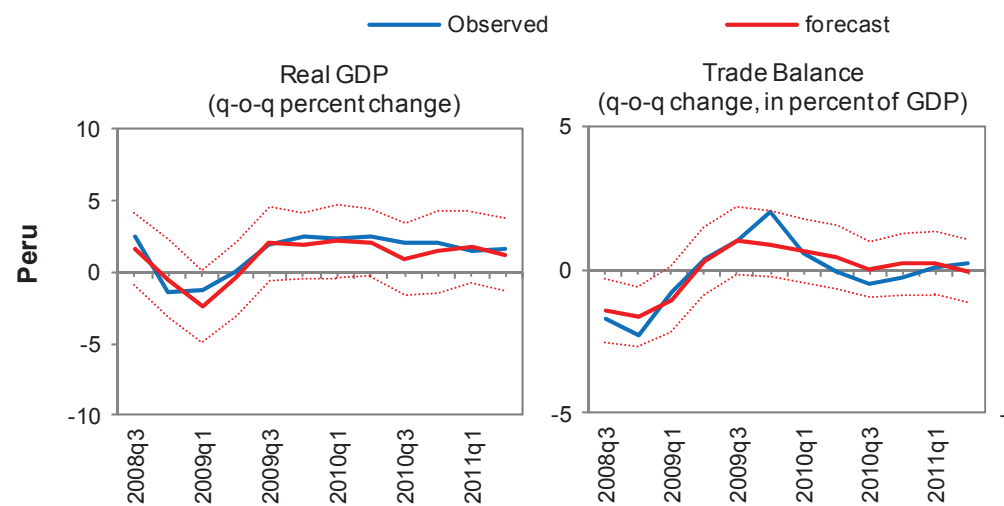

............. $95 \%$ C.I.
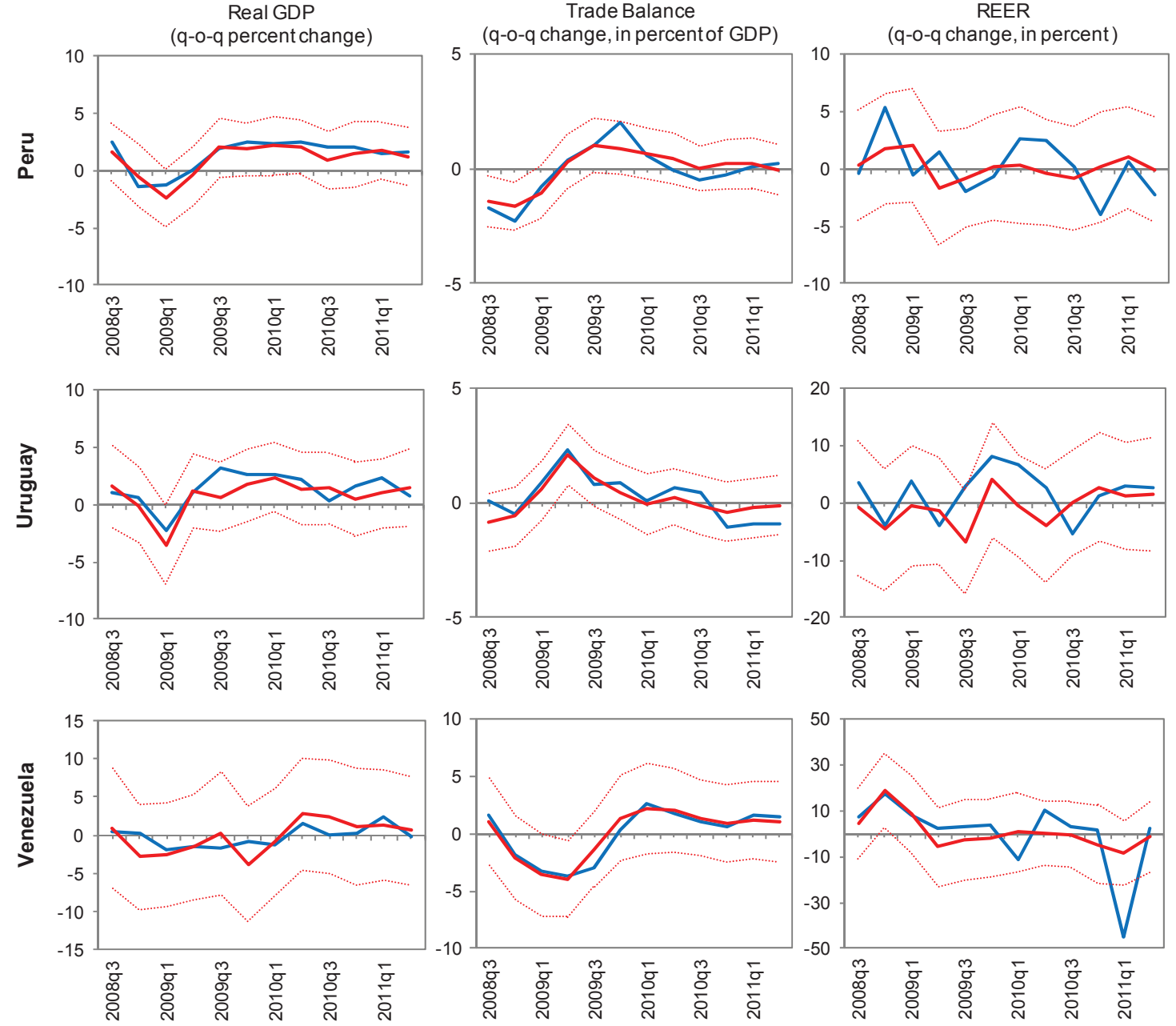

Source: Authors' estimates. 
Figures A3-A13.

\section{Argentina}

Factors Driving Public and External Debt Dynamics, 2003-2017 ${ }^{1 /}$ (percent of GDP)
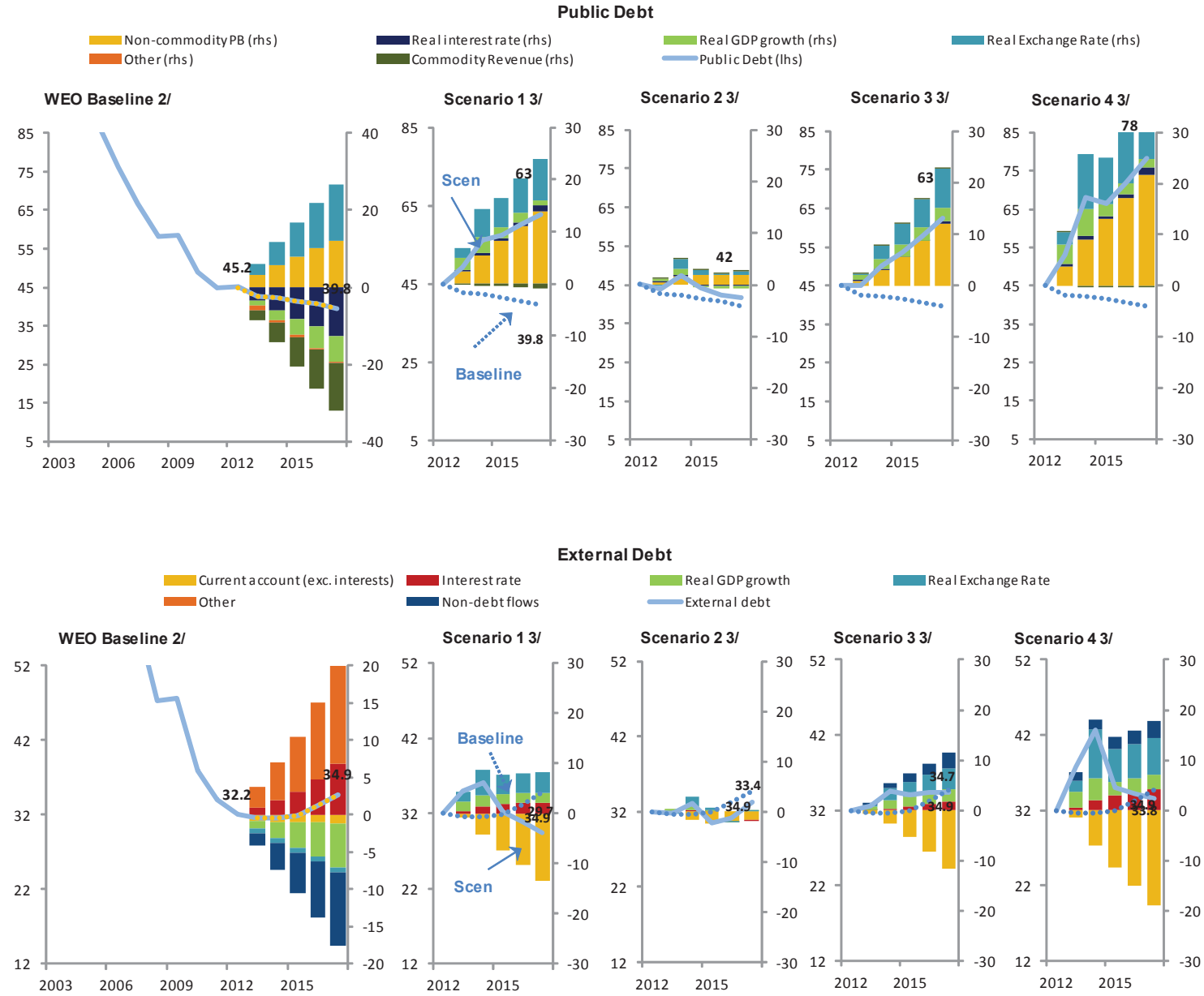

1/ Public and external debt dynamics under alternative global scenarios.

2/ Country desk projections (based on WEO baseline assumptions).

${ }^{3 /}$ Based on differential between VAR forecasts and VAR baseline. Bars denote contributions of different factors to the deviation of the debt ratios from the baseline.

Key Domestic Variables under Alternative Scenarios, 2012-2017 (deviations from baseline)

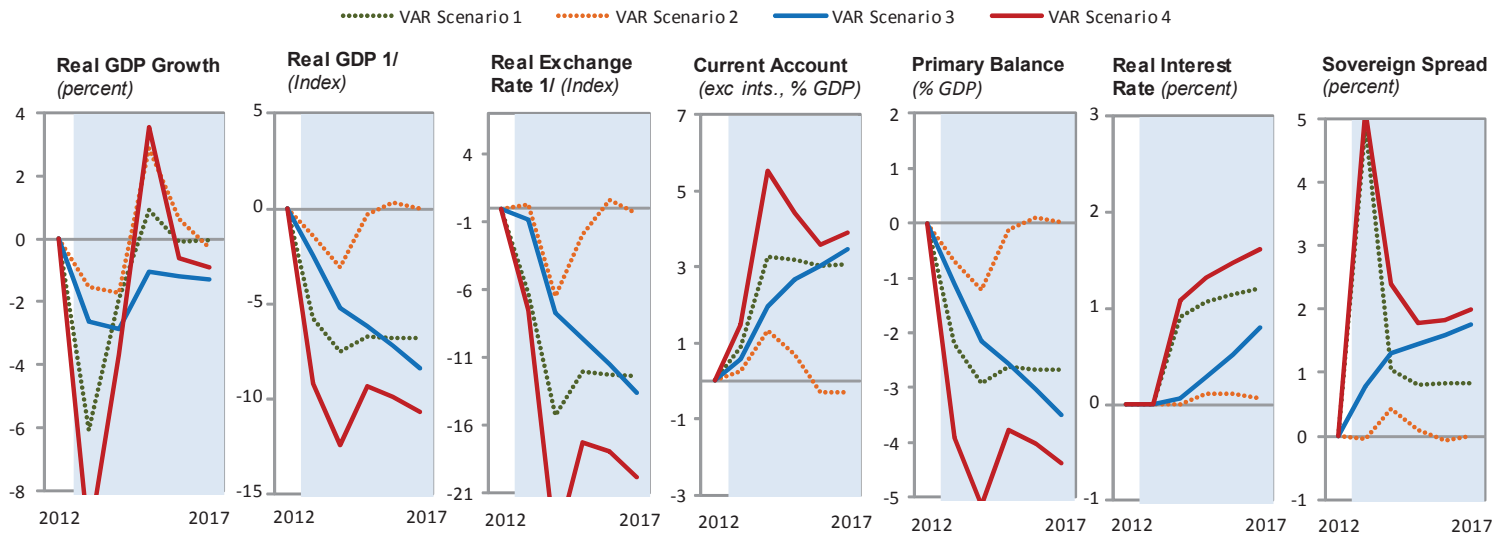

1/ Deviation in percent of baseline. 


\section{Bolivia}

Factors Driving Public and External Debt Dynamics, 2003-2017// (percent of GDP)
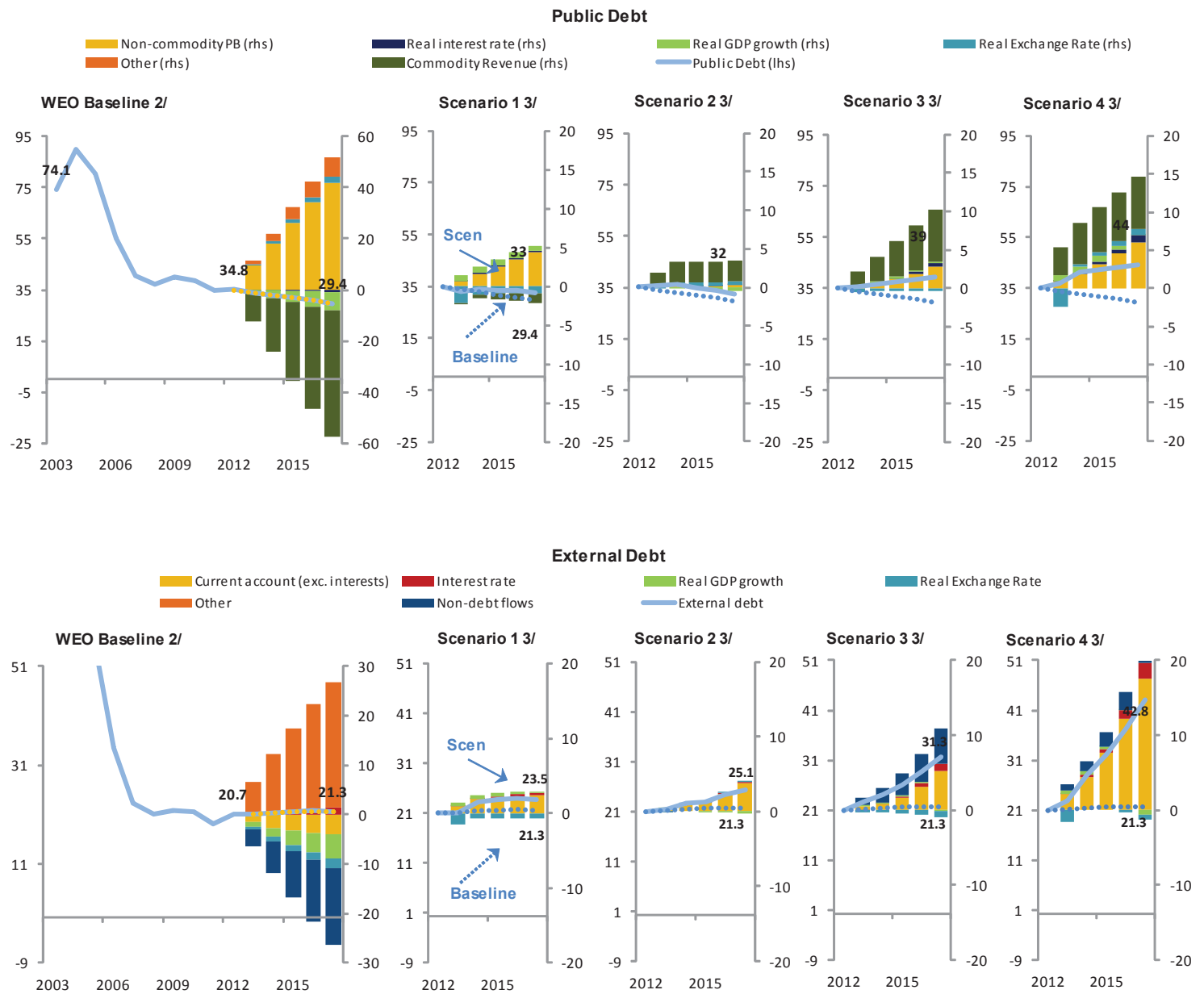

1/ Public and external debt dynamics under alternative global scenarios.

2/ Country desk projections (based on WEO baseline assumptions).

3/ Based on differential between VAR forecasts and VAR baseline. Bars denote contributions of different factors to the deviation of the debt ratios from the baseline.

Key Domestic Variables under Alternative Scenarios, 2012-2017 (deviations from baseline)

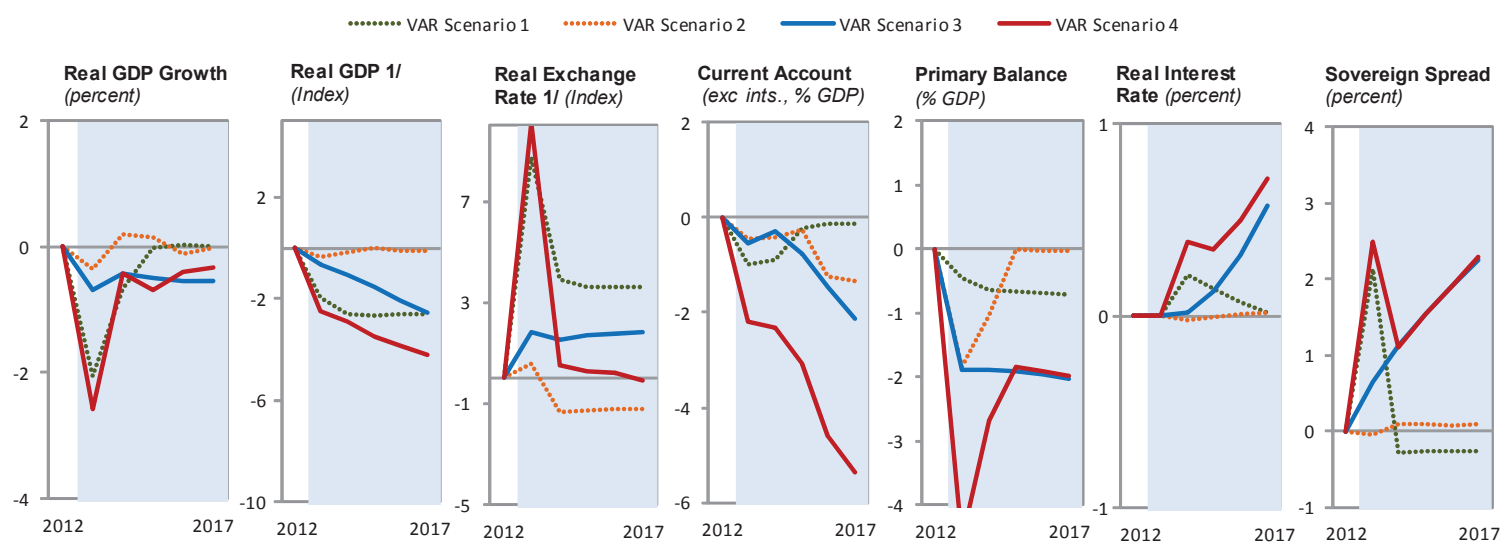

1/ Deviation in percent of baseline. 


\section{Brazil}

Factors Driving Public and External Debt Dynamics, 2003-2017// (percent of GDP)
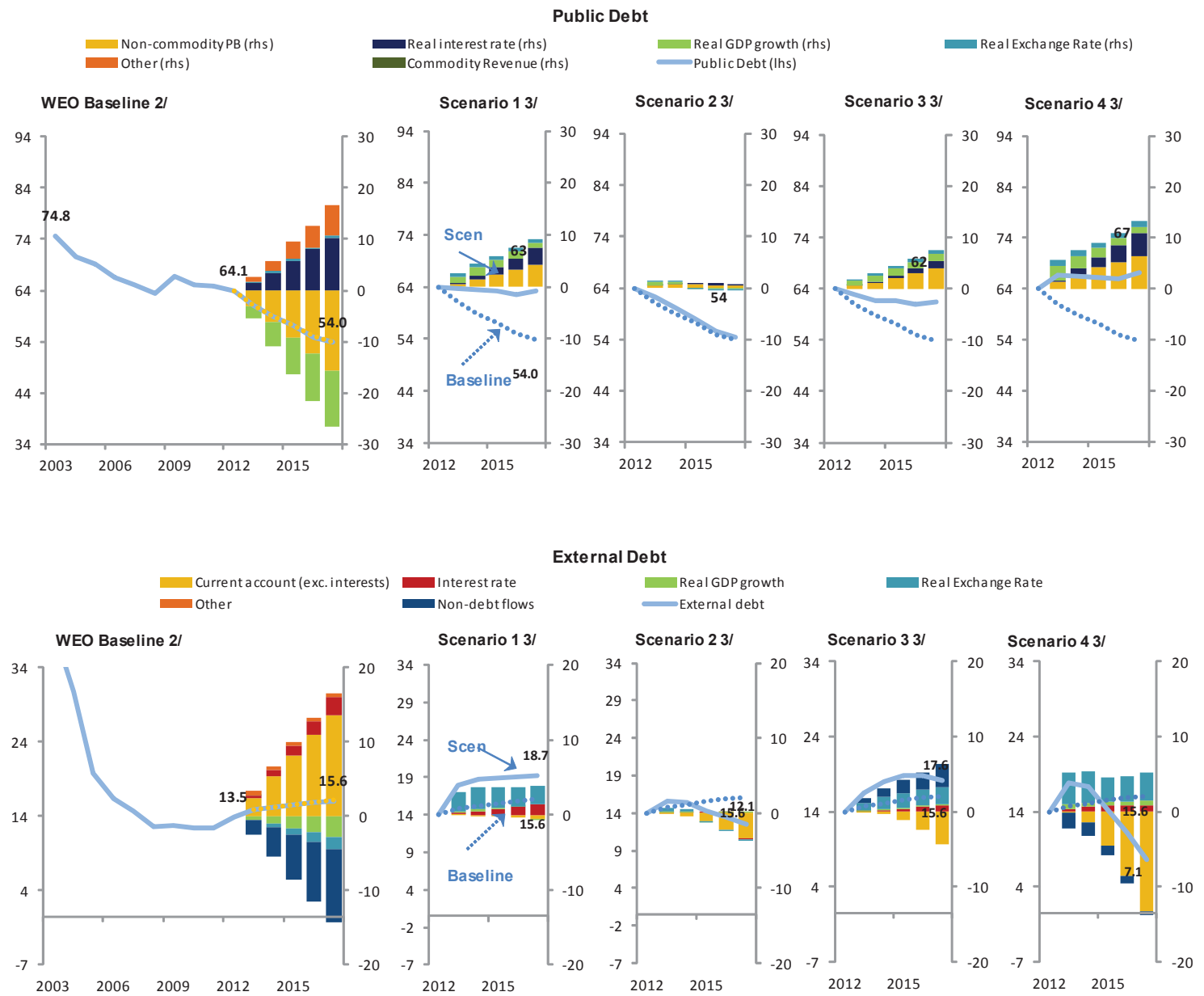

1/ Public and external debt dynamics under alternative global scenarios.

2/ Country desk projections (based on WEO baseline assumptions).

3/ Based on differential between VAR forecasts and VAR baseline. Bars denote contributions of different factors to the deviation of the debt ratios from the baseline.

Key Domestic Variables under Alternative Scenarios, 2012-2017 (deviations from baseline)

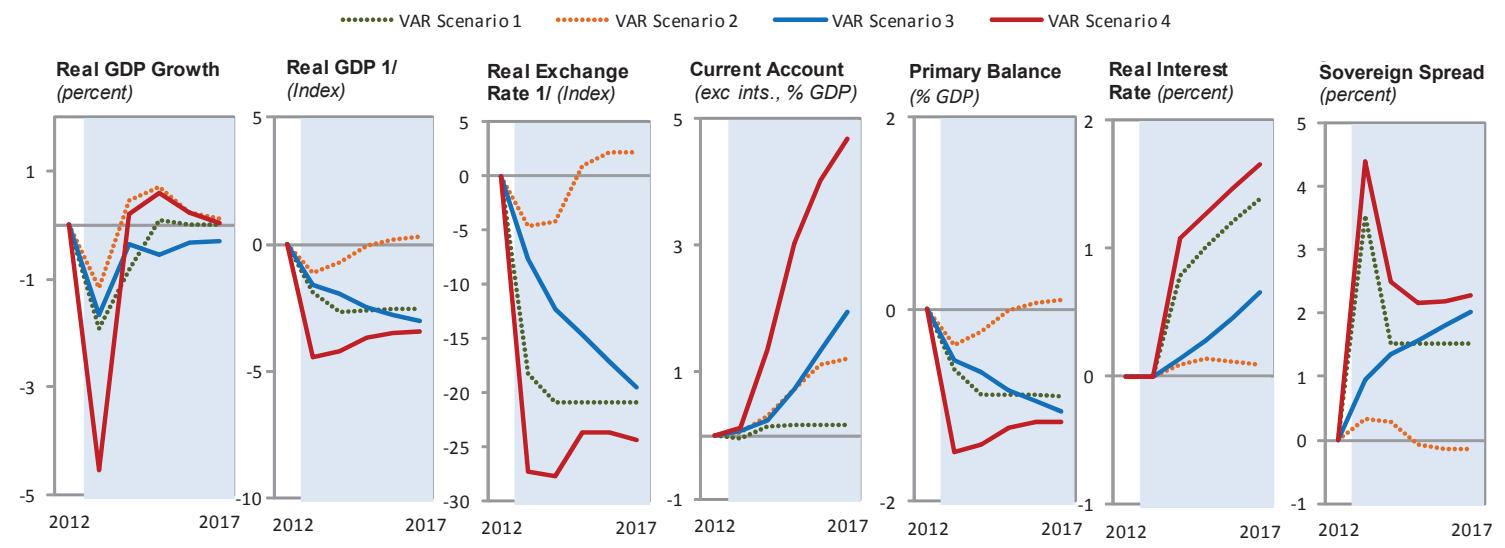

1/ Deviation in percent of baseline. 


\section{Chile}

Factors Driving Public and External Debt Dynamics, 2003-2017/ (percent of GDP)
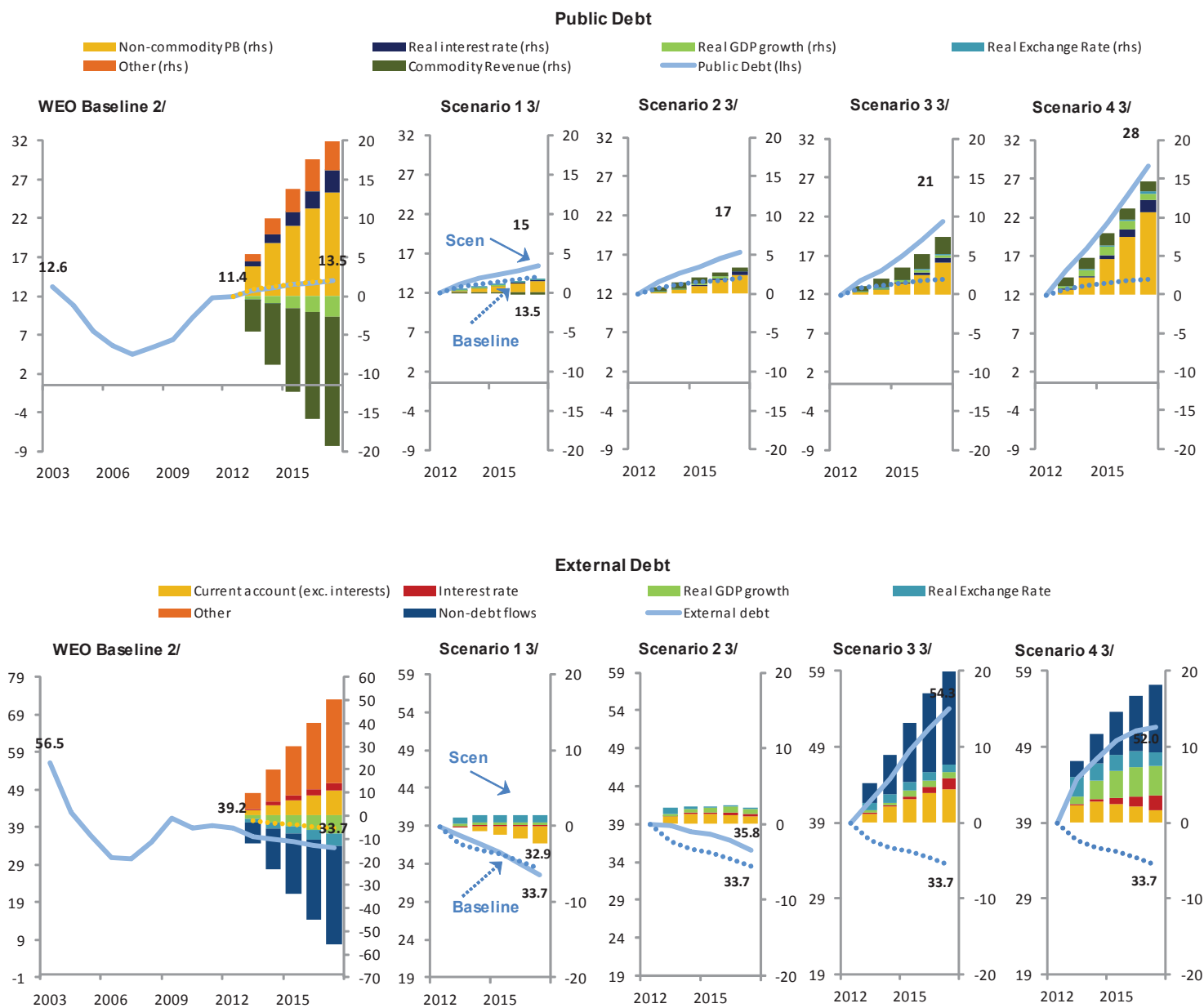

1/ Public and external debt dynamics under alternative global scenarios.

2/ Country desk projections (based on WEO baseline assumptions).

3/ Based on differential between VAR forecasts and VAR baseline. Bars denote contributions of different factors to the deviation of the debt ratios from the baseline.

Key Domestic Variables under Alternative Scenarios, 2012-2017 (deviations from baseline)

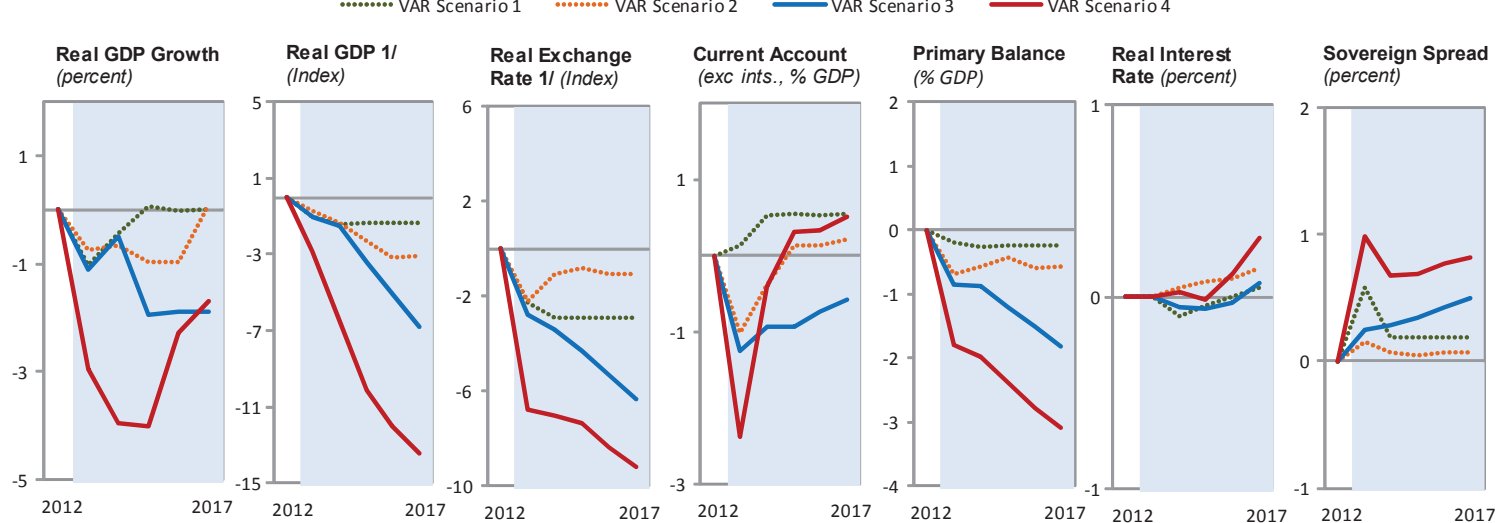

${ }^{1 /}$ Deviation in percent of baseline. 


\section{Colombia}

Factors Driving Public and External Debt Dynamics, 2003-2017// (percent of GDP)
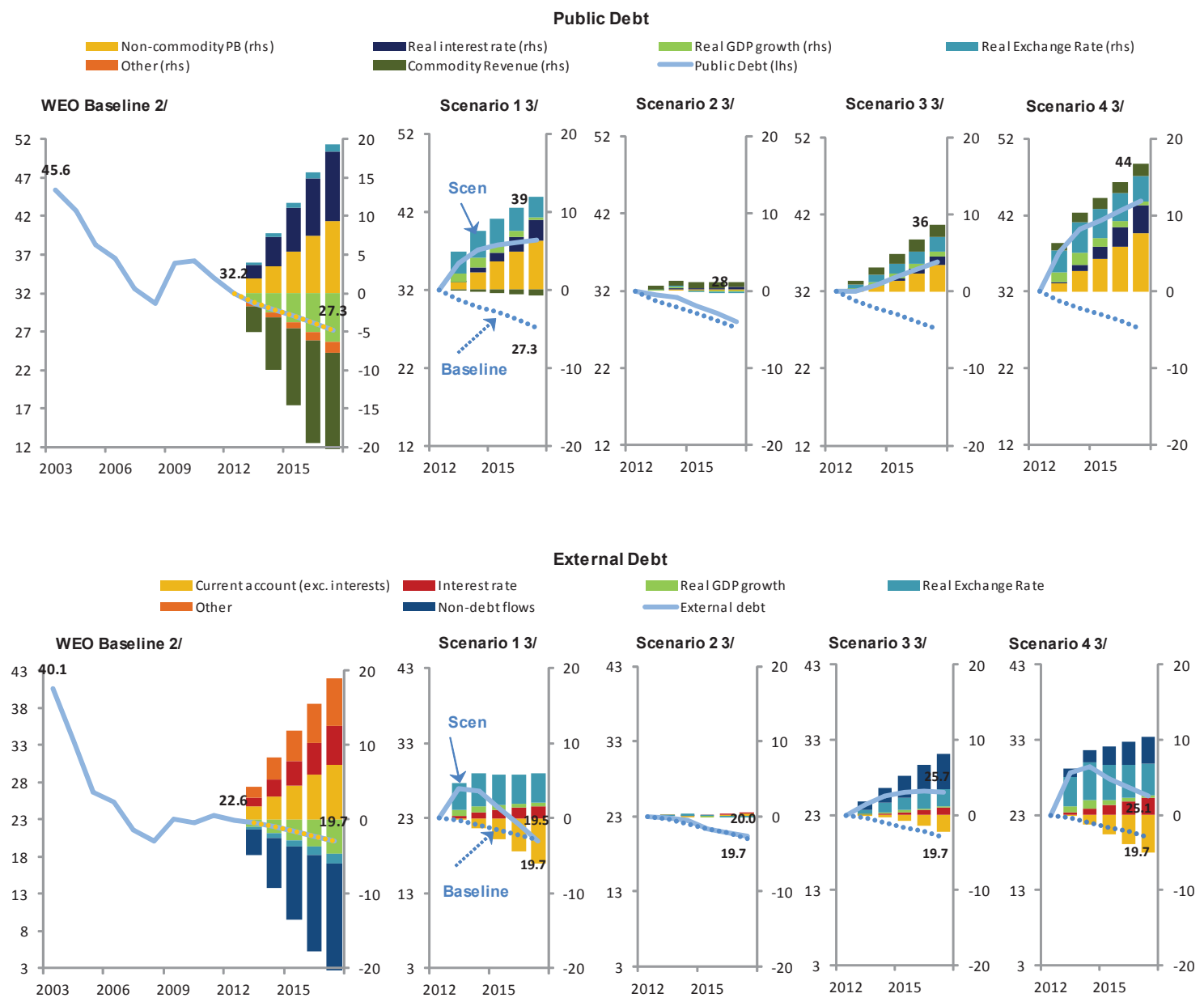

1/ Public and external debt dynamics under alternative global scenarios.

2/ Country desk projections (based on WEO baseline assumptions).

3/ Based on differential between VAR forecasts and VAR baseline. Bars denote contributions of different factors to the deviation of the debt ratios from the baseline.

Key Domestic Variables under Alternative Scenarios, 2012-2017 (deviations from baseline)

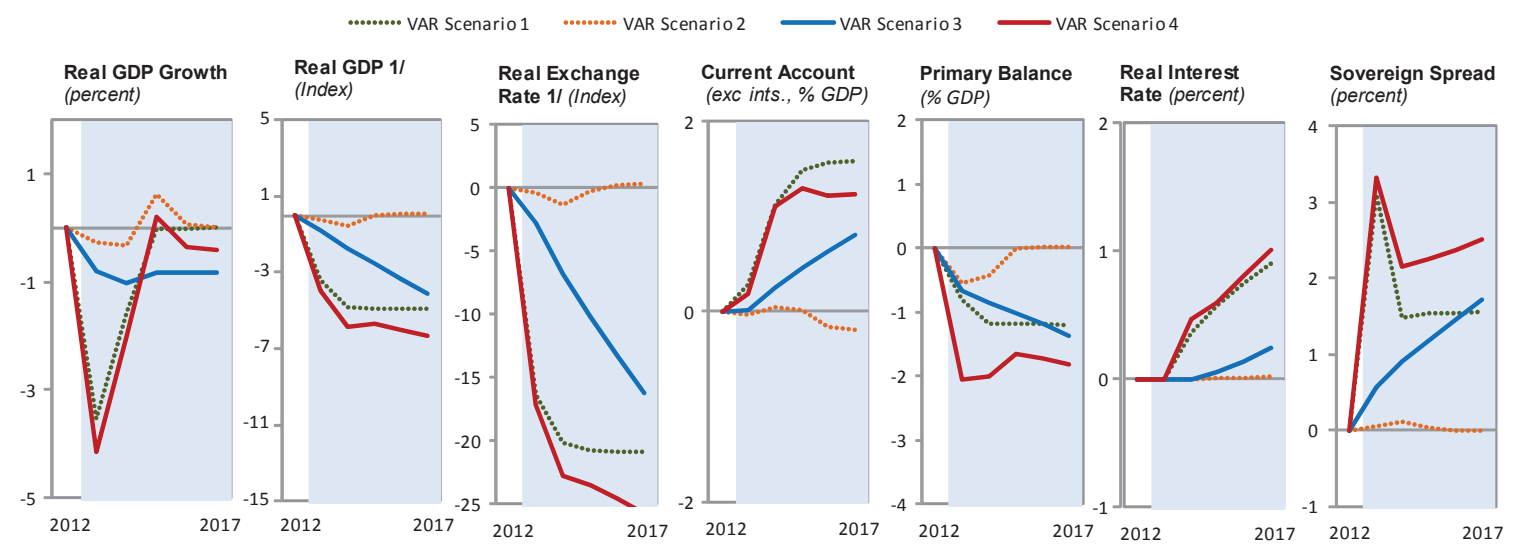

1/ Deviation in percent of baseline. 


\section{Ecuador}

Factors Driving Public and External Debt Dynamics, 2003-2017// (percent of GDP)
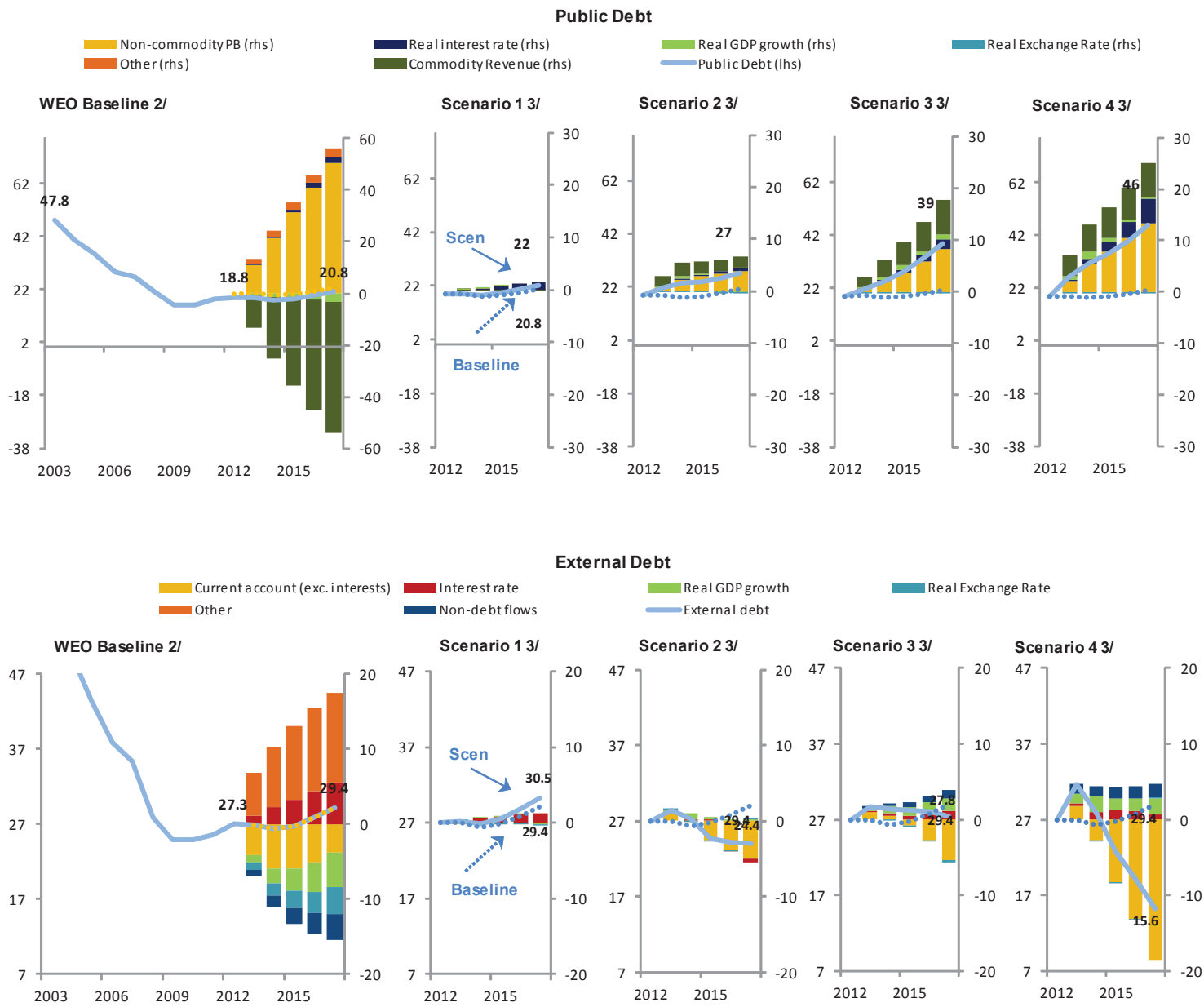

1/ Public and external debt dynamics under alternative global scenarios.

2/ Country desk projections (based on WEO baseline assumptions).

3/ Based on differential between VAR forecasts and VAR baseline. Bars denote contributions of different factors to the deviation of the debt ratios from the baseline.

Key Domestic Variables under Alternative Scenarios, 2012-2017 (deviations from baseline)

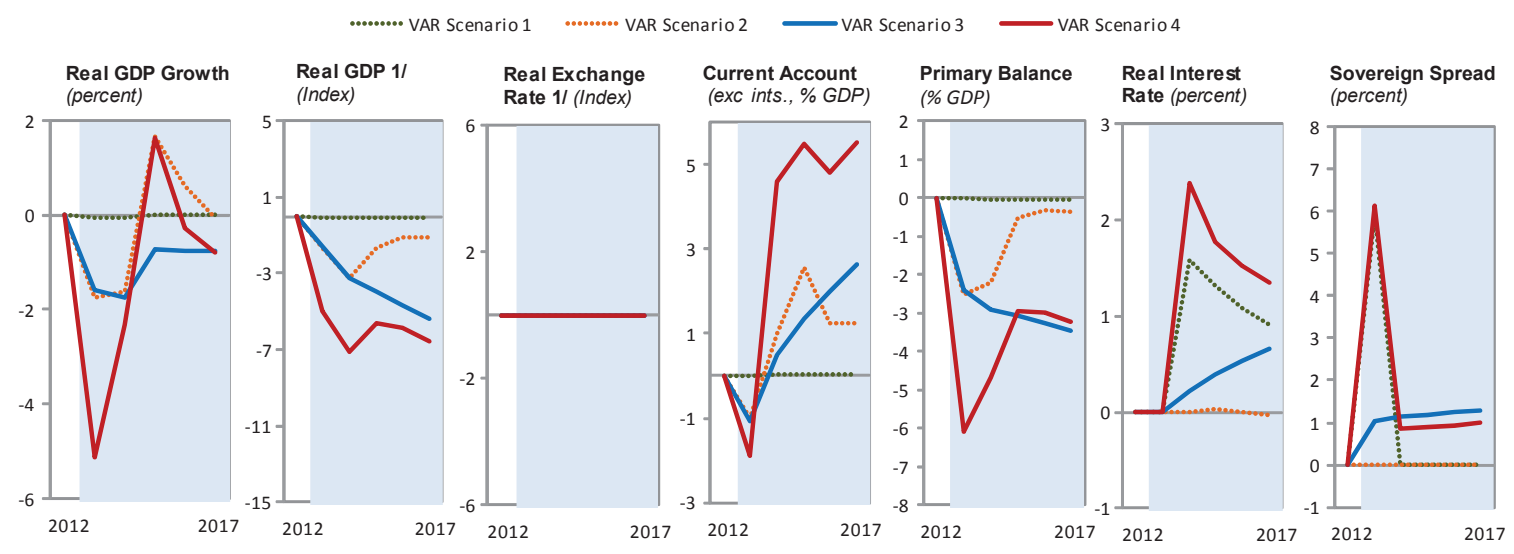

1/ Deviation in percent of baseline. 


\section{Mexico}

Factors Driving Public and External Debt Dynamics, 2003-2017// (percent of GDP)
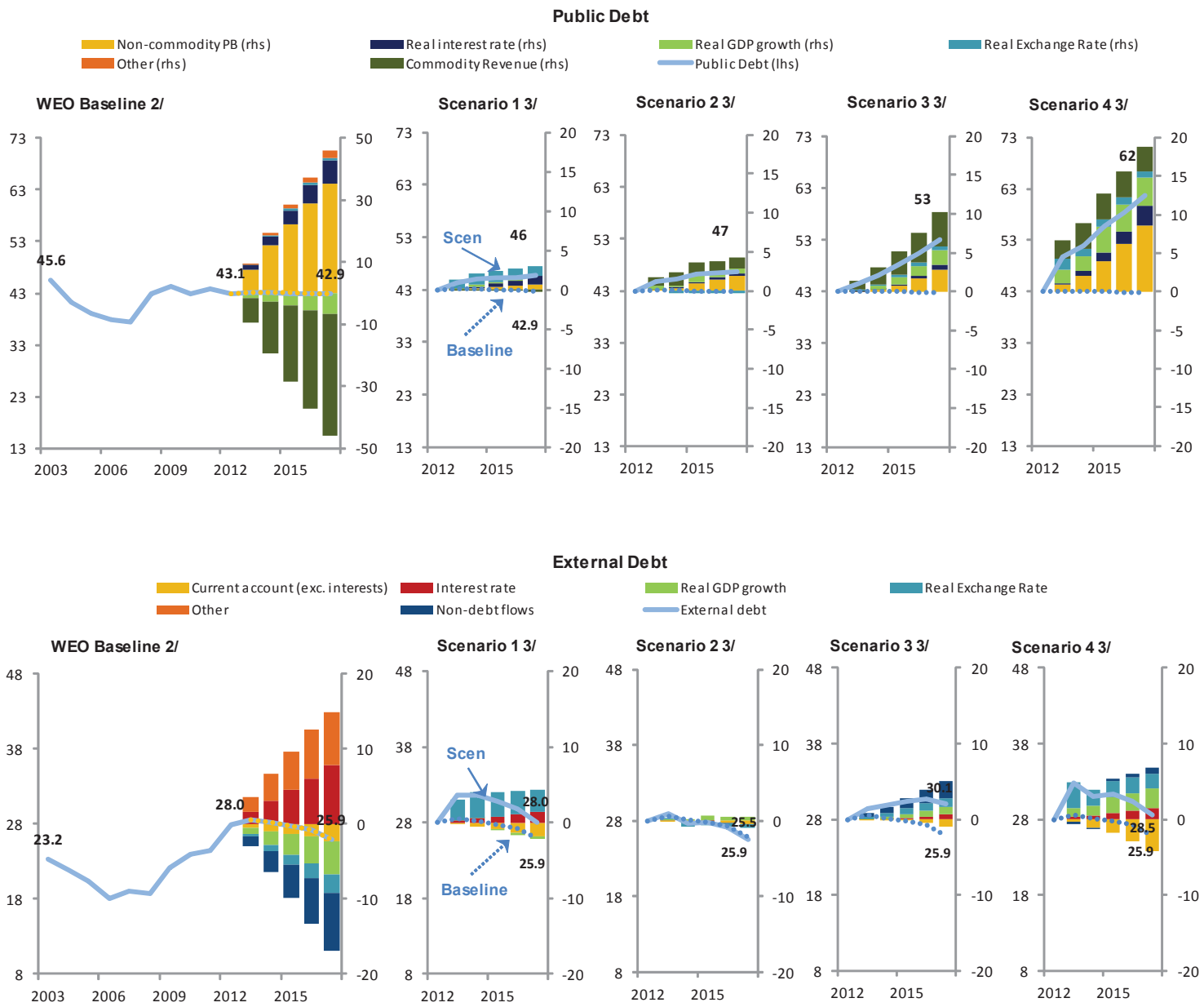

1/ Public and external debt dynamics under alternative global scenarios.

2/ Country desk projections (based on WEO baseline assumptions).

3/ Based on differential between VAR forecasts and VAR baseline. Bars denote contributions of different factors to the deviation of the debt ratios from the baseline.

Key Domestic Variables under Alternative Scenarios, 2012-2017 (deviations from baseline)

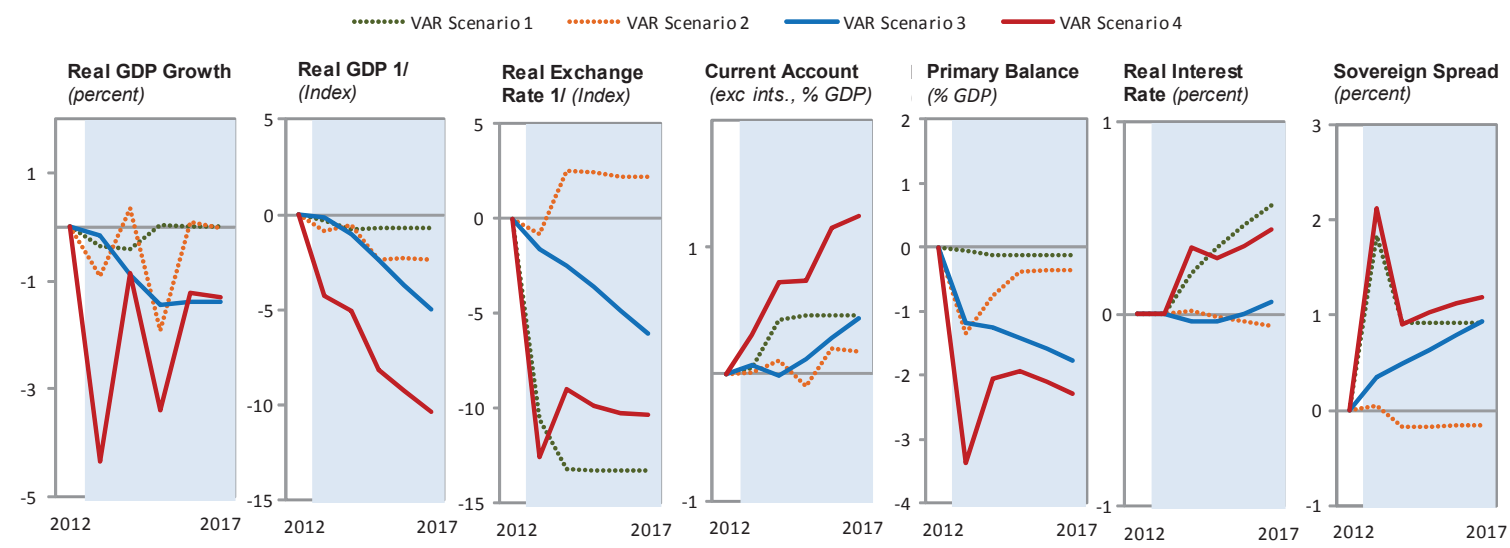

1/ Deviation in percent of baseline. 


\section{Paraguay}

Factors Driving Public and External Debt Dynamics, 2003-2017 ${ }^{1 /}$ (percent of GDP)
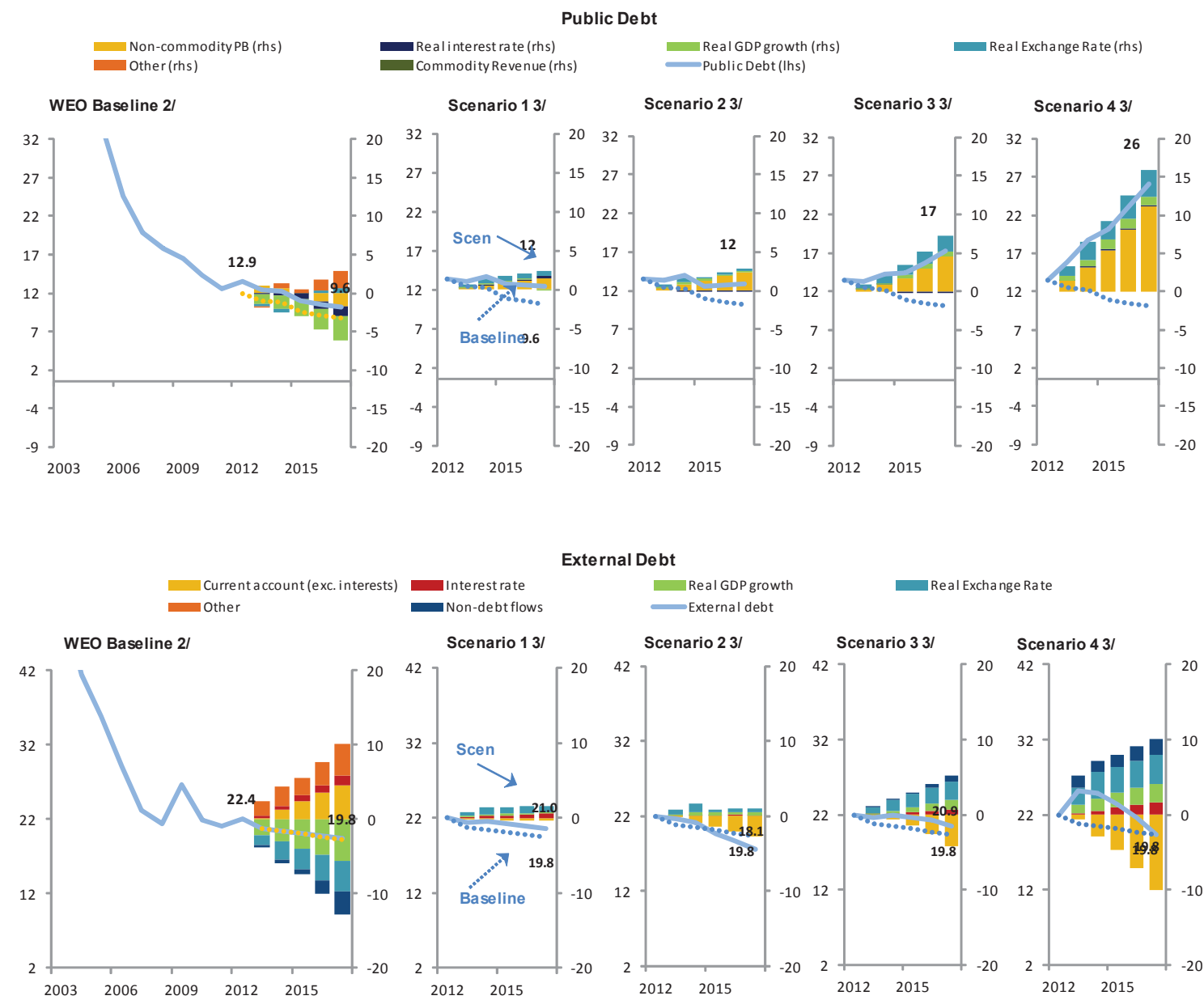

1/ Public and external debt dynamics under alternative global scenarios.

2/ Country desk projections (based on WEO baseline assumptions).

3/ Based on differential between VAR forecasts and VAR baseline. Bars denote contributions of different factors to the deviation of the debt ratios from the baseline.

Key Domestic Variables under Alternative Scenarios, 2012-2017 (deviations from baseline)

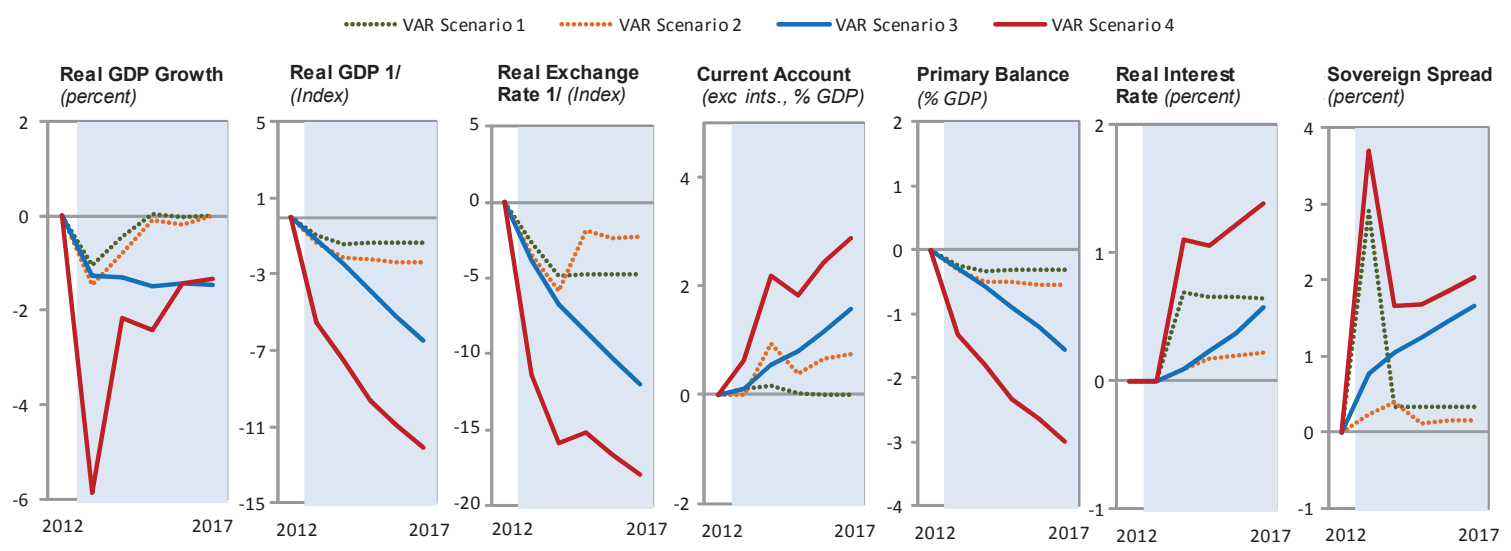

1/ Deviation in percent of baseline. 


\section{Peru}

Factors Driving Public and External Debt Dynamics, 2003-2017/ (percent of GDP)


1/ Public and external debt dynamics under alternative global scenarios.

2/ Country desk projections (based on WEO baseline assumptions).

3/ Based on differential between VAR forecasts and VAR baseline. Bars denote contributions of different factors to the deviation of the debt ratios from the baseline.

Key Domestic Variables under Alternative Scenarios, 2012-2017 (deviations from baseline)

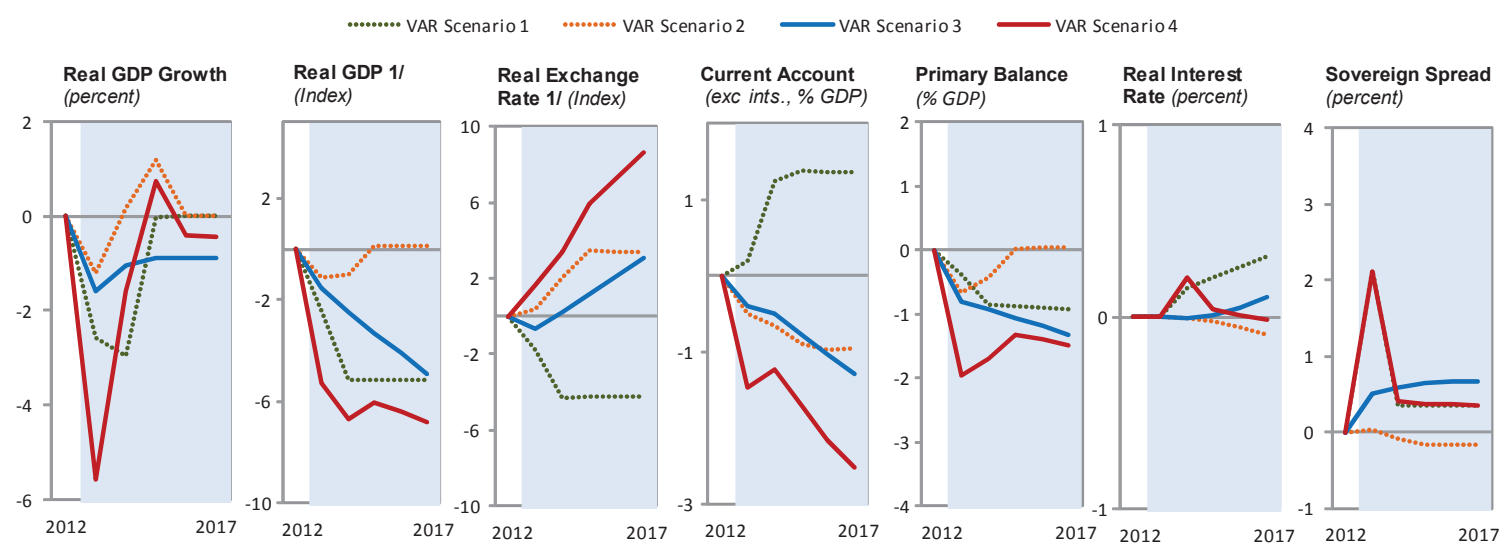

1/ Deviation in percent of baseline. 


\section{Uruguay}

Factors Driving Public and External Debt Dynamics, 2003-20171/ (percent of GDP)
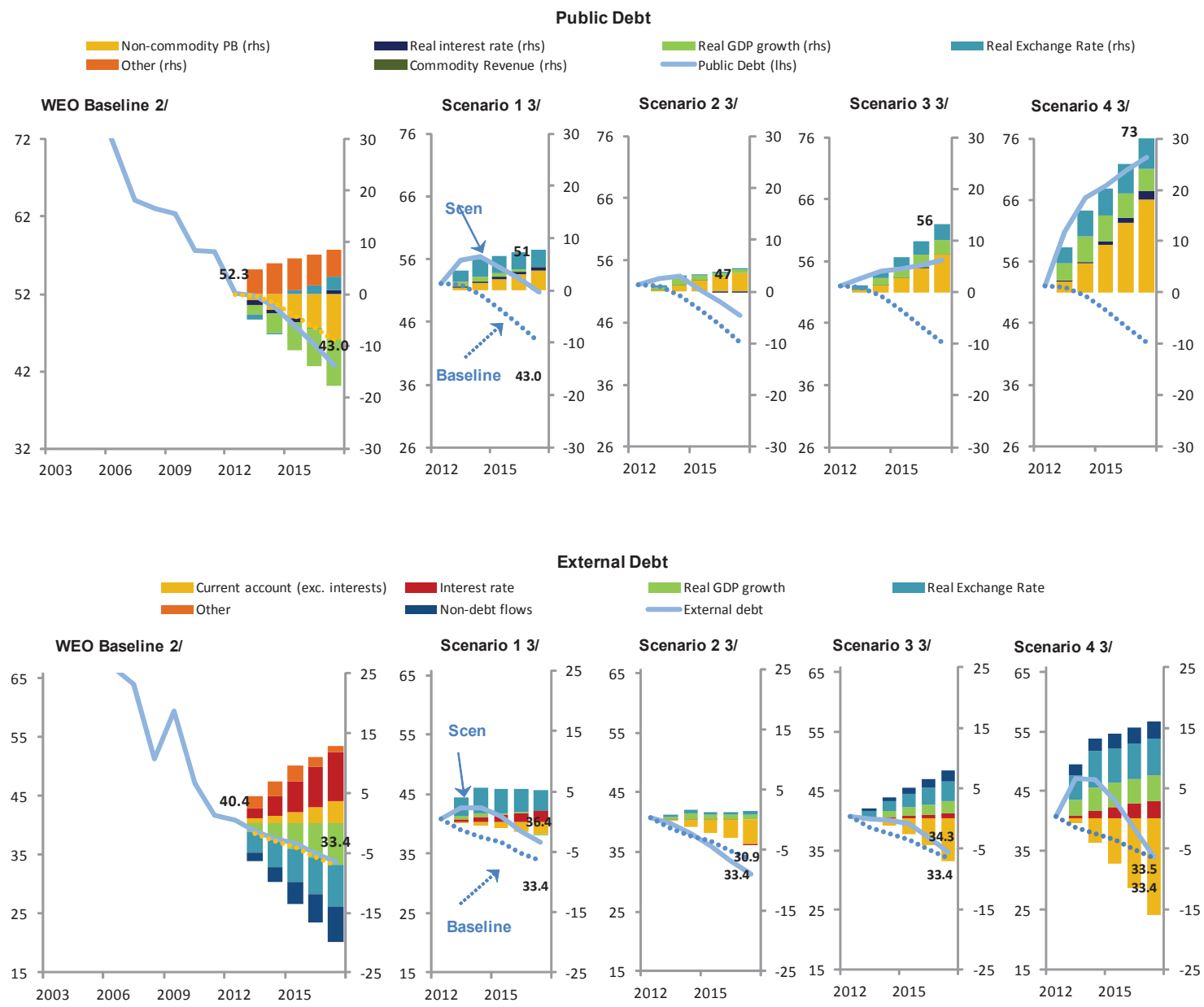

1/ Public and external debt dynamics under alternative global scenarios.

2/ Country desk projections (based on WEO baseline assumptions).

3/ Based on differential between VAR forecasts and VAR baseline. Bars denote contributions of different factors to the deviation of the debt ratios from the baseline.

Key Domestic Variables under Alternative Scenarios, 2012-2017 (deviations from baseline)

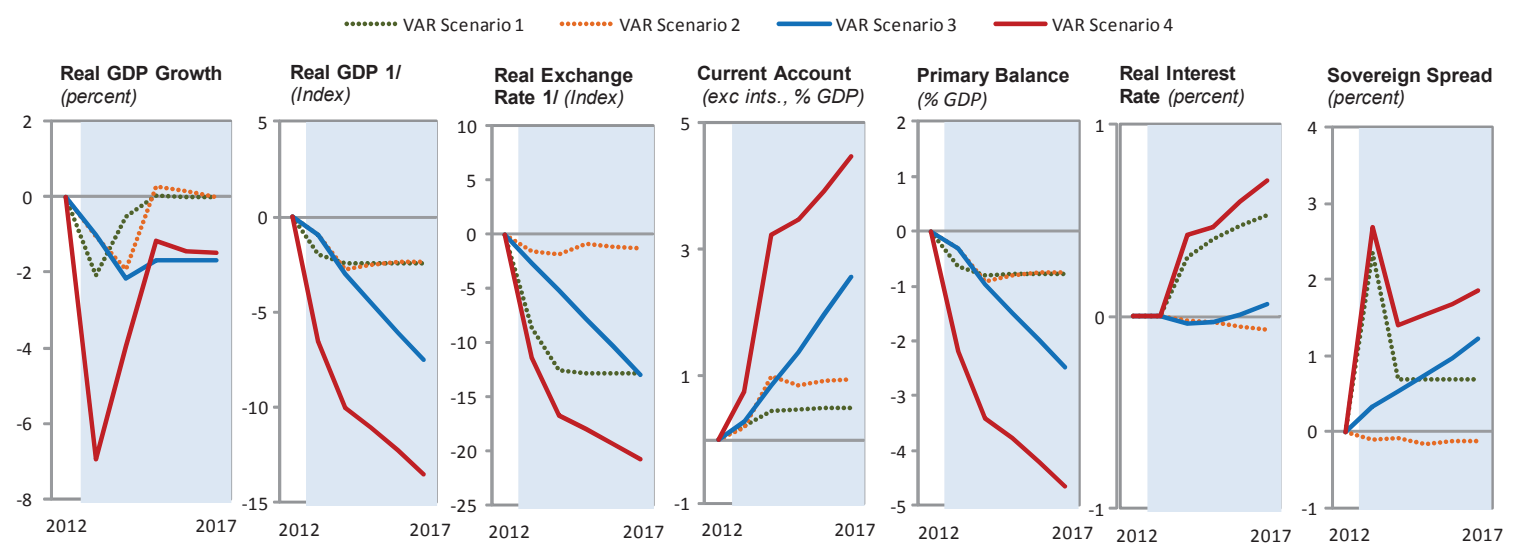

1/ Deviation in percent of baseline. 


\section{Venezuela, Rep. Bol.}

Factors Driving Public and External Debt Dynamics, 2003-2017// (percent of GDP)
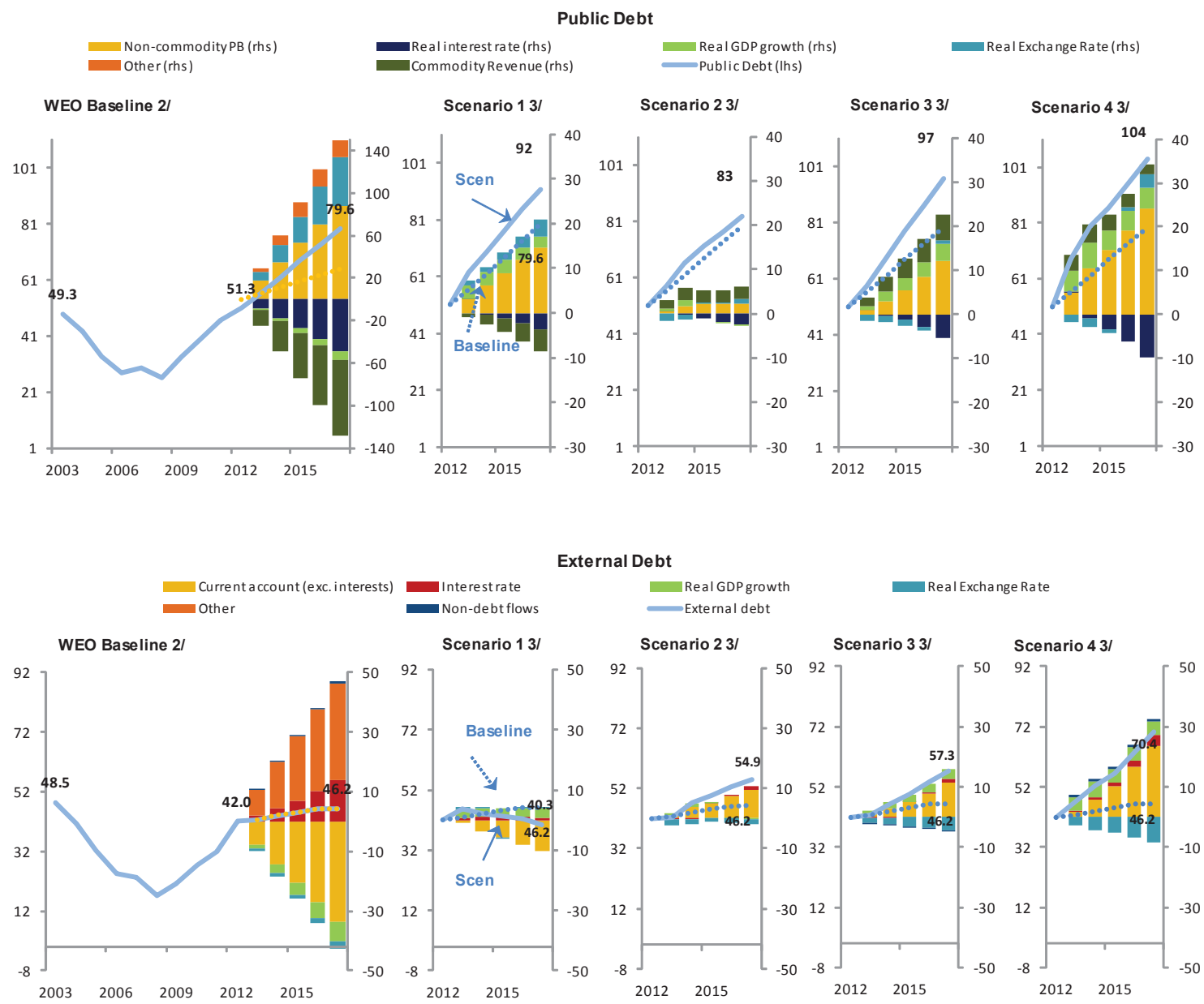

1/ Public and external debt dynamics under alternative global scenarios.

2/ Country desk projections (based on WEO baseline assumptions).

3/ Based on differential between VAR forecasts and VAR baseline. Bars denote contributions of different factors to the deviation of the debt ratios from the baseline.

Key Domestic Variables under Alternative Scenarios, 2012-2017 (deviations from baseline)

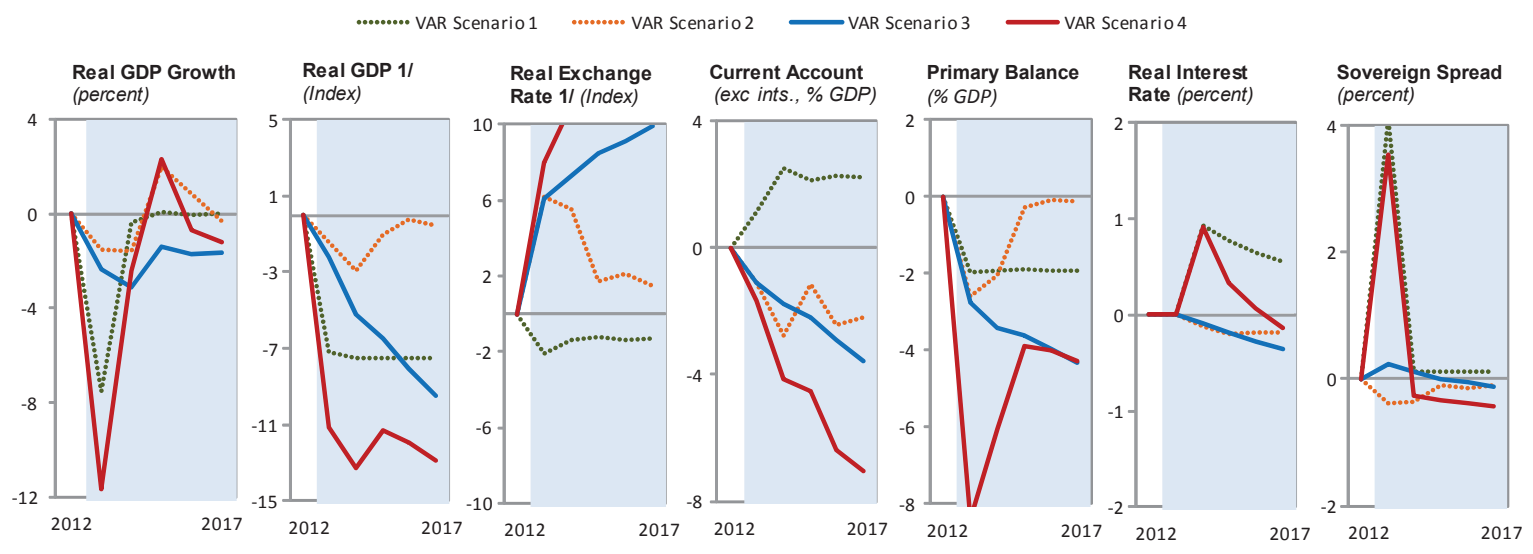

1/ Deviation in percent of baseline.

Sources: IMF International Financial Statistics and authors' estimations. 
Table A1.

VAR Estimation Results

\begin{tabular}{|c|c|c|c|c|c|c|c|c|c|c|c|c|}
\hline \multirow[b]{2}{*}{ VARIABLES } & & \multicolumn{3}{|c|}{ Argentina } & \multicolumn{4}{|c|}{ Brazil } & \multicolumn{4}{|c|}{ Bolivia } \\
\hline & & $\begin{array}{c}\text { (1) } \\
\text { growth }\end{array}$ & $\begin{array}{l}(2) \\
\mathrm{dtb}\end{array}$ & $\begin{array}{c}(3) \\
\text { dlnreer }\end{array}$ & & $\begin{array}{c}\text { (1) } \\
\text { growth }\end{array}$ & $\begin{array}{l}(2) \\
\mathrm{dtb}\end{array}$ & $\begin{array}{c}(3) \\
\text { dlnreer }\end{array}$ & & $\begin{array}{l}(1) \\
\text { growth }\end{array}$ & $\begin{array}{l}(2) \\
d t b\end{array}$ & $\begin{array}{c}(3) \\
\text { dlnreer }\end{array}$ \\
\hline \multirow[t]{2}{*}{ L.growth } & & $0.870^{* * *}$ & $-0.199^{* * *}$ & $1.401^{* *}$ & & 0.028 & $-0.092^{* * *}$ & -0.505 & & $-0.531^{* * *}$ & -0.03 & 0.237 \\
\hline & & $(0.118)$ & $(0.055)$ & $(0.659)$ & & -0.107 & -0.019 & -0.586 & & -0.104 & -0.071 & -0.218 \\
\hline \multirow[t]{2}{*}{ L2.growth } & & -0.110 & -0.006 & 0.712 & & $-0.172^{+}$ & -0.018 & -0.029 & & -0.083 & -0.089 & $0.541^{* * *}$ \\
\hline & & $(0.126)$ & $(0.060)$ & $(0.709)$ & & -0.115 & -0.02 & -0.628 & & -0.099 & -0.068 & -0.208 \\
\hline \multirow[t]{2}{*}{ L.dtb } & & $0.341^{*}$ & 0.055 & 1.276 & & 0.352 & $0.540^{* * *}$ & 1.695 & & -0.025 & $0.528^{* * *}$ & 0.09 \\
\hline & & $(0.180)$ & $(0.086)$ & $(1.023)$ & & -0.653 & -0.115 & -3.624 & & -0.163 & -0.112 & -0.341 \\
\hline \multirow[t]{2}{*}{ L2.dtb } & & 0.015 & $0.168^{* *}$ & -0.138 & & 0.506 & 0.12 & -0.364 & & 0.102 & 0.027 & -0.076 \\
\hline & & $(0.181)$ & $(0.080)$ & (1.018) & & -0.61 & -0.108 & -3.352 & & -0.157 & -0.108 & -0.328 \\
\hline \multirow[t]{2}{*}{ L.dlnreer } & & $-0.048^{* *}$ & -0.002 & $0.386^{* * *}$ & & 0.024 & $-0.005^{+}$ & 0.064 & & 0.059 & $-0.086^{* * *}$ & 0.124 \\
\hline & & $(0.020)$ & $(0.010)$ & $(0.110)$ & & -0.02 & -0.004 & -0.113 & & -0.052 & -0.033 & -0.109 \\
\hline \multirow[t]{2}{*}{ L2.dlnreer } & & $0.032^{*}$ & $-0.069^{* * *}$ & $-0.212^{*}$ & & $0.035^{*}$ & 0.001 & $-0.191^{*}$ & & $0.114^{* *}$ & -0.023 & -0.08 \\
\hline & & $(0.019)$ & $(0.009)$ & $(0.108)$ & & -0.021 & -0.004 & -0.105 & & -0.053 & -0.034 & -0.111 \\
\hline \multirow[t]{6}{*}{ wgdp_gr } & & & & & L3 & 0.113 & -0.032 & -1.592 & $\mathrm{~L} 2$ & 0.059 & 0.219 & 0.089 \\
\hline & & & & & & -0.365 & -0.065 & -2.024 & & -0.35 & -0.231 & -0.731 \\
\hline & & & & & L4 & 0.297 & $-0.185^{* * *}$ & 1.414 & $\mathrm{~L} 3$ & $-0.592^{*}$ & 0.204 & 0.42 \\
\hline & & & & & & -0.366 & -0.065 & -1.979 & & -0.338 & -0.231 & -0.706 \\
\hline & & & & & & & & & L4 & $0.528^{*}$ & -0.058 & -0.022 \\
\hline & & & & & & & & & & -0.307 & -0.212 & -0.641 \\
\hline \multirow[t]{4}{*}{ vix } & L0 & $-0.062^{*}$ & -0.000 & 0.012 & L0 & -0.015 & -0.002 & $-0.274^{* *}$ & L0 & $-0.048^{*}$ & 0 & $0.244^{* * *}$ \\
\hline & & $(0.032)$ & $(0.000)$ & $(0.184)$ & & -0.021 & -0.004 & -0.114 & & -0.027 & 0 & -0.057 \\
\hline & $\mathrm{L} 1$ & 0.032 & $0.000^{+}$ & -0.009 & & & & & $\mathrm{~L} 1$ & -0.005 & 0 & $-0.181^{* * *}$ \\
\hline & & $(0.033)$ & $(0.000)$ & $(0.185)$ & & & & & & -0.027 & 0 & -0.056 \\
\hline \multirow[t]{6}{*}{ energy } & L0 & $0.022^{+}$ & 0.005 & -0.087 & L2 & $-0.025^{+}$ & 0 & 0.048 & L0 & $-0.030^{* *}$ & -0.002 & $-0.043^{*}$ \\
\hline & & $(0.015)$ & $(0.007)$ & $(0.087)$ & & -0.016 & -0.003 & -0.08 & & -0.012 & -0.008 & -0.025 \\
\hline & $\mathrm{L} 1$ & -0.013 & 0.006 & $0.178^{* *}$ & L4 & $-0.031^{* *}$ & $0.004^{*}$ & $0.102^{+}$ & L1 & $0.022^{*}$ & 0.007 & 0.011 \\
\hline & & $(0.015)$ & $(0.007)$ & $(0.085)$ & & -0.013 & -0.002 & -0.071 & & -0.011 & -0.007 & -0.024 \\
\hline & $\mathrm{L} 2$ & 0.014 & -0.008 & -0.016 & & & & & $\mathrm{~L} 2$ & 0.001 & -0.008 & $0.034^{+}$ \\
\hline & & $(0.014)$ & $(0.007)$ & $(0.077)$ & & & & & & -0.011 & -0.007 & -0.022 \\
\hline \multirow[t]{6}{*}{ food } & $\mathrm{L} 2$ & $0.050^{*}$ & $-0.022^{+}$ & $-0.000^{*}$ & $\mathrm{~L} 1$ & 0.045 & 0.005 & 0.014 & L0 & $0.084^{* * *}$ & 0.004 & 0.011 \\
\hline & & $(0.028)$ & $(0.014)$ & $(0.000)$ & & -0.032 & -0.006 & -0.17 & & -0.026 & -0.018 & -0.055 \\
\hline & L3 & $0.044^{+}$ & 0.010 & $-0.000^{*}$ & L2 & 0.025 & 0.006 & $0.250^{+}$ & $\mathrm{L} 1$ & 0.028 & $0.060^{* * *}$ & 0.037 \\
\hline & & $(0.029)$ & $(0.014)$ & $(0.000)$ & & -0.03 & -0.005 & -0.165 & & -0.027 & -0.018 & -0.057 \\
\hline & & & & & & & & & $\mathrm{L} 2$ & 0.021 & -0.006 & -0.049 \\
\hline & & & & & & & & & & -0.031 & -0.021 & -0.064 \\
\hline \multirow[t]{4}{*}{ metals } & L0 & $0.036^{*}$ & -0.005 & -0.052 & L0 & $0.043^{* *}$ & -0.003 & $0.368^{* * *}$ & L1 & $0.031^{+}$ & $-0.029^{* *}$ & -0.059 \\
\hline & & $(0.020)$ & $(0.009)$ & $(0.114)$ & & -0.019 & -0.003 & -0.108 & & -0.021 & -0.014 & -0.043 \\
\hline & L1 & -0.011 & $-0.017^{*}$ & -0.113 & $\mathrm{~L} 1$ & $0.035^{*}$ & 0.003 & -0.041 & $\mathrm{~L} 2$ & 0.01 & -0.003 & -0.012 \\
\hline & & $(0.021)$ & $(0.010)$ & $(0.115)$ & & -0.021 & -0.004 & -0.119 & & -0.022 & -0.015 & -0.046 \\
\hline \multirow[t]{4}{*}{ dprbal } & L1 & & & & L1 & 0.496 & 0.056 & $-0.000^{* * *}$ & $\mathrm{~L} 2$ & -0.189 & $0.569^{* *}$ & -0.064 \\
\hline & & & & & & -0.353 & -0.062 & 0 & & -0.372 & -0.244 & -0.777 \\
\hline & & & & & L2 & -0.17 & $0.082^{+}$ & $0.000^{* *}$ & L3 & -0.263 & $-0.688^{* * *}$ & 0.498 \\
\hline & & & & & & -0.289 & -0.051 & 0 & & -0.313 & -0.211 & -0.653 \\
\hline \multirow[t]{2}{*}{ Constant } & & $0.769^{*}$ & $0.188^{* *}$ & -2.922 & & 0.879 & $0.296^{* * *}$ & $5.849^{*}$ & & $2.633^{* * *}$ & -0.097 & $-2.300^{*}$ \\
\hline & & $(0.467)$ & $(0.080)$ & $(2.636)$ & & -0.647 & -0.114 & -3.357 & & -0.643 & -0.229 & -1.335 \\
\hline Observations & & 76 & 76 & 76 & & 82 & 82 & 82 & & 81 & 81 & 81 \\
\hline df_eq & & 14.7 & 14.7 & 14.7 & & 17.3 & 17.3 & 17.3 & & 21.3 & 21.3 & 21.3 \\
\hline r2_2 & & 0.72 & 0.72 & 0.72 & & 0.67 & 0.67 & 0.67 & & 0.57 & 0.57 & 0.57 \\
\hline r2_1 & & 0.66 & 0.66 & 0.66 & & 0.40 & 0.40 & 0.40 & & 0.45 & 0.45 & 0.45 \\
\hline aic & & 12.3 & 12.3 & 12.3 & & 10.3 & 10.3 & 10.3 & & 10.5 & 10.5 & 10.5 \\
\hline
\end{tabular}

Standard errors in parentheses: ${ }^{* * *} \mathrm{p}<0.01,{ }^{* *} \mathrm{p}<0.05,{ }^{*} \mathrm{p}<0.10,{ }^{+} \mathrm{p}<0.15$. 
Table A1 (cont.).

VAR Estimation Results

\begin{tabular}{|c|c|c|c|c|c|c|c|c|c|c|c|c|}
\hline \multirow[b]{2}{*}{ VARIABLES } & \multicolumn{4}{|c|}{ Chile } & \multicolumn{4}{|c|}{ Colombia } & \multicolumn{4}{|c|}{ Ecuador } \\
\hline & & $\begin{array}{l}\text { (1) } \\
\text { growth }\end{array}$ & $\begin{array}{l}\text { (2) } \\
\text { dtb }\end{array}$ & $\begin{array}{c}(3) \\
\text { dlnreer }\end{array}$ & & $\begin{array}{l}\text { (1) } \\
\text { growth }\end{array}$ & $\begin{array}{c}(2) \\
\mathrm{dtb} 2\end{array}$ & $\begin{array}{c}(3) \\
\text { dlnreer }\end{array}$ & & $\begin{array}{c}\text { (1) } \\
\text { growth }\end{array}$ & $\begin{array}{l}\text { (2) } \\
\text { dtb }\end{array}$ & $\begin{array}{c}(3) \\
\text { dlnreer }\end{array}$ \\
\hline \multirow[t]{2}{*}{ L.growth } & & 0.116 & -0.026 & $0.743^{* * *}$ & & $-0.232^{* *}$ & $-0.068^{* * *}$ & 0 & & 0.049 & $-0.161^{* *}$ & -0.22 \\
\hline & & -0.094 & -0.047 & -0.227 & & -0.098 & -0.025 & 0 & & -0.129 & -0.073 & -0.423 \\
\hline \multirow[t]{2}{*}{ L2.growth } & & -0.077 & $-0.175^{* * *}$ & $-0.413^{*}$ & & $0.222^{* *}$ & $-0.059^{* *}$ & 0 & & -0.151 & -0.036 & $0.902^{*}$ \\
\hline & & -0.098 & -0.05 & -0.238 & & -0.098 & -0.026 & 0 & & -0.144 & -0.081 & -0.472 \\
\hline \multirow[t]{2}{*}{ L.dtb } & & $-0.383^{*}$ & $0.471^{* * *}$ & $-1.069^{* *}$ & & $-0.000^{+}$ & $0.736^{* * *}$ & -0.282 & & $-0.497^{* *}$ & $0.629^{* * *}$ & -0.977 \\
\hline & & -0.227 & -0.115 & -0.486 & & 0 & -0.107 & -1.44 & & -0.227 & -0.129 & -0.745 \\
\hline \multirow[t]{2}{*}{ L2.dtb } & & $0.354^{*}$ & -0.12 & 0 & & 0 & -0.017 & -1.121 & & 0.147 & -0.133 & $-1.414^{* *}$ \\
\hline & & -0.205 & -0.103 & 0 & & 0 & -0.104 & -1.482 & & -0.203 & -0.116 & -0.669 \\
\hline \multirow[t]{2}{*}{ L.dlnreer } & & 0.003 & -0.009 & 0.091 & & 0.015 & -0.004 & -0.06 & & -0.005 & -0.022 & $0.284^{* * *}$ \\
\hline & & -0.042 & -0.021 & -0.103 & & -0.029 & -0.007 & -0.103 & & -0.034 & -0.019 & -0.11 \\
\hline \multirow[t]{2}{*}{ L2.dlnreer } & & $0.101^{* *}$ & -0.018 & $-0.408^{* * *}$ & & 0.025 & $0.012^{+}$ & $-0.159^{+}$ & & 0.002 & -0.009 & $-0.485^{* * *}$ \\
\hline & & -0.041 & -0.021 & -0.099 & & -0.028 & -0.007 & -0.098 & & -0.033 & -0.019 & -0.109 \\
\hline \multirow[t]{2}{*}{ wgdp_gr } & L4 & $1.570^{* * *}$ & $0.274^{*}$ & 0.138 & $\mathrm{~L} 1$ & 0 & 0.025 & 0 & L0 & $0.668^{+}$ & -0.199 & 1.135 \\
\hline & & -0.311 & -0.158 & -0.744 & & 0 & -0.069 & 0 & & -0.446 & -0.222 & -1.446 \\
\hline \multirow[t]{4}{*}{ vix } & L0 & -0.011 & 0 & -0.028 & L0 & $-0.044^{* * *}$ & 0 & $-0.251^{* * *}$ & & & & \\
\hline & & -0.012 & -0.006 & -0.027 & & -0.017 & 0 & -0.06 & & & & \\
\hline & & & & & & & & & L1 & -0.001 & 0 & 0.039 \\
\hline & & & & & & & & & & -0.025 & 0 & -0.077 \\
\hline \multirow[t]{10}{*}{ energy } & L3 & -0.001 & $-0.028^{* * *}$ & -0.019 & $\mathrm{~L} 2$ & 0.01 & 0 & -0.005 & L0 & 0.019 & $0.042^{* * *}$ & $-0.147^{* *}$ \\
\hline & & -0.013 & -0.007 & -0.033 & & -0.01 & -0.003 & -0.036 & & -0.02 & -0.011 & -0.067 \\
\hline & L4 & $-0.038^{* * *}$ & -0.007 & -0.049 & L3 & 0.01 & -0.002 & 0.039 & $\mathrm{~L} 1$ & 0.017 & $0.024^{* *}$ & $0.123^{*}$ \\
\hline & & -0.014 & -0.007 & -0.034 & & -0.01 & -0.002 & -0.034 & & -0.021 & -0.012 & -0.069 \\
\hline & & & & & & & & & L2 & $0.047^{* *}$ & 0.004 & 0.046 \\
\hline & & & & & & & & & & -0.022 & -0.013 & -0.074 \\
\hline & & & & & & & & & L3 & 0.028 & -0.012 & $0.229^{* * *}$ \\
\hline & & & & & & & & & & -0.022 & -0.013 & -0.073 \\
\hline & & & & & & & & & L4 & $0.036^{*}$ & $-0.032^{* * *}$ & $0.191^{* * *}$ \\
\hline & & & & & & & & & & -0.021 & -0.012 & -0.068 \\
\hline \multirow[t]{6}{*}{ food } & & & & & $\mathrm{L} 1$ & $0.045^{*}$ & 0.004 & 0.104 & L0 & 0.043 & $0.034^{+}$ & 0.1 \\
\hline & & & & & & -0.026 & -0.007 & -0.092 & & -0.038 & -0.022 & -0.125 \\
\hline & & & & & & & & & $\mathrm{L} 1$ & 0.052 & $-0.036^{+}$ & 0.027 \\
\hline & & & & & & & & & & -0.04 & -0.023 & -0.131 \\
\hline & & & & & & & & & L2 & $0.058^{+}$ & 0.016 & 0.172 \\
\hline & & & & & & & & & & -0.039 & -0.022 & -0.13 \\
\hline \multirow[t]{8}{*}{ metals } & L0 & $0.035^{*}$ & $0.054^{* * *}$ & $0.222^{* * *}$ & & & & & L3 & 0.011 & -0.02 & -0.007 \\
\hline & & -0.019 & -0.01 & -0.047 & & & & & & -0.039 & -0.022 & -0.129 \\
\hline & L1 & $0.043^{*}$ & $0.018^{+}$ & -0.061 & & & & & & & & \\
\hline & & -0.024 & -0.012 & -0.058 & & & & & & & & \\
\hline & L2 & -0.001 & 0.011 & 0.074 & & & & & & & & \\
\hline & & -0.024 & -0.012 & -0.055 & & & & & & & & \\
\hline & L3 & -0.022 & 0.002 & $0.088^{*}$ & & & & & & & & \\
\hline & & -0.021 & -0.011 & -0.05 & & & & & & & & \\
\hline dprbal & L4 & $-0.373^{* *}$ & 0.023 & 0.055 & L4 & -0.203 & 0.005 & 0.609 & L3 & $-0.357^{*}$ & -0.08 & $-1.227^{*}$ \\
\hline & & -0.189 & -0.096 & -0.454 & & -0.305 & -0.078 & -1.105 & & -0.205 & -0.116 & -0.674 \\
\hline & & & & & & & & & L4 & -0.104 & $0.172^{+}$ & 0.225 \\
\hline & & & & & & & & & & -0.195 & -0.111 & -0.642 \\
\hline Constant & & & & & & $1.752^{* * *}$ & 0.079 & $5.757^{* * *}$ & & 0.168 & 0.261 & -3.235 \\
\hline & & & & & & -0.428 & -0.063 & -1.332 & & -0.837 & -0.221 & -2.627 \\
\hline Observations & & 77 & 77 & 77 & & 85 & 85 & 85 & & 67 & 67 & 67 \\
\hline df_eq & & 14.7 & 14.7 & 14.7 & & 10.7 & 10.7 & 10.7 & & 20.7 & 20.7 & 20.7 \\
\hline r2_2 & & 0.75 & 0.75 & 0.75 & & 0.68 & 0.68 & 0.68 & & 0.85 & 0.85 & 0.85 \\
\hline r2_1 & & 0.64 & 0.64 & 0.64 & & 0.28 & 0.28 & 0.28 & & 0.35 & 0.35 & 0.35 \\
\hline aic & & 10.6 & 10.6 & 10.6 & & 9.6 & 9.6 & 9.6 & & 12.7 & 12.7 & 12.7 \\
\hline
\end{tabular}

Standard errors in parentheses: ${ }^{* * *} \mathrm{p}<0.01,{ }^{* *} \mathrm{p}<0.05,{ }^{*} \mathrm{p}<0.10,{ }^{+} \mathrm{p}<0.15$. 
Table A1 (cont.).

VAR Estimation Results

\begin{tabular}{|c|c|c|c|c|c|c|c|c|c|c|c|c|}
\hline \multirow[b]{2}{*}{ VARIABLES } & & \multicolumn{3}{|c|}{ Mexico } & \multicolumn{4}{|c|}{ Paraguay } & \multicolumn{4}{|c|}{ Peru } \\
\hline & & $\begin{array}{c}\text { (1) } \\
\text { growth }\end{array}$ & $\begin{array}{l}(2) \\
\text { dtb }\end{array}$ & $\begin{array}{c}(3) \\
\text { dlnreer }\end{array}$ & & $\begin{array}{c}\text { (1) } \\
\text { growth }\end{array}$ & $\begin{array}{c}(2) \\
d t b 2\end{array}$ & $\begin{array}{c}(3) \\
\text { dlnreer }\end{array}$ & & $\begin{array}{c}\text { (1) } \\
\text { growth }\end{array}$ & $\begin{array}{l}(2) \\
d t b\end{array}$ & $\begin{array}{c}(3) \\
\text { dlnreer }\end{array}$ \\
\hline \multirow[t]{2}{*}{ L.growth } & & -0.079 & $-0.073^{* *}$ & $-1.074^{+}$ & & $-0.273^{* *}$ & $-0.166^{*}$ & 0.193 & & $0.234^{* *}$ & $-0.109^{* * *}$ & $0.607^{* * *}$ \\
\hline & & -0.127 & -0.029 & -0.733 & & -0.123 & -0.089 & -0.181 & & -0.101 & -0.031 & -0.171 \\
\hline \multirow[t]{2}{*}{ L2.growth } & & 0.015 & $-0.122^{* * *}$ & 0.728 & & -0.147 & -0.067 & -0.208 & & -0.093 & -0.01 & -0.178 \\
\hline & & -0.104 & -0.024 & -0.571 & & -0.127 & -0.092 & -0.187 & & -0.11 & -0.034 & -0.187 \\
\hline \multirow[t]{2}{*}{ L.dtb } & & 0.16 & $0.621^{* * *}$ & 0 & & -0.249 & $0.465^{* * *}$ & -0.262 & & -0.511 & $0.704^{* * *}$ & 0.032 \\
\hline & & -0.376 & -0.095 & 0 & & -0.19 & -0.13 & -0.28 & & -0.392 & -0.122 & -0.665 \\
\hline \multirow[t]{2}{*}{ L2.dtb } & & 0.195 & -0.113 & 0 & & 0.147 & $0.180^{+}$ & 0.046 & & 0.213 & $-0.258^{* *}$ & 0.048 \\
\hline & & -0.338 & -0.086 & 0 & & -0.172 & -0.125 & -0.254 & & -0.355 & -0.108 & -0.602 \\
\hline \multirow[t]{2}{*}{ L.dlnreer } & & $0.102^{* * *}$ & -0.006 & 0.099 & & -0.035 & -0.005 & $0.287^{* *}$ & & -0.019 & -0.001 & $0.223^{* *}$ \\
\hline & & -0.021 & -0.005 & -0.126 & & -0.085 & -0.061 & -0.126 & & -0.066 & -0.02 & -0.111 \\
\hline \multirow[t]{2}{*}{ L2.dlnreer } & & 0.027 & 0.002 & -0.057 & & 0.004 & 0.07 & $-0.181^{+}$ & & 0.029 & -0.025 & $-0.181^{*}$ \\
\hline & & -0.023 & -0.005 & -0.134 & & -0.081 & -0.058 & -0.119 & & -0.056 & -0.017 & -0.094 \\
\hline \multirow[t]{8}{*}{ wgdp_gr } & L0 & $0.975^{* * *}$ & -0.022 & $2.524^{+}$ & L0 & 0.842 & -0.257 & 1.527 & L0 & 0.151 & $0.221^{*}$ & $-1.587^{* *}$ \\
\hline & & -0.288 & -0.062 & -1.729 & & -0.786 & -0.518 & -1.159 & & -0.423 & -0.126 & -0.717 \\
\hline & $\mathrm{L} 1$ & $0.833^{* *}$ & 0.046 & -1.353 & $\mathrm{~L} 1$ & 0.855 & 0.371 & -1.1 & & & & \\
\hline & & -0.331 & -0.076 & -1.976 & & -0.845 & -0.591 & -1.244 & & & & \\
\hline & L2 & -0.103 & $0.216^{* * *}$ & -1.143 & L2 & -0.521 & 0.259 & 0.602 & & & & \\
\hline & & -0.36 & -0.083 & -2.113 & & -0.839 & -0.599 & -1.235 & & & & \\
\hline & & & & & L3 & 0.74 & -0.328 & 0.106 & & & & \\
\hline & & & & & & -0.726 & -0.52 & -1.069 & & & & \\
\hline \multirow[t]{2}{*}{ vix } & L0 & 0.007 & 0 & $-0.139^{+}$ & L1 & -0.024 & 0 & -0.045 & L1 & $-0.043^{*}$ & 0 & -0.018 \\
\hline & & -0.015 & 0 & -0.092 & & -0.053 & 0 & -0.078 & & -0.024 & 0 & -0.039 \\
\hline \multirow[t]{6}{*}{ energy } & L0 & 0.001 & $0.008^{* * *}$ & 0.036 & L2 & 0.004 & -0.007 & -0.025 & $\mathrm{~L} 1$ & $0.031^{* *}$ & -0.001 & -0.017 \\
\hline & & -0.01 & -0.002 & -0.057 & & -0.032 & -0.023 & -0.046 & & -0.015 & -0.005 & -0.026 \\
\hline & L1 & $0.015^{+}$ & $-0.003^{+}$ & 0.056 & L3 & -0.037 & $-0.037^{+}$ & 0.065 & & & & \\
\hline & & -0.009 & -0.002 & -0.054 & & -0.032 & -0.023 & -0.047 & & & & \\
\hline & L2 & -0.01 & $0.005^{* *}$ & 0.027 & L4 & $-0.055^{*}$ & 0.021 & -0.058 & & & & \\
\hline & & -0.01 & -0.002 & -0.057 & & -0.029 & -0.021 & -0.043 & & & & \\
\hline \multirow[t]{10}{*}{ food } & & & & & L0 & 0.018 & 0.024 & 0.098 & & & & \\
\hline & & & & & & -0.058 & -0.042 & -0.086 & & & & \\
\hline & & & & & L1 & 0.076 & 0.03 & $0.246^{* * *}$ & & & & \\
\hline & & & & & & -0.058 & -0.042 & -0.086 & & & & \\
\hline & & & & & L2 & 0.008 & $-0.071^{+}$ & 0.079 & & & & \\
\hline & & & & & & -0.067 & -0.047 & -0.098 & & & & \\
\hline & & & & & L3 & $0.103^{*}$ & 0.023 & $0.143^{+}$ & & & & \\
\hline & & & & & & -0.062 & -0.045 & -0.091 & & & & \\
\hline & & & & & L4 & 0.08 & 0.014 & -0.042 & & & & \\
\hline & & & & & & -0.064 & -0.046 & -0.094 & & & & \\
\hline \multirow[t]{2}{*}{ metals } & & & & & & & & & L0 & $0.055^{* *}$ & $0.016^{* *}$ & $0.070^{*}$ \\
\hline & & & & & & & & & & -0.023 & -0.007 & -0.039 \\
\hline \multirow[t]{2}{*}{ dprbal } & L2 & $-1.470^{* *}$ & $-0.272^{+}$ & -3.194 & L4 & -0.874 & 0.036 & -0.518 & $\mathrm{~L} 2$ & -0.175 & -0.004 & 0.193 \\
\hline & & -0.723 & -0.166 & -4.294 & & -0.666 & -0.46 & -0.982 & & -0.367 & -0.112 & -0.623 \\
\hline \multirow[t]{2}{*}{ Constant } & & $-0.806^{+}$ & -0.076 & 2.832 & & 0.126 & 0.179 & 0.16 & & $1.812^{* *}$ & 0.015 & 0.929 \\
\hline & & -0.55 & -0.069 & -3.352 & & -1.914 & -0.515 & -2.842 & & -0.734 & -0.114 & -1.211 \\
\hline Observations & & 88 & 88 & 88 & & 69 & 69 & 69 & & 77 & 77 & 77 \\
\hline df_eq & & 14.0 & 14.0 & 14.0 & & 20.7 & 20.7 & 20.7 & & 11.7 & 11.7 & 11.7 \\
\hline r2_3 & & 0.16 & 0.16 & 0.16 & & 0.40 & 0.40 & 0.40 & & 0.29 & 0.29 & 0.29 \\
\hline r2_2 & & 0.73 & 0.73 & 0.73 & & 0.44 & 0.44 & 0.44 & & 0.64 & 0.64 & 0.64 \\
\hline r2_1 & & 0.57 & 0.57 & 0.57 & & 0.28 & 0.28 & 0.28 & & 0.30 & 0.30 & 0.30 \\
\hline aic & & 9.3 & 9.3 & 9.3 & & 14.9 & 14.9 & 14.9 & & 9.7 & 9.7 & 9.7 \\
\hline
\end{tabular}

Standard errors in parentheses: ${ }^{* * *} \mathrm{p}<0.01,{ }^{* *} \mathrm{p}<0.05,{ }^{*} \mathrm{p}<0.10,{ }^{+} \mathrm{p}<0.15$. 
Table A1 (cont.).

VAR Estimation Results

\begin{tabular}{|c|c|c|c|c|c|c|c|c|}
\hline & & \multicolumn{3}{|c|}{ Uruguay } & \multicolumn{4}{|c|}{ Venezuela } \\
\hline \multicolumn{2}{|l|}{ VARIABLES } & $\begin{array}{c}\text { (1) } \\
\text { growth }\end{array}$ & $\begin{array}{l}(2) \\
\mathrm{dtb}\end{array}$ & $\begin{array}{c}(3) \\
\text { dlnreer }\end{array}$ & & $\begin{array}{l}\text { (1) } \\
\text { growth }\end{array}$ & $\begin{array}{c}(2) \\
\mathrm{dtb} 2\end{array}$ & $\begin{array}{c}(3) \\
\text { dlnreer }\end{array}$ \\
\hline \multirow{2}{*}{\multicolumn{2}{|c|}{ L.growth }} & $0.221^{+}$ & -0.009 & 0 & & -0.135 & $-0.119^{* * *}$ & 0.289 \\
\hline & & -0.148 & -0.064 & 0 & & -0.102 & -0.034 & -0.226 \\
\hline \multirow{2}{*}{\multicolumn{2}{|c|}{ L2.growth }} & 0.106 & 0.02 & 0 & & $-0.332^{* * *}$ & -0.045 & 0.33 \\
\hline & & -0.128 & -0.056 & 0 & & -0.109 & -0.037 & -0.247 \\
\hline \multirow{2}{*}{\multicolumn{2}{|c|}{ L.dtb }} & 0 & $0.309^{* *}$ & -0.299 & & $-1.025^{* * *}$ & $0.762^{* * *}$ & 0.135 \\
\hline & & 0 & -0.139 & -1.141 & & -0.356 & -0.12 & -0.794 \\
\hline \multirow{2}{*}{\multicolumn{2}{|c|}{ L2.dtb }} & $-0.000^{*}$ & $0.225^{*}$ & -0.961 & & $0.967^{* * *}$ & $-0.239^{* *}$ & 0.626 \\
\hline & & 0 & -0.126 & -0.932 & & -0.324 & -0.109 & -0.719 \\
\hline \multirow{2}{*}{\multicolumn{2}{|c|}{ L.dlnreer }} & -0.002 & $-0.042^{* *}$ & 0.097 & & -0.034 & $-0.033^{*}$ & 0.017 \\
\hline & & -0.058 & -0.021 & -0.152 & & -0.054 & -0.018 & -0.121 \\
\hline \multirow{2}{*}{\multicolumn{2}{|c|}{ L2.dlnreer }} & -0.021 & 0.023 & 0.077 & & 0.071 & -0.021 & 0.097 \\
\hline & & -0.055 & -0.02 & -0.153 & & -0.055 & -0.019 & -0.124 \\
\hline \multirow[t]{4}{*}{ wgdp_gr } & L0 & $1.672^{* * *}$ & $0.382^{+}$ & 0 & L1 & 0.882 & 0.163 & 0.812 \\
\hline & & -0.612 & -0.235 & 0 & & -1.201 & -0.385 & -2.54 \\
\hline & L1 & -0.645 & $-0.623^{* *}$ & 0 & L2 & -0.195 & 0.34 & -2.636 \\
\hline & & -0.635 & -0.26 & 0 & & -1.142 & -0.384 & -2.539 \\
\hline \multirow[t]{2}{*}{ vix } & L0 & -0.024 & $0.000^{* *}$ & -0.106 & L0 & $-0.116^{*}$ & 0 & 0 \\
\hline & & -0.039 & 0 & -0.11 & & -0.061 & 0 & 0 \\
\hline \multirow[t]{8}{*}{ energy } & L0 & $-0.049^{*}$ & -0.01 & $0.131^{+}$ & L1 & $0.089^{*}$ & 0.019 & -0.072 \\
\hline & & -0.028 & -0.01 & -0.084 & & -0.049 & -0.017 & -0.11 \\
\hline & $\mathrm{L} 1$ & $0.062^{* *}$ & 0.009 & $-0.133^{*}$ & $\mathrm{~L} 2$ & 0.066 & -0.008 & $0.186^{*}$ \\
\hline & & -0.029 & -0.011 & -0.076 & & -0.05 & -0.017 & -0.11 \\
\hline & L2 & -0.034 & $-0.018^{+}$ & 0.06 & L3 & -0.015 & 0.01 & 0.026 \\
\hline & & -0.03 & -0.011 & -0.078 & & -0.049 & -0.017 & -0.11 \\
\hline & & & & & L4 & $0.102^{* *}$ & $-0.025^{*}$ & 0.034 \\
\hline & & & & & & -0.043 & -0.015 & -0.097 \\
\hline \multirow[t]{8}{*}{ food } & L3 & 0.074 & -0.005 & $0.267^{+}$ & L0 & $0.140^{+}$ & $0.047^{+}$ & $-0.576^{* * *}$ \\
\hline & & -0.06 & -0.022 & -0.18 & & -0.091 & -0.031 & -0.203 \\
\hline & L4 & 0.006 & 0.023 & $-0.267^{+}$ & $\mathrm{L} 1$ & -0.115 & -0.009 & $-0.313^{+}$ \\
\hline & & -0.055 & -0.02 & -0.171 & & -0.094 & -0.032 & -0.213 \\
\hline & & & & & L2 & -0.018 & 0.046 & -0.264 \\
\hline & & & & & & -0.095 & -0.033 & -0.215 \\
\hline & & & & & L3 & 0.089 & $-0.062^{*}$ & -0.045 \\
\hline & & & & & & -0.094 & -0.032 & -0.211 \\
\hline \multicolumn{9}{|l|}{ metals } \\
\hline \multirow[t]{2}{*}{ dprbal } & L2 & -0.51 & $-0.000^{* * *}$ & $0.000^{* *}$ & L3 & -0.206 & 0.147 & -0.972 \\
\hline & & -0.927 & 0 & 0 & & -0.324 & -0.11 & -0.726 \\
\hline \multirow[t]{2}{*}{ Constant } & & 0.421 & 0.223 & 2.365 & & 2.343 & -0.175 & 1.739 \\
\hline & & -1.222 & -0.175 & -2.652 & & -2.023 & -0.319 & -2.108 \\
\hline Observations & & 42 & 42 & 42 & & 73 & 73 & 73 \\
\hline df_eq & & 13.0 & 13.0 & 13.0 & & 18.3 & 18.3 & 18.3 \\
\hline r2_3 & & 0.23 & 0.23 & 0.23 & & 0.28 & 0.28 & 0.28 \\
\hline r2_2 & & 0.51 & 0.51 & 0.51 & & 0.74 & 0.74 & 0.74 \\
\hline r2_1 & & 0.35 & 0.35 & 0.35 & & 0.37 & 0.37 & 0.37 \\
\hline aic & & 13.2 & 13.2 & 13.2 & & 16.7 & 16.7 & 16.7 \\
\hline
\end{tabular}


Table A2.

Estimation of Country Sovereign Spreads - OLS

(1) (2) (3)

VARIABLES

\begin{tabular}{|c|c|c|c|c|c|c|c|c|}
\hline L.dca & $\begin{array}{l}-11.302 \\
(9.021)\end{array}$ & & & & & & & \\
\hline L.ded & $\begin{array}{c}1.377 \\
(5.975)\end{array}$ & $\begin{array}{c}0.242 \\
(5.904)\end{array}$ & & & & & & \\
\hline L.dpb & $\begin{array}{c}-3.570 \\
(11.671)\end{array}$ & $\begin{array}{c}-4.495 \\
(12.032)\end{array}$ & $\begin{array}{c}-4.504 \\
(11.969)\end{array}$ & & & & & \\
\hline L.dpd & $\begin{array}{l}18.814^{*} \\
(10.595)\end{array}$ & $\begin{array}{c}18.589^{*} \\
(10.586)\end{array}$ & $\begin{array}{l}18.743^{*} \\
(9.760)\end{array}$ & $\begin{array}{l}18.759^{*} \\
(9.756)\end{array}$ & $\begin{array}{c}19.675^{* *} \\
(9.728)\end{array}$ & $\begin{array}{c}11.962 \\
(19.584)\end{array}$ & $\begin{array}{c}14.350 \\
(19.344)\end{array}$ & $\begin{array}{c}27.990 \\
(20.638)\end{array}$ \\
\hline L.dfxresy & $\begin{array}{c}-9.070^{* * *} \\
(3.424)\end{array}$ & $\begin{array}{c}-9.139^{* * *} \\
(3.408)\end{array}$ & $\begin{array}{c}-9.124^{* * *} \\
(3.277)\end{array}$ & $\begin{array}{c}-9.310^{* * *} \\
(3.238)\end{array}$ & & $\begin{array}{l}-9.506 * * * \\
(3.341)\end{array}$ & & \\
\hline dlnreer & $\begin{array}{l}-6.597^{* *} \\
(2.626)\end{array}$ & $\begin{array}{l}-6.594^{* *} \\
(2.626)\end{array}$ & $\begin{array}{l}-6.591^{* *} \\
(2.607)\end{array}$ & $\begin{array}{l}-6.587^{* *} \\
(2.606)\end{array}$ & $\begin{array}{l}-6.621^{* *} \\
(2.627)\end{array}$ & $\begin{array}{l}-6.675^{* *} \\
(2.598)\end{array}$ & $\begin{array}{l}-6.691^{* *} \\
(2.619)\end{array}$ & \\
\hline dvix & $\begin{array}{c}13.148^{* * *} \\
(3.955)\end{array}$ & $\begin{array}{c}13.255^{* * *} \\
(3.965)\end{array}$ & $\begin{array}{c}13.254^{* * *} \\
(3.963)\end{array}$ & $\begin{array}{c}13.257^{* * *} \\
(3.973)\end{array}$ & $\begin{array}{c}13.197^{* * *} \\
(4.025)\end{array}$ & $\begin{array}{c}13.234^{* * *} \\
(3.990)\end{array}$ & $\begin{array}{c}13.178^{* * *} \\
(4.040)\end{array}$ & $\begin{array}{c}12.846^{* * *} \\
(4.006)\end{array}$ \\
\hline L.dpd_sq & & & & & & $\begin{array}{c}0.038 \\
(0.104)\end{array}$ & $\begin{array}{c}0.030 \\
(0.103)\end{array}$ & $\begin{array}{l}-0.019 \\
(0.107)\end{array}$ \\
\hline Constant & $\begin{array}{c}2.241 \\
(2.818)\end{array}$ & $\begin{array}{c}2.061 \\
(2.820)\end{array}$ & $\begin{array}{c}2.055 \\
(2.822)\end{array}$ & $\begin{array}{c}2.084 \\
(2.822)\end{array}$ & $\begin{array}{c}0.559 \\
(2.639)\end{array}$ & $\begin{array}{c}2.015 \\
(2.867)\end{array}$ & $\begin{array}{c}0.479 \\
(2.721)\end{array}$ & $\begin{array}{c}0.531 \\
(2.765)\end{array}$ \\
\hline Observations & 2,990 & 2,990 & 2,990 & 2,990 & 2,990 & 2,990 & 2,990 & 2,990 \\
\hline R-squared & 0.148 & 0.147 & 0.147 & 0.147 & 0.145 & 0.147 & 0.145 & 0.122 \\
\hline $\mathrm{N}$ & 2990 & 2990 & 2990 & 2990 & 2990 & 2990 & 2990 & 2990 \\
\hline F & 24.59 & 25.18 & 26.07 & 27.10 & 29.26 & 26.10 & 28.05 & 26.53 \\
\hline
\end{tabular}

Robust standard errors in parentheses: ${ }^{* * *} \mathrm{p}<0.01,{ }^{* *} \mathrm{p}<0.05,{ }^{*} \mathrm{p}<0.10,{ }^{+} \mathrm{p}<0.15$.
(5)

(6)

(7)

(8) 